NBER WORKING PAPER SERIES

THE LEVEL AND DISTRIBUTION

OF ECONOMIC WELL-BEING

Al an S. B1inder

Working Paper No. 488

NATIONAL BUREAU OF ECONOMIC RESEARCH

1050 Massachusetts Avenue

Cambridge MA 02138

June 1980

This paper will be published by the University of Chicago Press in a volume titled The American Economy in Transitton, edited by Martin Feldstein. My gratitude goes to C. R. Lindsey for skillful and diligent research assistance; to my NBER reading committee, Stanley Lebergott and Eugene Smolensky, for much good advice; and to Edgar Browning, Sheldon Danziger, Angus Deaton, Roger Gordon, Harvey Rosen, and Timothy Smeeding for helpful suggestions. I should also acknowledge the National Science Foundation for support over the years for my research on income distribution. None of these persons or institutions, however, are accomplices to the conclusions. Any opinions expressed are those of the author and not those of the National Bureau of Economic Research. 


\title{
The Level and Distribution of Economic We11-Being
}

\section{$\underline{\text { ABSTRACT }}$}

This paper summarizes and critically evaluates what is known about postwar trends in both the level and distribution of economic well-being. Although certain non-income aspects of well-being are considered, the primary focus is on the level and inequality of income. Considerable attention is paid to recent controversies over the effects of transfers in kind and changing life-cycle income patterns on the overall trend in income inequality.

\author{
Alan S. Blinder \\ Department of Economics \\ Princeton University \\ Princeton, New Jersey 08544 \\ (609) $452-4010$
}


"The more things change, the more they remain the same." -- Anon

\section{Intróduction_and Preview}

The ultimate purpose of an economy, it may fairly be said, is to enhance the material well-being of its people. In the philosophical pecking order, such a crass and narrow -goal may not appear as lofty as, let us say, inner peace and spiritual uplift. But, as has oft been remarked, it is difficult to feed the soul while the stomach is empty. Because of the absolutely central position of the task of producing more and better goods, and aistributing them equitably (what a loaded word that is:) among the citizenry, the topics of the other chapters in this book may justifiably be considered subservient to this one. Changes in the financial system, in taxation and public expenditure, in the structure of industry, in international economic relations, and so on, are all most naturally appraised by asking how much they contribute to economic well-being. Thus this chapter may, without stretching the imagination too far, be thought of as the "outputs" produced by the other chapters' "inputs." At least this is the preeminence I claim for my topic.

How well has the U.S. economy performed the two central tasks of raising living standards and enhancing economic equality during the postwar period: The basic story is 
simple enough to summarize in a few words, though complex enough to require volumes for a complete account. Where the average level of economic well-being is concerned, the record is one of steady improvement. Not an unblemished record to be sure, and not as spectacular a record as the postwar "economic miracles" of Germany and Japan, but a creditable record nonetheless.

However, when we turn to consider the distribution of economic welfare--economic equality, as it is commonly called--the central stylized fact is one of constancy. As measured in the official data, income inequality was just about the same in 1977 (the last year for which data were available when this was written) as it was in 1947. Though this seems a straightforward conclusion, it actually conceals a host of controversies and puzzles. For the stability we observe in the income distribution is not the result of a boring, static economy, nor the result of some "natural economic law," as Pareto (1897) thought. Rather it is the result of a confluence of powerful forces, some pulling toward greater equality and some pulling toward greater inequality, which together produced a great underwater swirl while causing barely a ripple on the surface.

For example, the American population experienced substantial demographic changes during this 30-year period. The causes of these changes were varied, complex, in part 
obvious and in part obscure, but in any case well beyond the scope of this chapter. ${ }^{1}$ What matters for our purposes is that, given the way income distribution data are compiled, these demographic shifts would have produced a substantial trend toward greater inequality had not other factors intervened. It will not be giving away the plot to suggest that government transfer programs played a major role in that intervention.

Even the basic stylized fact that income inequality has remained constant since worla War II has not gone unchallenged. It has been argued, for example, that if we measured income more comprehensively than we do, or if we measured it over periods longer than a year, a clearer trend toward equality would emerge. As we shall see, seemingly mundane issues like how to define and measure income are of considerable importance in appraising the economy's postwar performance; and they also raise some surprisingly profound (and perhaps insoluble) issues.

Since this chapter is a long one, it will be useful to provide a reader's guide at the outset. Section 2 disposes briefly of some preliminary issues of measurement-the measurement of welfare, the measurement of income, and the measurement of inequality. The next two sections, which comprise the bulk of the paper, address the two central topics of the chapter--postwar trends in the level of income (Section 3) and its inequality (Section 4). Section 4, in particular, examines in some depth the controversies alluded to just above. 
Section 5 then takes up several peripheral aspects of the distribution of income which seem to be of special interest-poverty, black/white income differentials, and male/female income differentials. Finally, in section 6, the myopic concentration on income is remedied by examining postwar developments in non-income aspects of well-being such as leisure, wealth, health, and so on. Section 7 offers some brief concluding remarks.

\section{2.-_Preliminaries}

\section{A. From the Sublime to the Ridiculous}

The essay begins with a strategic retreat which moves farther and farther from a concept that is interesting but unmeasurable (welfare) and closer and closer to a concept that is measureable but possibly uninteresting (money income as defined by the Census Bureau). Like most strategic retreats, this one does accomplish something. But it must be admitted that its direction is dictated more by expedience than by principle. The retreat takes place in several stages.

The first step is to admit that man does not live on bread alone. Political freedom, peace, inner tranquility, a happy family life, and so on may be far more important to many people than the bill of goods and services they consume. Still, it would be the height of folly for an economist to write an essay on these more ephemeral aspects of human welfare. 
On grounds of comparative advantage, therefore, I will for the most part restrict my attention to what is normally considered ecconomic well-being.

The second step is to concede that there is little scientific basis for deciding how much "utility" any specific individual gets at any particular time, and even less for deciding whether Laurel gets more or less than Hardy. Two avenues therefore remain open. We can look at levels and distributions of items which are presumed to yield utility, such as consumption goods and leisure time. Or we can look at peoples' opportunities, as summarized by their endowments and the prices they face, on the assumption that people with more generous opportunities achieve correspondingly higher levels of satisfaction.?

While part of our army will stop to fight the battle here, most of it will retreat one step more--to the use of current income to summarize the whole opportunity set. Now we know this is not quite right. Two individuals with identical opportunities will have different incomes if their preferences differ. 3 Ill health may mean that more current income is necessary to achieve any given level of satisfaction, or a large store of accumulated wealth may mean that less is necessary. While several of these qualifications will be dealt with in what follows, the data dictate that the analysis be conducted mainly in terms of income. 


\section{B. The Measurement of Income}

Perhaps the worst news is saved for last. The only reasonably consistent time series of income distributions covering a long period comes from the annual current Population Survey (CPS), which uses an income definition that is far from the economist's (or anyone else's) ideal. 4 Economists define an individual's income as the amount he could consume without depleting his wealth--the sum of his expenditures plus any increase in his wealth. What does the CPS offer us? Basically, a distribution of money income in which some sources of income are grossly underreported, capital gains are excluded, cash transfers are included but transfers in kind are excluded, and from which no deduction is made for income and payroll taxes. Measured income thus falls far short of the ideal concept of income. Given the wide cleavage that already exists between well-being and even this ideal concept of income, one might well wonder if our data do not leave us with a grin without a cat. I proceed nonetheless in this essay to analyze the grin. However, some time will be spent in section 4 questioning whether a better measure of income might tell a different story about postwar trends in income inequality.

Our interest in the level and distribution of income clearly is motivated by a belief that we can use these two numbers as approximate indicators of economic welfare. Specifically, we would like to believe that higher or more 
equally distributed incomes mean that society is "better off." Having decided, for lack of a superior alternative, to use census money income, the next step is to decide on the recipient unit. Whose incomes shall we study?

This question, which may seem foolish and "academic" at first, is in fact very important because of the demographic changes mentioned earlier. For it appears that one of the items that Americans have purchased with their postwar prosperity has been the privilege of living apart from their relatives. Think what happens, for example, when higher living standards and/or more generous public transfer programs enable junior, or grandma and grandpa, to move into an apartment of their own. A new economic unit is formed, with a rather low income, thus bringing down the average level of income and raising its inequality. Both economic indicators will therefore signal a deterioration in welfare, though we may presume that these changes in living arrangements actually make the parties involved better off. 5

We, therefore, must exercise extreme caution in interpreting postwar trends in income distribution. The census Bureau offers separate income distributions for familiies ("a group of two or more persons related by blood, marriage, or adoption and residing together") and for un unelated indivíiduals, as well as a pooled distribution that combines both types of units. In this essay, we will pay attention 
to each of these distributions, and to the interrelationships among them.

Further perplexities enter when we ask another question: why should we be interested in distributions of annua 1 incomes instead of incomes measured over some alternative accounting period? One answer is straightforward and prosaic: that's the way the data come. But a deeper answer is not so easily obtained. If we could measure income over any accounting period we wished, what accounting period would be best?

It seems clear that periods like a day or a week are far too short to generate meaningful data on income inequality. All of us have weeks of zero income (at least on a cash accounting basis), without being "poor" in any real sense. So longer periods are necessary. But why stop at a year? clearly a year is far too short an accounting period to place many people meaningfully within the income distribution. For example, since investment in human capital typically leads to rising age-earnings profiles, many people who are quite well off in a lifetime sense may appear quite "poor" during certain years. For these and other reasons many economists, including myself (Blinder, 1974, 1976), have been attracted to the distribution of liffetime incomes, though even this choice is not unobjectionable.

As we shall see, there is evidence that income distributions over multi-year accounting periods display less inequality than income distributions for a single year. More importantly, there is reason to believe that a stronger trend toward 
equality might emerge if somehow we were able to measure the distribution of lifetime income.

c. The Measurement of Inegua litity ${ }^{6}$

There are many ways to measure how "equal" or "unequal" any given distribution of income is; but the availability of data dictates that we concentrate on two. The first is straightforward and requires no elaboration: we can examine trends in the shares of total income accruing to specific income groups such as the poorest fifth, the richest fifth, etc. The second is something called the Gini riatio, and requires some explanation. ${ }^{7}$

Income distributions are typically displayed in a convenient graphical device invented by M.O. Lorenz (1905); two such Lorenz curves are depicted in Figure 1. To construct a Lorenz curve, begin with a square whose dimensions represent $100 \%$. Along the horizontal axis, measure the cumulative percentage of consumer units, starting from the poorest; along the vertical axis, measure the cumulative share of income received by these units. Data on income shares then appear as points within the square, and the curvilinear line connecting them is the Lorenz curve.

Every Lorenz curve has four basic properties:

1. It must begin at the origin, since zero units have zero income.

2. It must end at the upper-right corner of the diagram since $100 \%$ of the units must receive all the income.

3. If incomes were distributed equally, the Lorenz curve would be a diagonal line connecting these two points, 


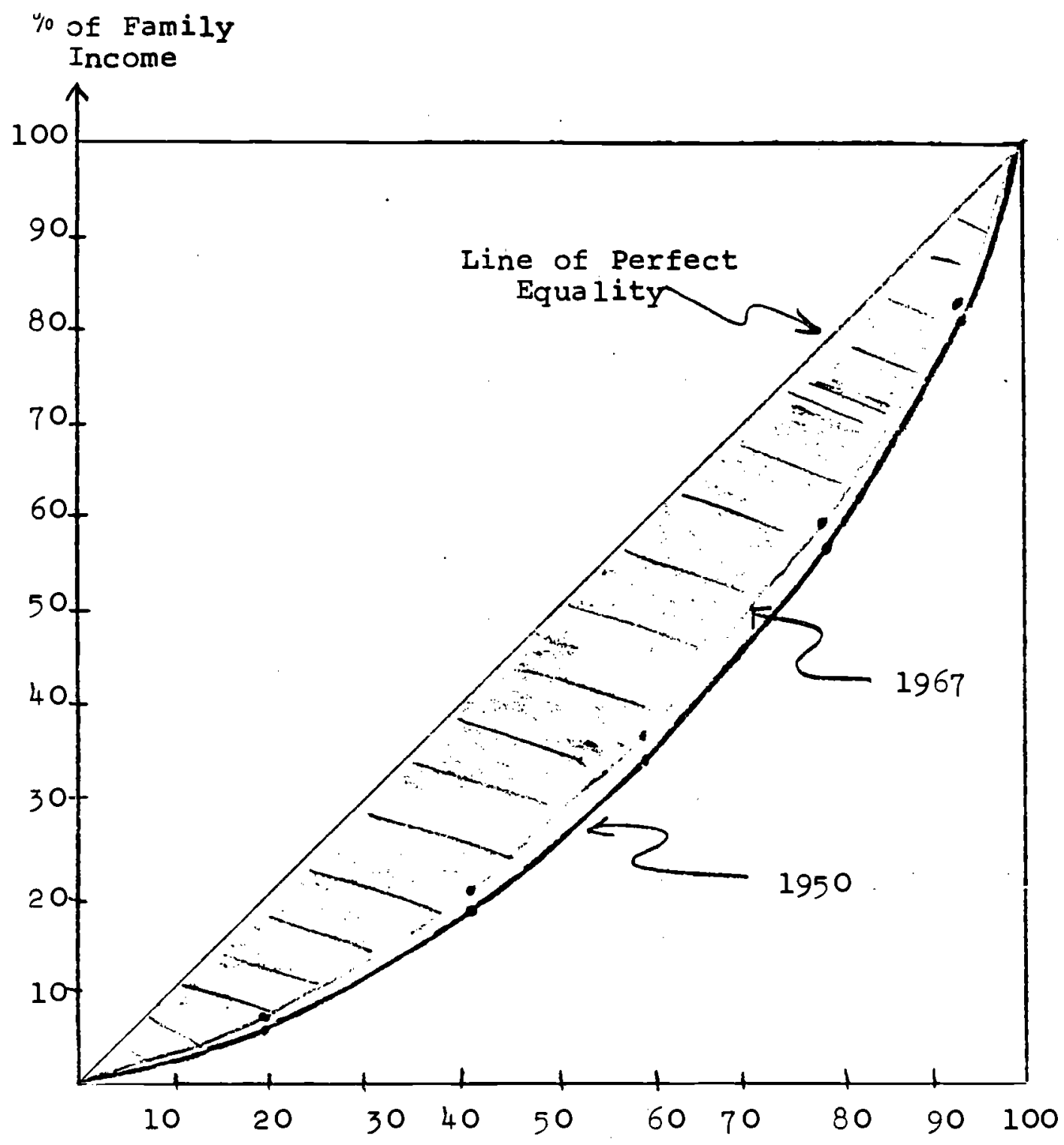

$\%$ of Families

Figure 1

Two Lorenz Curves for Family Income 
since the "poorest" $20 \%$ of units would receive $20 \%$ of the income, the "poorest" $40 \%$ would receive $40 \%$, and so on. 4. In a real economy, in which significant income differentials exist, the Lorenz curve will "sag" downward from this diagonal line representing perfect equality. The reason is straightforward. If there is any inequality at a11, the poorest $20 \%$ of units must receive less than $20 \%$ of the income, the poorest $40 \%$ must receive less than $40 \%$, and so on.

Lorenz curves are useful in depicting inequality because curves that lie closer to the diagonal represent distributions with less inequality. This is also illustrated in Figure 1 which shows, for the family income distribution, the most equal and most unequal distributions during the entire postwar period. (The fact that they are so close together illustrates the aforementioned stability of the income distribution.) In fact, the area between the Lorenz curve and the diagonal (shaded in Figure 1), expressed as a fraction of the area beneath the diagonal, ${ }^{8}$ is often used as a summary measure of inequality. This fraction is called the Gini ration, after its inventor Corrado Gini (1936), and it is clear that higher Gini ratios connote greater inequality.

Since Gini ratios appear so frequently in this essay, a word on their interpretation is in order. The Gini ratio 
is a purely mechanical measure of inequality, while our interest in inequality is as an indicator of social welfare. Suppose in comparing two income distributions we find that distribution A assigns less income both to the poorest $20 \%$ of families and to the richest $20 \%$ than does distribution $B$. (Distribution $A$ naturally has to assign more income to the midale $60 \%$ of families.) Which distribution has more "equality"? Clearly $A$ is more equal at the upper tail (the rich are not quite so $\mathrm{rich}$ ), but $B$ is more equal at the lower tail (the poor are not quite so poor). But which distribution is "better"? It is clear that the answer is unclear. It depends on whether society attaches more importance to income differences at the high or low end of the income distribution. But the Gini ratio (ox, for that matter, any summary statistic) tolerates no such ambiguity. It will state for example, that the Gini ratio for distribution $A$ is .36 while that for distribution $B$ is .37 . For this reason, we must take care in pronouncing distributions with lower Gini ratios as "better." There is, however, one important circumstance in which the Gini ratio can be relied upon to properly rank different income distributions. This is the case where the Lorenz curves do not cross (as in Figure 1), for then the more unequal distribution will always get the higher Gini ratio. The conclusion then is this. When Lorenz curves cross, the Gini ratio may rank income distributions incorrectly, 
and thus cannot be taken very seriously. However, when Lorenz curves do not cross, such misrankings cannot occur and the Gini ratio provides useful information. Fortunately for us, most of the inequality comparisons we have to make are between Lorenz curves that do not cross. 9

\section{Trends in the Level of Income and Consumption}

I turn now to the first of the two major concerns of this chapter: what has happened to the average level of economic well-being in the United States since World War II? As noted earlier, I will at first stealthily translate this question to: what has happened to the average level of income?, postponing the consideration of non-income aspects of wellbeing to section 6 .

The basic story is, of course, extremely well known. The postwar U.S. economy has generally produced growth of per capita incomes, though that growth has been punctuated by periodic recessions. 10 This stylized fact is illustrated in Figure 2, which charts the behavior of real disposable income per capita from 1947 to 1978. The trend in consumption, naturally enough, has followed the trend in income rather closely. But the aggregate data conceal some dramatic changes in patterns of consumption.

A. The Growth of Incomes, $1947=1977$

Many serious shortcomings of Census income were mentioned in Section 2. Fortunately, in studying trends in 


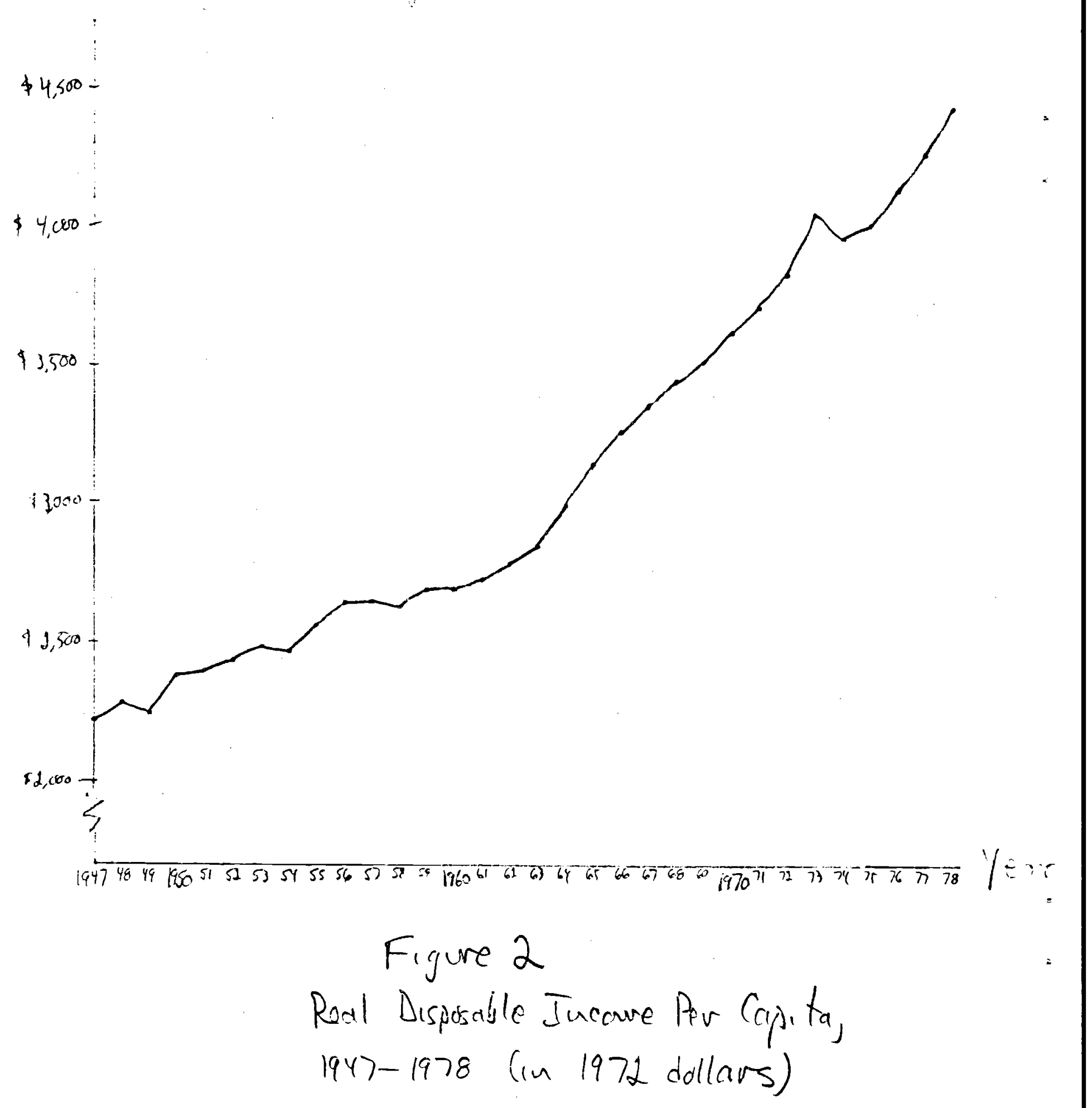


the level of income, we need not restrict ourselves to census income since much better measures are available in the national income accounts (NIA).

The NIA concept that comes closest to Census income is Personal Income (PI). And it is easy to remedy several problems with Census income by supplementing PI with other NIA data. First, as a crude way of accounting for (a smoothed version of) capital gains, we can add corporate retained earnings to personal income. Second, we can put PI on a more consistent post-transfer but pre-tax basis (like Census income) by including not only the employee's share of the payroll tax but also the employer's share. Making both these changes in the NIA data leads me to an income concept that I call Augumented Personō I Income. 11

A more fundamental problem with Census income, however, is the illogic of adding in transfers but failing to deduct the taxes that pay for them. This is easily remedied in the aggregate data by deducing both personal income taxes and payroll taxes (both shares) from augmented personal income to arrive at an income concept that I call Augmented﹎ㅁisposable Income. 12

The decade-by-decade annual growth rates in real census income, real augmented personal income, and real augmented disposable income ${ }^{13}$ are presented in Table 1. Not surprisingly, for the postwar period as a whole the growth rates of census income and augmented personal income are almost identical, while the growth rate of real augmented disposable income is 
Table 1

Annualized Growth Rates in Real

Income Per Family and Per Unrelated

Individual, By Taree Different Definitions

\begin{tabular}{|c|c|c|c|c|c|c|}
\hline \multirow[t]{2}{*}{ 므르도므모 } & \multicolumn{2}{|c|}{ Cens } & \multirow{2}{*}{\multicolumn{2}{|c|}{ 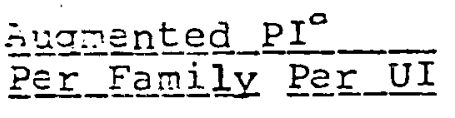 }} & \multirow{2}{*}{\multicolumn{2}{|c|}{ 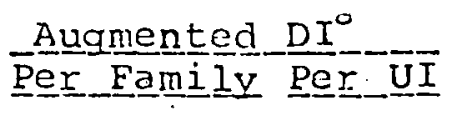 }} \\
\hline & per Family & Per U & & & & \\
\hline $19: 7-1977$ & $2.22 \%$ & $2.14 \%$ & $2.25 \%$ & $2.17 \%$ & $1.92 \%$ & $1.84 \%$ \\
\hline $19 \div 7-1957$ & 1.83 & 1.00 & 2.18 & 1.35 & 1.97 & 1.14 \\
\hline $1957-1967$ & 3.01 & 2.71 & 3.01 & 2.72 & 2.68 & 2.39 \\
\hline $1967-1977$ & 1.84 & 2.72 & 1.55 & 2.44 & 1.11 & 1.98 \\
\hline
\end{tabular}

Sources: Computed by the author from cata in Currrenent Population

Reports, Series P-60, No. Ile; Survey of Currrent Business, July 1979; and The Nationoni Income end Product Accounts

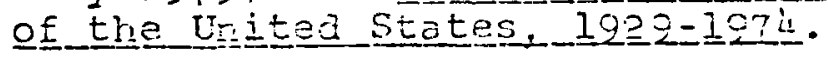

$a_{\text {Fugnented }} \mathrm{PI}$ and eugnented DI are ceeined in the text. It was assumed that each of these aggregßtes was divirled between families and UI's in the same proportion as census income. 
about one-third of a percentage point less. Compounded over 30 years, these figures mean that from 1947 to 1977 real augmented PI per family increased $95 \%$, while real augmented DI per family increased $77 \%$. The gap is accounted for by an increasing burden of personal taxation (with, presumably, a corresponding increase in public services).

When we break the 30-year period down into decades, the close agreement between census income and augmented personal income starts to melt away. More importantly, a striking difference between the postwar economic progress of families and unrelated individuals (UIs) emerges. For both groups, and for any of the income measures, the middle decade (which was dominated by the long boom of the 1960s) exhibited the strongest growth. But the rankings of the other two decades is reversed. Apparently, families fared much better than UIs between 1947 and 1957, while UIs fared much better than families during the most recent decade. Why? The reasons are to be found in the demographic shifts summarized in Tables 2 and 3 . These tables show that while demographic changes during 1947-1957 were mostly minor for families, UIs become more likely to be female or elderly. By contrast, during the last decade UIs became much less likely to be female, while more families became female-headed. (Both groups became younger on average.) 
Table 2

Selected Changes in Family Structure, $1947-1977$

Characteristic

$\begin{array}{llll}1947 & 1257 & 1267 & 1977\end{array}$

Average number of:

Persons

3.64

3.65

3.67

$3 \cdot 33$

Children

1.19

1.37

1.41

1.10

Earners

NA

NA

1.67

1.66

Percent headed by:

Male

90.0

90.6

89.3

85.6

Female

10.0

9.4

10.7

14.4

Percent having:

2 members

30.6

32.1

33.9

$38 \cdot 5$

3 members

25.2

21.5

20.6

22. 1

4 members

20.1

20.5

19.0

20.6

5 members

11.4

12.6

$12 \cdot 5$

11.0

6 or more members

12.7

13.4

14.0

$7 \cdot 9$

Percent headed by person:
Age $14-24$
5.0
5.2
$6 \cdot 3$
6.7
Ase $25-34$
22.8
22.1
$19 \cdot 7$
$23 \cdot 5$
Age $35-64$
60.7
59.8
59.8
55.4
Age 65 and over
11.5
$12 \cdot 9$
14.2
14.4
Percent on Farms
$17 \cdot 5$
11.0
5.4
3.8

Soures: Current population Recorts, Series P-60, No. 118 , Series 
Table 3

Selected Demographic Changes among Unrelated

Individua 1s, 1947-1977

\begin{tabular}{lcccc}
\hline Percentage & 1947 & 1957 & 1967 & 1977 \\
Male & 45.1 & 39.1 & 36.9 & 43.3 \\
Eema le & 54.9 & 60.9 & 63.1 & 56.7 \\
Who Are Earners & 65.5 & 67.2 & 61.8 & 63.7 \\
Age $14-24$ & 10.1 & 9.3 & 11.6 & 17.8 \\
Age 25-34 & 13.0 & 11.8 & 9.3 & 19.7 \\
Age 35-54 & 46.5 & 45.8 & 40.5 & 30.8 \\
Age 65 and over & 30.4 & 33.0 & 38.6 & 31.7 \\
Living on Forms & 11.8 & 6.2 & 2.6 & 1.7 \\
\hline
\end{tabular}

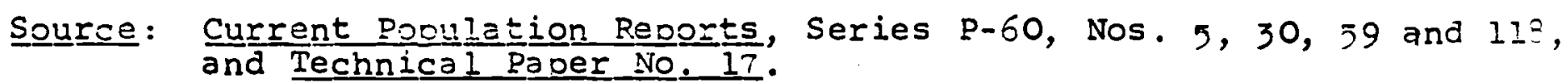


Where Did It Come From?

Naturally, all the components of personal income participated in the postwar growth, though certainly not equally. Table 4 shows that wages, interest, and transfers accounted for greater shares of augmented personal income in 1977 than was true in 1947, whereas proprietor's income, rents, and corporate profits accounted for smaller shares. 14 Where Did It Go?

The concept of augmented personal income as defined here can be divided into three principal uses:

1. spending: the sum of personal consumption expenditures, interest paid to businesses, and transfers to foreigners, minus indirect taxes;

2. saving: personal saving as in the NIA plus retained earnings

3. taxes: personal taxes as in the NIA plus contributions for social insurance plus indirect taxes. (This can be viewed as purchases of public consumption.)

Using this three-way split, Table 5 shows that spending has commanded a dwindling share and taxes have commanded an expanding share during the postwar period. The share of savings exhibits no trend, though saving rates were unusually low in three of the last four years. Closer inspection of these data reveals that the share of consumption stabilized between 62 and $63 \%$ around 1966, or so, and the share of taxes stabilized near 30 percent around 1968. Thus since 1968 
Table 4

Sources of Augmented Personal

Income, 1947-1977

\begin{tabular}{|c|c|c|c|c|c|c|}
\hline \multirow[b]{2}{*}{ Yea } & \multicolumn{6}{|c|}{ Percentage Share of: } \\
\hline & Wuages $^{a}$ & $\begin{array}{l}\text { Proprietor's } \\
\text { Income }\end{array}$ & Rents & Interest & 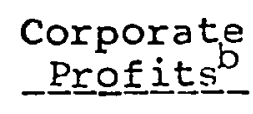 & Transfers \\
\hline $\begin{array}{l}\text { Postwar } \\
\text { Average }\end{array}$ & 67.6 & 10.9 & 2.7 & $5 \cdot 7$ & 5.6 & $7 \cdot 5$ \\
\hline 1947 & $64 \cdot 5$ & 17.9 & 2.6 & 3.6 & 5.5 & 5.9 \\
\hline 1957 & 68.7 & 12.0 & 3.3 & 4.6 & 5.5 & 5.8 \\
\hline 1957 & $67 \cdot 7$ & 8.7 & 2.8 & 6.5 & 6.7 & 7.5 \\
\hline 1977 & $67 \cdot 7$ & 5.9 & 1.4 & 8.3 & 4.5 & 12.2 \\
\hline
\end{tabular}

Sounrce: National income accounts.

a Compensation of employees

${ }^{b}$ Corporate profits (with inventory valuation adjustment and capital consumption adjustment) minus corporate tax liabilities. This is equel to the sum of dividends and retained earnings. 
Table 5

Uses of Augmented Personal Income, $1947-1977$

\begin{tabular}{lccc}
\hline \multicolumn{4}{c}{ Percentage Share of : } \\
\multicolumn{1}{c}{ Spending $^{a}$} & Saving $^{b}$ & Taxes $^{c}$ \\
Postwar average & 65.5 & 7.6 & 26.9 \\
1947 & 72.4 & 4.7 & 22.8 \\
1957 & 66.7 & 8.0 & 25.4 \\
1967 & 62.2 & 9.7 & 28.1 \\
1977 & 62.9 & 5.7 & 31.3 \\
\hline
\end{tabular}

Soluㅗㅗㄹㅡ: National income accounts.

${ }^{a}$ Personal outlays less indirect taxes

${ }^{b}$ personal savings plus retained earnings

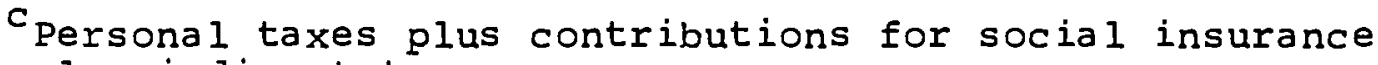
plus indirect taxes. 
American consumers have paid about 30 percent of their gross incomes to the tax collector, saved about 7 percent, and spent the remaining 63 percent.

\section{B. Patterns of Consumption, 1947-1927}

So income and consumption have grown mightily over the postwar period. How have American consumers spent this largesse? An examination of postwar changes in consumption patterns is interesting for the profile it draws of the American way of life. And it also holds a few surprises. A logical place to start is with changes in budget shares. What fraction of each dollar of consumer spending was spent on various items in 1947 and 1977? Which items commanded an increasing share of the consumer's budget and which a decreasing share?

Table 6 contains some answers; but there are too many numbers in this table for it to "speak for itself," and many others hidden in the data that underlie it. Let us see what story these data tell.

At the coarsest level of aggregation, the table shows just about what we expect. Americans are now spending more of their budgets on housing, medical care, private transportation, recreation, and personal services than they were in 1947 . At the same time, they are spending less on food, clothing, and public transportation. But if we peer a bit below the surface, some fascinating details emerge. 


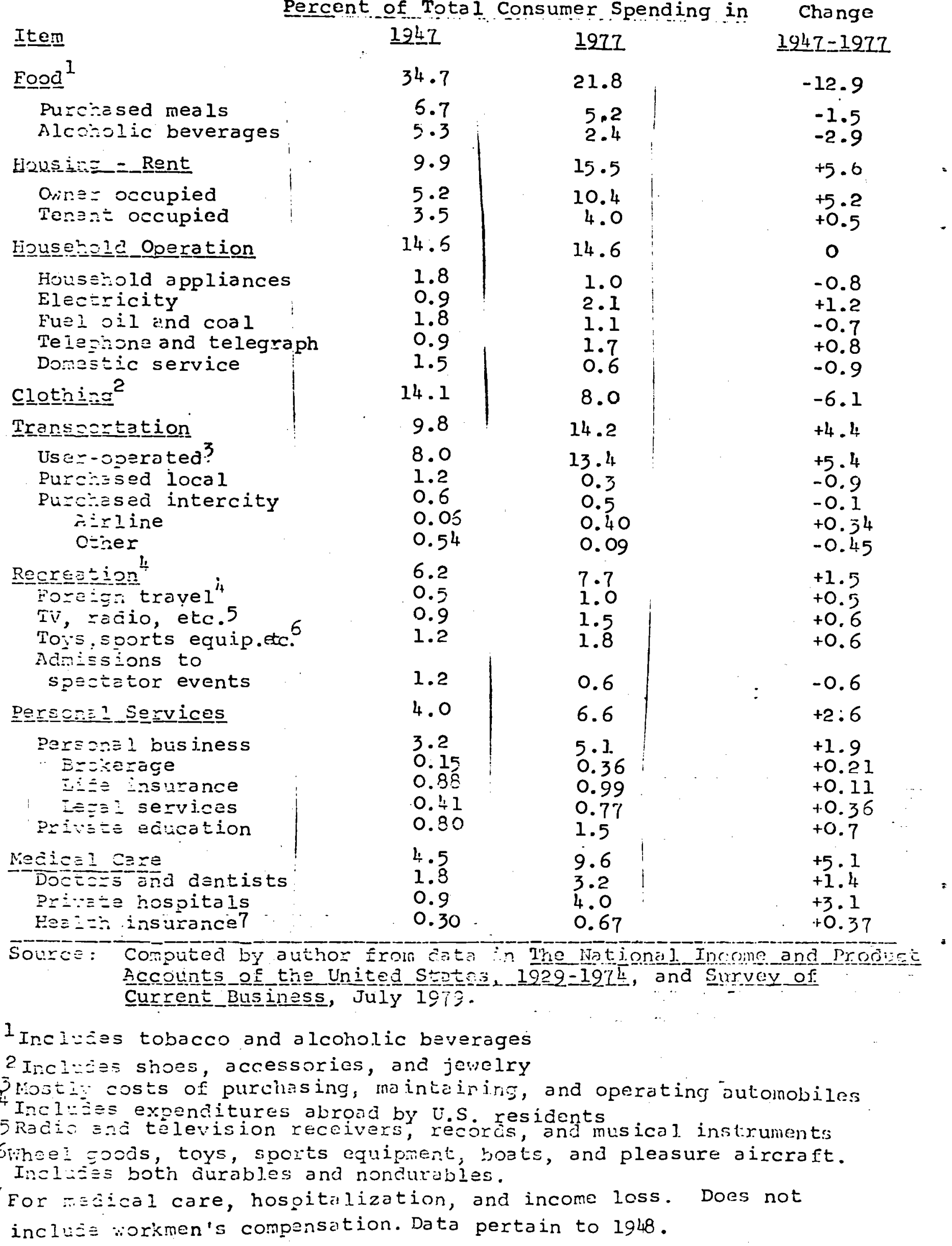


Food

Spending on virtually every category of food declined in relative importance over this 30 -year period, including even meals away frgom home (which came as a surprise to me). They claimed $6.7 \phi$ out of every dollar in 1947, but only $5.2 \phi$ in 1977. (One can only imagine what the French would think of this:)

The most dramatic decline, again surprisingly, was for al 1 coholic beverages--which accounted for only $2.4 \%$ of the 1977 budget as against $5.3 \%$ in 1947. In fact, real consumption of alcoholic beverages per capita increased only $12 \%$ over the 30 year period, despite the fact that its price relative to all consumption items fell by $26 \%$. Americans are indeed drinking (relatively) less.

Accompanying the decline in relative spending on food came a noticeable upgrading in diets (though not necessarily in their nutritive content). As Table 7 indicates, per capita consumption of beef almost doubled, per capita consumption of chicken almost tripled, and consumption of such luxury and convenience items as ice cream, processed fruits, and processed vegetables registered dramatic increases. Concurrent with these increases came sharp declines in per capita consumption of such obviously inferior goods as pork, lard, potatoes, and corn meal. Consumption of fresh fruits and vegetables also declined, though one may legitimately question whether this marked an increase in living siandards. (Adelle Davis lives:) 
Table 7

Civilian Per Capita Consumption of Selected

Food Items, 1940 and 1970 (in pounds per year)

\begin{tabular}{|c|c|c|c|c|c|c|c|c|}
\hline & $\begin{array}{l}\text { Beef and } \\
\text { Veal } 1 \\
\end{array}$ & $\begin{array}{l}\text { Chicken } \\
\text { Turkey }\end{array}$ & nd & \multicolumn{2}{|c|}{ 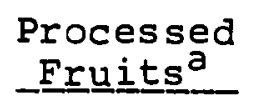 } & $\begin{array}{l}\text { Processed } \\
\text { Veqeetablebs }\end{array}$ & \multicolumn{2}{|c|}{ Ice Crealm } \\
\hline 1940 & 62 & 17 & & 34 & & 35 & 11 & \\
\hline \multirow[t]{2}{*}{1970} & 117 & 50 & & 54 & & 74 & 18 & \\
\hline & Pork & Laad & Pont & atㅡㅇㅡes & $\begin{array}{l}\text { Cor } \\
\text { and }\end{array}$ & 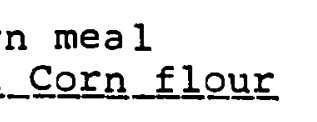 & $\begin{array}{l}\text { Fresh } \\
\text { Fruuㅡㄴ }\end{array}$ & $\begin{array}{c}\text { Fresh } \\
\text { Vegaetab } b \text { les }\end{array}$ \\
\hline 1940 & 74 & 14 & & 39 & & 22 & 139 & 117 \\
\hline 1970 & 66 & 5 & & 95 & & 7 & 81 & 99 \\
\hline
\end{tabular}

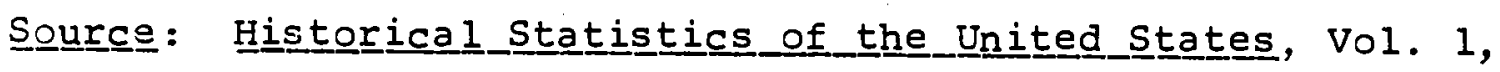
Series G881-915.

${ }^{a}$ Canned or frozen fruits and fruit juices; dried fruit

banned or frozen 
Hous ing

The costs of owning or renting a home or apartment claimed $15.5 \%$ of consumer budgets in 1977 as against $9.9 \%$ in 1947. Almost all of the increase is accounted for by ownner-occupiéd_housing, as growing income levels and strong incentives set up by the income tax system combined to induce a substantial shift from renting to owning. In 1940 only $44 \%$ of Americans owned their own home; by $1970,63 \%$ did (See Table 8, Part A).

It is worth noting that the rapid escalation of housing prices that we have experienced in recent years was not characteristic of the postwar period as a whole. In fact, between 1947 and 1977 housing prices increased only $151 \%$ while consumer prices in general increased $165 \%$. Housing commanded an increasing budget share because real per capita consumption of housing tripled.

Some data compiled by Lebergott (1976) enable us to go somewhat beyond these rather dry statistics. (See Table 8, Part A.) Between 1940 and 1970, crowding diminished significantly. The fraction of housing units with more persons than rooms declined from 20 percent to 8 percent, and the average number of parsons per room fell from .74 to .62 . The guality of housing also improved. The average age of the housing stock fell by 4 years, the fraction of housing units with running water increased from $70 \%$ to $98 \%$, and the fraction with flush toilets increased from $60 \%$ to $96 \% \cdot 15$ 
Table 8

Selected Changes in U.S. Housing, $1940-1970$

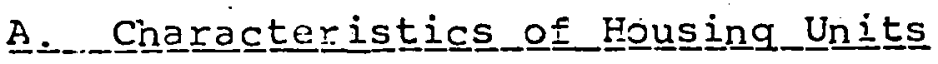

Average Age Percent Owner- Parsons per prorom (in yea몽) $19 \div 0 \quad 31.7$

$1970 \quad 27 \cdot 7$
44

63
Avierage Percent $>1$.0

.74

.62
20.3

8.0
Percent Hiaving Running Flush Water Toilets

70

60

98

96

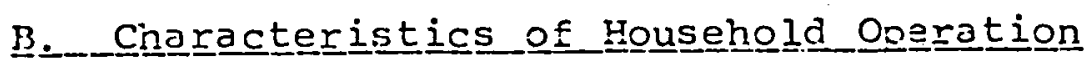

Percent with 파르느 Iíghting Central Electric

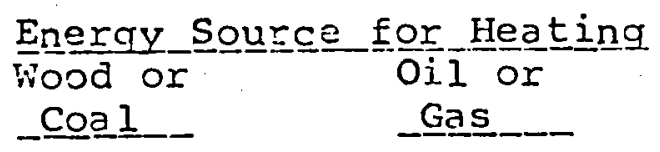

Energy Sou 드믄

78

4
.22

82
Percent Fenving Fechanical TeleRefrigerators visijon

44

o

$1970 \quad 78$

99

99

99

Solnrcess: Lebergott (1976); except For average age of (private nonfarm) housing stock and percent owner-occupied,

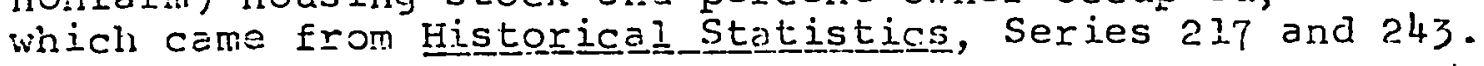




\section{Household}

Other improvements in the way Americans are housed become apparent only when we look at expenditures on household operation. While the total budget share spent on this category did not change, its composition underwent radical surgery. Table 6 shows, for example, that the budget share allocated to household appliances fell almost in half between 1947 and 1977. What this conceals is that the very steep decline in the relative prices of these items ${ }^{16}$ enabled Americans to have more and more while spending less and less. By 1977 , real spending per capita on household appliances was more than double what it had been in 1947, and the stoock of household durables must have increased by much more than this. Lebergott (1976) reports, for example, that the fraction of American families owning mechanical refrigerators increased from $44 \%$ to $99 \%$ between 1940 and 1970. The penetration of televisions went from zero in 1940 to virtually $100 \%$ by 1970.

Sources of power for household operation tell a fascinating tale. Spending on electricity more than doubled despite a decline in its relative price; real spending per capita increased more than five-fold. Concurrently, fuel oil and coal demanded a decreasing share of consumers' budgets despite a sharply inçreasing relative price. In fact, household usage of fuel oil and coal was unchanged in absolute terms between 1947 and 1977 despite a $53 \%$ increase in population. There was, in brief, a veritable revolution in the way homes 
were heated--away from dirty fuels like coal and wood, which also require considerable effort to use, and toward cleaner and more convenient fuels like oil, gas, and electricity. Lebergott (1976), for example, reports that the fraction of U.S. families heating by wood or coal dropped from $78 \%$ to $4 \%$, while the fraction using oil or gas rose from $22 \%$ to $82 \%$, between 1940 and 1970. (See Table 8, Part B.)

There were other notable changes as well. The average American used the telelephone about $51 / 2$ times as much in 1977 as in 1947 , but did so while allocating a budget share only twice as large.

One further item which is of trivial importance in consumer budgets nowadays, but is nonetheless interesting for the light it sheds on postwar chonges in America, is spending on domesticicservice. In 1947, Americans spent $1.5 \%$ of their budgets on domestic service--a sum almost as large as what they spent on doctors and dentists, and even larger than what they spent on either local public transportation or private education. About one household in 14 had a domestic employee. By 1977, the price of domestic service had increased $321 \%$ (versus $165 \%$ for consumer prices in general); only about one household in 27 had a domestic worker; ${ }^{17}$ and this budget item claimed only $0.6 \notin$ out of every consumer dollar. In real terms, the consumption of domestic services declined absolutely by $31 \%$ (or $55 \%$ on a per capita basis). In the murder mysteries of the 1970s, the butler was never there to do it. 


\section{Cllothing}

Food, clothing, and shelter are supposed to be the three basic necessities. Like food, clothing gobbled up a smaller and smaller share of the consumer's budget during the postwar period. By 1977 , consumers were spending only $8 \notin$ of every dollar on clothing (including shoes, jewelry, and accessories) as compared to $14 \notin$ in 1947 . In part, this was due to a decline in the relative price of clothing (by $28 \%$ from 1947 to 1977); but even real spending on clothing grew noticeably slower than total spending.

Food, clothing, and shelter together, it may be noted, absorbed fully $88 \%$ of total spending in 1947 but less than $75 \%$ in 1977. Room was being made for non-necessities.

\section{Transportaㅡ느으므}

Spending patterns on transportation goods and services reveal a pattern that is fascinating even though its basic outlines are well-known. The almighty automobilie was already well ensconced on the American scene by 19̀4--claiming $8 \%$ of consumer budgets for its purchase, care, and feeding (as compared with only $1.8 \%$ for all forms of purchased transportation). But the automobilization of America accelerated during the postwar period. By 1977 , consumers were spending $13.4 \phi$ out of every dollar on their cars, and a negligible $0.8 \notin$ on purchased transportation.

When we recall that air $\underline{\text { trravel }}$ was almost non-existent in 1947, but dominated purchased inter-city travel by 1977 , the comparison is more dramatic still. Purchased transportation 
excluding air travel took $1.7 \notin$ out of every consumer dollar in 1947, but only $0.4 \mathrm{k}$ in 1977. It is only a slight exaggeration to say that the postwar period witnessed the death of the train, the bus, and the subway.

Reccreation

Spending patterns on recreational goods and services offer some surprises. Even including foreign travel as recreation, 18 the share of recreational spending in consumer budgets increased only 1.5 percentage points during the postwar period. This is much less than Madison Avenue has led us to expect. Furthermore, more than all of this increase was accounted for by only three categories of spending: foreign travel (from $0.5 \%$ to $1.0 \%$ ); purchases of televisions, radios, and similar goods (from $0.9 \%$ to $1.5 \%$ ); and purchases of recreational hardgoods such as toys, sports equipment, bicycles, boats, etc. (from $1.2 \%$ to $1.8 \%$ ). The case of TV's is particularly remarkable since they claimed an increasing budget share despite a price that fell absolutely by $16 \%$ (that's right:). 19 America's love affair with the television is a notable feature of the postwar period.

Several categories of recreational spending actually made decreasing claims on the consumer's budget, notably admiss ions to to spectator events (movies, theater, sport events) which received only $0.6 \notin$ out of every consumer dollar in 1977 as compared to $1.2 \not$ in 1947 . And this occurred despite the fact that prices for such events rose $300 \%$ (as compared to only $165 \%$ for overall consumer prices). Real purchases of 
such admissions actually declined $16 \%$ despite rising population and rising real income. So much for the alleged boom in movies and spectator sports.

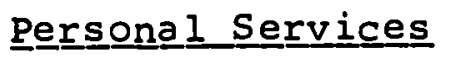

Personal services are an odd mixture including such diverse items as private educational spending, life insurance, legal fees, and the costs of stock brokerage. All of these grew rapidly, with spending on stockbrokers displaying the fastest growth (increasing more than 18-fold) and life insurance costs having the smallest (increasing more than 8-fold).

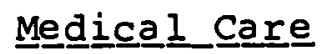

Everyone knows that Americans are spending more on medical care than they did early in the postwar period $(9.6 \%$ of consumer budgets as compared to $4.5 \%$ ). And everyone knows that consumers are unhappy about the soaring costs of medical care. The tremendous increase in the share of the budget going to medical care is due both to its increasing relative price and to a rapid increase in real consumption of medical services, especially hospital services. While health has improved demonstrably during the last 30 years (more on this in section 6), this may have been due more to advances in public health than to increased personal expenditures on medical care. Summary

During the 30-year period from 1947 to 1977 , real consumption per capita increased by more than $80 \%$. As compared to their counterparts in 1947, Americrns in 1977 travelled by 
airplane and watched TV vastly more. They replaced pork, lard, corn meal and fresh vegetables in their diets by beef, paultry, and processed fruits and vegetables. They made much greater use of electricity, the telephone, and hospitals, and they spent much more on their own homes--which they heated by gas and oil rather than by coal and wood. They bought more toys, sports equipment, and other recreational goods (but not more admission tickets), and devoted a good deal more of their budgets to nurturing their cars.

During the same period, travel by bus, rail, and subway diminished greatly; domestic servants nearly disappeared from the scene; and the basic necessities of life--food, clothing, and sinelter--commanded ever decreasing shares of the consumer budget.

One seems forced to the conclusion that the average level of economic well-being both changed in content and improved drastically. Virtually everyone shared in economic growth, but not equally. I turn my attention now to trends in income inequality.

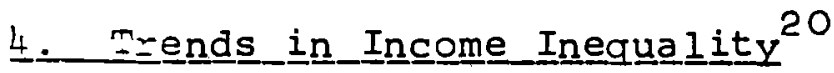

Whereas the level of income was mostly increasing during the postwar period, the central stylized fact about incore inequality has been its constancy. Table 9 displays the basic data that support this fact, and they certainly seem 
Table 9

The Distribution of Income, Families

and Unrelated Indiviłuals Pooled, 1947-1977

\begin{tabular}{lccccccc}
\hline & \multicolumn{7}{c}{ Percentage Share of : } \\
Year & $\begin{array}{l}\text { Lowest } \\
\text { Fifth_ }\end{array}$ & $\begin{array}{l}\text { Second } \\
\text { Fifth }\end{array}$ & $\begin{array}{l}\text { Middle } \\
\text { Eifth }\end{array}$ & $\begin{array}{l}\text { Fourth } \\
\text { Fifth }\end{array}$ & $\begin{array}{c}\text { Highest } \\
\text { Fifth }\end{array}$ & Top 5\% & $\begin{array}{l}\text { Gini } \\
\text { Ratio }\end{array}$ \\
1947 & 3.5 & 10.6 & 16.8 & 23.6 & 45.5 & 18.7 & .418 \\
1952 & 3.5 & 10.9 & 17.3 & 24.1 & 44.3 & 18.4 & .408 \\
1957 & 3.4 & 10.9 & 18.0 & 24.7 & 42.9 & 16.5 & .397 \\
1962 & 3.4 & 10.4 & 17.5 & 24.8 & 43.9 & 16.8 & .407 \\
1967 & 3.6 & 10.6 & 17.5 & 24.8 & 43.4 & 16.5 & .400 \\
1972 & 3.7 & 10.0 & 16.9 & 24.7 & 44.8 & 17.4 & .414 \\
1977 & 3.8 & 9.7 & 16.5 & 24.9 & 45.2 & 17.3 & .419 \\
Highest & 3.9 & 11.2 & 18.0 & 24.9 & 45.5 & 18.7 & .420 \\
Mean & 3.5 & 10.5 & 17.3 & 24.6 & 44.1 & 17.2 & .408 \\
Lowest & 3.1 & 9.7 & 16.5 & 23.6 & 42.9 & 16.5 & .397 \\
\hline
\end{tabular}

Source: Current Population Reports, Series P-60, No. 118, Table 13. 
unequivocal. According to the Gini ratio, for example, 1957 was the most equal year and 1961 was the most unequal. Inequality in 1977 was the same as it was in 1947. If we accept these data at face value, there clearly is no postwar trend in income inequality.

But there are a host of very good reasons not to accept these data at face value--which is why this section occupies __ pages instead of one sentence. First, the changing structure of the U.S. population by age, by sex, and by family composition raise questions about the comparability of the data over time. Rough "corrections" for these demographic shifts point to a slight trend toward equality which the raw data mask. Second, attempts to improve the measurement of income by subtracting taxes, adding transfers in kind, and so on seem to produce an income concept whose distribution displays greater equalization over the period than does census income. Third, and most speculatively, it has been suggested that the portion of measured inequality that is simply due to the fact that different people are at different stages in their life cycles has increased over the postwar period so that, if we could measure it, the distribution of lifetime incomes would show a greater trend toward equality than the distribution of annuala incomes. It turns out, most disagreeably for students of the subject, that the sensitivity of the distribution of income in the United States to subtle changes in the recipient population, the definition of income, or the choice of accounting period is 
extremely large--much greater in fact than any changes we can find in inequality through time. This, I think, is the most fundamental sense in which we can say that inequality has been relatively constant; but it also explains the urgency of sorting out these seemingly boring issues of definition.

Such issues will occupy the bulk of this section. But before getting buried in the details, I pause briefly to consider a prior question: Does the (relatively constant) postwar income distribution, with its Gini ratio in the $.40-.42$ range, represent a lot of inequality or a little?

A. Is the Bottle le Half Full or Ha lf Empty?

Clearly, to paraphrase an exceedingly wise folk saying, where you stand on this question depends on where you sit in the income distribution. While an "objective" answer is clearly out of the question, let me attempt several ways of providing a frame of reference. Comparisons Over Time

I have already noted that changes in inequality during the postwar period have been too small to provide useful intertemporal comparisons. According to the Gini measure, 1957 had the most equal distribution while 1961 had the least equal. Yet the difference between their Gini ratios is a scant $6 \%$ (see also Figure 1). So if we want to draw useful comparisons through time, we will have to look back further into U.S. history. Naturally, the quality of the data tails off rather quickly as we do this; but some distributions for earlier years 
have been constructed. Budd (1967, Introduction) has compiled more or less consistent income distributions for several prewar and several postwar years (See Table 10)..$^{21}$ The conclusion seems to be that there was substantial equalization during the years of the Great Depression and World War II, but very little change since then. The postwar distribution seems noticeably more equal than the distribution in 1929.

Compar $\underline{i}$ sons Over_Space

Instead of comparing the postwar income distribution of the United States with the U.S. income distribution in earlier years, we might compare the U.S. with other countries at the same time. The hazard here is that different countries use different concepts of income and different definitions of the recipient unit than the United States and, as just mentioned, income distributions can be quite sensitive to these choices. of the many international comparisons that have been made, two seem worth reporting here. Some years ago Irving Kravis (1960, 1962) made a careful series of binary comparisons by taking the income distributions of 10 foreign countries and comparing each one with a diffeerent U.S. distribution selected to be conceptually alike. His conclusion was that income inequality in the U.S. was rather less than in several less developed countries, but somewhere near the middle of a group of modern industrial nations. More recently, a study by Malcolm Sawyer for the OECD (1976) attempted to put the distributional statistics of the various $O E C D$ nations on an equal footing so that comparisons could be 
Table 10

Prewar and Postwar Income Distributions ${ }^{a}$

\begin{tabular}{|c|c|c|c|c|c|c|c|}
\hline \multirow[b]{2}{*}{ Yea모 } & \multicolumn{3}{|c|}{ Percentare } & \multicolumn{2}{|l|}{ Share of: } & \multirow[b]{2}{*}{$\begin{array}{l}\text { Top } \\
5 \%\end{array}$} & \multirow[b]{2}{*}{ 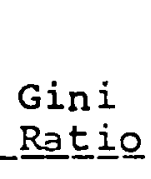 } \\
\hline & $\begin{array}{l}\text { Lowest } \\
\text { Fifth }\end{array}$ & $\begin{array}{l}\text { Second } \\
\text { Fifth }\end{array}$ & $\begin{array}{l}\text { Middle } \\
\text { Fifth_- }\end{array}$ & $\begin{array}{l}\text { Fourth } \\
\text { Fif트므- }\end{array}$ & $\begin{array}{l}\text { Highest } \\
\text { Fifth }\end{array}$ & & \\
\hline & & & & & & & $\ldots$ \\
\hline 19.29 & $3 \cdot 5$ & 9.0 & 13.8 & $19 \cdot 3$ & 54.4 & 30.0 & .49 \\
\hline $1935-36$ & 4.1 & 9.2 & 14.1 & 20.9 & $5 I .7$ & 26.5 & .47 \\
\hline 1941 & 4.1 & 9.5 & $15 \cdot 3$ & $22: 3$ & 48.8 & 24.0 & .44 \\
\hline $1947^{b}$ & 5.0 & 11.0 & 16.0 & 22.0 & 46.0 & 20.9 & .40 \\
\hline $196 a^{b}$ & 4.6 & 10.9 & 16.3 & $22 \cdot 7$ & $45 \cdot 5$ & 19.6 & .40 \\
\hline
\end{tabular}

Source: Budd (1967), Table 1, p. xiii.

Families and unrelated individuals, pooled. Based on Office of Business Economics (now Bureau of Economic Analys is) income concept.

$b_{\text {These Lorenz curves cross. }}$ 
28.

made. He found the U.S. and France to have the most income inequality among OECD nations.

The overall conclusion, then, seems to be that income inequality in the U.S. is higher than in many industrialized nations, but lower than in most less developed countries. Interpreting the 1977 Distribution

Another way to appraise the degree of inequality is to subject the most recent data on income shares to further scrutiny along the following lines. (See Table 11.) Data for 1977 tell us that the richest fifth of American families received 8 times as much income as the poorest fifth. ${ }^{22}$ This $8: 1$ ratio, which is characteristic of the entire postwar period, strikes me as a very substantial income gap. But some further facts make this inequality seem less severe.

First, it turns out that richer families tend to be larger. The richest fifth of families in 1977 actually included $28 \%$ more persons than the poorest fifth. Adjusting income to a per capita basis would bring the $8: 1$ income ratio down to $6 \frac{1}{4}: 1$. Second, it turns out that the richest fifth of families in 1977 contained $29 \%$ of all the wage earners in the country, whereas the poorest fifth contained only $91 / 2 \%$. Thus on a per-earner basis, the income ratio was only 2.6:1. And even this ratio can be lowered by considering work effort. The richest fifth of families supplied over $30 \%$ of the total weeks worked in the economy during 1977, while the poorest fifth supplied only $7.5 \%$. Thus, on a per-week-of-work basis, the income ratio 
Table 11

Characteristics of the Upper and Lower Tails of the Distribution of Family

Income, 1977

\section{Percentage Share of:}

Income Group Income Persons Earners Weeks of

$\begin{array}{lrrrr}\text { Top Fifth } & 41.6 & 22.4 & 28.9 & 30.4 \\ \text { Bottom Fifth } & 5.2 & 17.5 & 9.5 & 7.5 \\ & & & & \\ \text { Top Tenth } & 25.6 & 11.4 & 15.1 & 15.7 \\ \text { Bottom Tenth } & 1.7 & 8.8 & 4.0 & 2.9\end{array}$

Source: Cuurrent Population_Reports, Series P-60, No. 118, Table 3, p. 21 . 
between rich and poor was only $2: 1$. This certainly does not seem like an unreasonable degree of inequality. ${ }^{23}$

Thus we can use the very same data to show that the income gap between the rich and the poor is anything from $8: 1$ to 2:1--an ambiguity that will make propagandists (from either side) happy. Which ratio is "right?" I certainly do not know. On the one hand, if differences in family size are voluntary (richer parents "buy" more children), and decisions over whether and how much to work are involuntary (due mostly to whether jobs are available), then none of the corrections are warranted and the $8: 1$ ratio seems most meaningful. On the other hand, if we assume that people voluntarily choose their labor supply but not their family size, then all the corrections leading to a 2:1 ratio are appropriate. To state the issue this way is to demonstrate its irresolvability. Clearly, all of these choices have voluntary and involuntary aspects.

B.-_Demographic Changes and the Problems They Cause I turn now to the first of our problems in interpreting the postwar income distribution data, and in accepting the conclusion that inequality has not changed: demographic changes. ${ }^{24}$ This section makes three main points. First, demographic changes have been substantial. ${ }^{25}$ second, measured income inequality is quite sensitive to the composition of the underlying population of recipient units. Third, many of the demographic changes that occurred were of the sort that raise 
measured inequality.

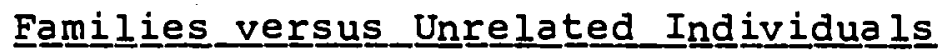

A logical place to start is with the division of the U.S. population between families and unrelated individuals. As Table 12 shows, this division has changed dramatically over the postwar period, and especially over the last decade. In this ten-year period, the population of the United states over the age of 16 increased $19 \%$, but the number of census families increased only $14 \%$, and average family size fell from 3.67 to 3.33 persons. By contrast, the number of unrelated individuals grew by an astounding $75 \%$ in these same 10 years. These figures reflect several striking demographic trends, including a grcwing propensity for both the young and the old to live apart and an increasing incidence of brcken marriages.

Table 13 shows why these developments are important for interpreting income distribution data. Unrelated individuals have always had much lower and much more unequally distributed incomes than have families, though there was some convergence in both respects during the last decade. Thus the demographic shifts that underlie Table 12, many of which clearly represent improvements in well-being, lowered average income and increased income inequality when families and unrelated individuals are pooled in a single distribution.

A first step, therefore, is to look separately at trends in the distributions among families and among unrelated individuals (UIs). These are summarized in Tables 14 and 1 ; 
Table 12

Compositition of Income Units, $1247=1277$

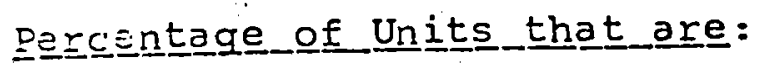

Families

Unrelated indiviàuals
1E:-

$82.1 \quad \equiv 0.8 \quad 79.1 \quad 71.2$

$\begin{array}{llll}17.9 & 19.2 & 20.9 & 28.8\end{array}$

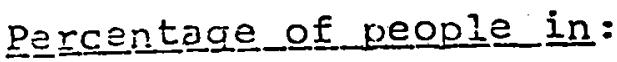

Families

Unrelated indivicuals
$93.4 \quad 33.0 \quad 93.3 \quad 89.2$

$\begin{array}{llll}6 & 7.0 & 6.7 & 10.8\end{array}$

Sourree: Current population Revorts, Series p-60, Nos. 59, 114 , li8, ana series P-20, Nos. 21,33 . 
Tabla 13

Comparison of Income Distributions Among Eamilies and Among Unrelated Individuals. 101:-10?7

\begin{tabular}{|c|c|c|c|c|c|}
\hline & & ean Rea & $=0 m e^{a}$ & & \\
\hline & & 1247 & 1257 & 1267 & 1977 \\
\hline (1) & Dar family & $\$ 9,620$ & $\$ 11,719$ & $\$ 15,974$ & $\$ 18,264$ \\
\hline (2) & $\begin{array}{l}\text { Per unrelated } \\
\text { individual }\end{array}$ & 4,306 & 4,834 & 6,403 & 7,981 \\
\hline (3) & Pstio (2)/(1) & .45 & .41 & .40 & .44 \\
\hline & & Gini $\underline{i} \underline{a}$ & & & \\
\hline (4) & Among families & .376 & .351 & .348 & .364 \\
\hline (5) & $\begin{array}{l}\text { himang unrelated } \\
\text { insividuals }\end{array}$ & .552 & .489 & .490 & .443 \\
\hline (6) & Pacio $(5) /(4)$ & 1.47 & 1.39 & 1.41 & 1.22 \\
\hline & & & & . & ${ }^{\circ}$ \\
\hline
\end{tabular}

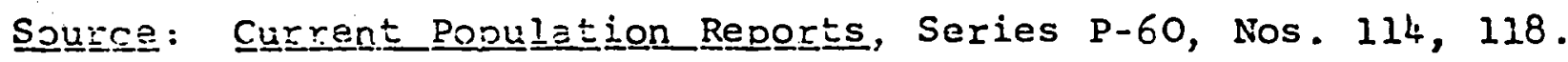

a Mean income in 1977 dollars. Price deflation by Consumer Price Insex. 
Table 14

The Distribution of Income Among Families, $1947-1977$

\section{Percentage Share of:}

\begin{tabular}{|c|c|c|c|c|c|c|c|}
\hline Yeea모 & $\begin{array}{l}\text { Lowest } \\
\text { Fifth }\end{array}$ & $\begin{array}{l}\text { Second } \\
\text { Fifth }\end{array}$ & $\begin{array}{l}\text { Middle } \\
\text { Fifth }\end{array}$ & $\begin{array}{l}\text { Fourth } \\
\text { Fifth }\end{array}$ & $\begin{array}{l}\text { Highest } \\
\text { Fifthㅡ }\end{array}$ & Top $5 \%$ & $\begin{array}{l}\text { Gini } \\
\text { Ratíio }\end{array}$ \\
\hline 1947 & 5.0 & 11.9 & 17.0 & 23.1 & 43.0 & $17 \cdot 5$ & .376 \\
\hline 1952 & 4.9 & $12 \cdot 3$ & 17.4 & 23.4 & 41.9 & $17 \cdot 4$ & .368 \\
\hline 1957 & 5.1 & $12 \cdot 7$ & 18.1 & 23.8 & 40.4 & 15.6 & .351 \\
\hline 1962 & 5.0 & 12.1 & $17 \cdot 6$ & 24.0 & 41.3 & $15 \cdot 7$ & .362 \\
\hline 1967 & $5 \cdot 5$ & 12.4 & $17 \cdot 9$ & 23.9 & 40.4 & 15.2 & .348 \\
\hline 1972 & 5.4 & 11.9 & $17 \cdot 5$ & 23.9 & 41.4 & $15 \cdot 9$ & .360 \\
\hline 1977 & 5.2 & 11.5 & $17 \cdot 5$ & 24.2 & 41.5 & $15 \cdot 7$ & .364 \\
\hline Highest & $5: 6$ & $12 \cdot 7$ & 18.1 & 24.2 & 43.0 & $17 \cdot 5$ & .379 \\
\hline Mean & 5.1 & 12.2 & 17.6 & 23.8 & 41.3 & 16.0 & .361 \\
\hline Lowest & 4.5 & 11.6 & 17.0 & 23.1 & 40.4 & 15.2 & .348 \\
\hline
\end{tabular}

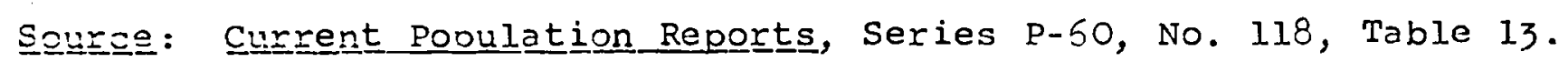


Table 15

The Distribution of Income Among

Unrelated Individuals, 1947-1977

\section{Percentage Share of:}

\begin{tabular}{|c|c|c|c|c|c|c|c|}
\hline Yea프 & $\begin{array}{l}\text { Lowest } \\
\text { Eifth }\end{array}$ & $\begin{array}{l}\text { Second } \\
\text { Fifth }\end{array}$ & $\begin{array}{l}\text { Middle } \\
\text { Fifth }\end{array}$ & $\begin{array}{l}\text { Fourth } \\
\text { Fifth }\end{array}$ & $\begin{array}{l}\text { Highest } \\
\text { Fifth }\end{array}$ & Top $5 \%$ & $\begin{array}{l}\text { Gini } \\
\text { Ratii으. }\end{array}$ \\
\hline 1947 & 2.0 & 6.2 & $12 \cdot 7$ & $22 \cdot 5$ & 56.6 & 29.3 & .552 \\
\hline 1952 & 2.6 & $7 \cdot 7$ & 14.7 & 25.4 & 49.7 & 20.2 & .480 \\
\hline 1957 & 2.6 & $7 \cdot 3$ & $13 \cdot 7$ & 25.4 & 50.9 & 19.7 & .489 \\
\hline 1962 & 2.6 & $7 \cdot 5$ & 12.8 & 24.4 & 52.7 & 20.8 & .502 \\
\hline 1967 & 3.0 & $7 \cdot 5$ & $13 \cdot 5$ & 24.5 & 51.5 & 21.1 & .490 \\
\hline 1972 & 3.3 & 8.2 & 13.8 & 23.9 & 50.9 & 21.4 & .478 \\
\hline 1977 & 4.1 & 9.0 & $14 \cdot 7$ & 24.0 & 48.2 & 19.6 & .443 \\
\hline Highest & 4.2 & 9.0 & 14.8 & 27.0 & 56.6 & 29.3 & .552 \\
\hline Mean & 2.8 & 7.6 & $13 \cdot 7$ & $24 \cdot 7$ & 51.1 & 21.0 & .489 \\
\hline Lowest & 1.4 & 6.2 & $12 \cdot 7$ & $22 \cdot 5$ & 47.9 & 18.7 & .442 \\
\hline
\end{tabular}

Source: Current Population Reports, Series p-60, No. 118, Table 13. 
but before considering these data one technical point must be made (with due apologies to the casual reader). Data on percentile shares for the years 1958 through 1977 were computed in the obvious way: by ranking consumer units and adding up their incomes. For the years 1947 through 1957, however, the micro data required to do this were unavailable, so shares were estimated and interpolated from grouped data. The post-1958 data are thus more trustworthy than the pre-1958 data, and we must keep this in mind in looking for trends. 26

In the case of families, the data show some trend toward equality before 1957 though little since then-which raises the question of whether we are seeing a trend or a statistical illusion. Between 1947 and 1957, there were clear (if modest) upward trends in the shares of the second, middle, and fourth fifths. All of these gains came at the expense of the upper fifth (and especially the top 5\%), whose shares declined quite markedly. Since 1958, however, there is little trend of any kind. The only development worth noting is the climb of the share of the lowest fifth from the $4.5-5 \%$ range to around $5.5 \%$ during the years 1961-1966. The host of public assistance policies introduced or expanded around that time is, of course, the leading explanation for this improvement in the lot of poor families.

Using the Gini ratio to summarize these data, all of this can be said more concisely by noting that, once cyclical effects are removed, the Gini ratio exhibits a mild downward 
trend (about -.002 per year) until 1957 and no trend thereafter. 27

The story with unrelated individuals seems to have been just the reverse: relative stability until 1957, followed by a marked trend toward equality. 28

The share of the lowest fifth fluctuated aimlessly through 1957, apparently underwent a shift (not shown in Table 15) when the nature of the data changed in 1958, and marched steadily upward thereafter. The shares of the second and third fifths did very little until about 1964, and then also started to move up strongly. In total, the combined share of the lower $60 \%$ of the income distribution increased from $25.4 \%$ to $28 \%$ between 1964 and $1975--a$ substantial improvement. The upper $40 \%$, naturally, were the losers. Beginning around 1960 or so, the shares of these two quintiles exhibit a noticeable downward trend.

All of these conflicting forces:

*an equalizing trend in the family distribution until 1957 but not after (Table 14);

*an equalizing trend in the distribution among UI's since 1957 but not before (Table 15):

*a decrease in the portion of the population in families (Table 12):

*a widening of the income gap between families in UI's between 1947 and 1957 and a narrowing of that gap from 1967 to 1977 (Table 13):

get amalgamated in the pooled distribution to produce very 
little overall trend despite some equalization in both component distributions.

\section{The Changing American Family}

But we do not. solve the problem of demographic change simply by separating families from unrelated individuals (UIs). For, as we learned in Tables 2 and 3 , both the composition of families and the nature of the UI population underwent substantial demographic change during the postwar period. To keep the discussion manageable, I limit myself to families in what follows. But the reader should keep in mind that equally dramatic changes were occurring in the demography of unrelated individuals, with corresponding effects on the income distribution.

Just what were the changes in the structure of the American family, and how did they affect the distribution of income? We can answer these questions with the help of Table 2 (on page ___), which lists some important demographic changes, and Table 16, which illustrates the extreme sensitivity of income inequality to the nature of the recipient unit. 29

Average family size was constant between 1947 and 1967 , but fell dramatically during the following ten years due to a sharp decline in the number of children. This means that family income per capita grew more rapidly than mean family income. The distribution of families by size shows that most of the statistical "action" came in the two tails. At one extreme the fraction of families with two members drifted up slowly from 1947-1967, and then skyrocketed between 1967 and 
Gini Ratios for Various Types of Families, 1964

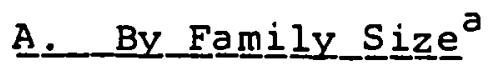

$\begin{array}{ll}\text { Two persons } & .408 \\ \text { Three persons } & .337 \\ \text { Four persons } & .311 \\ \text { Five persons } & .316 \\ \text { Six persons } & .335 \\ \text { Seven persons or more } & .355\end{array}$

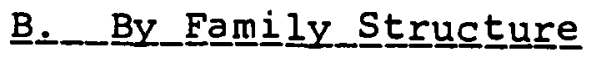

$\begin{array}{lll}\text { Female headed } \quad .434 & & \\ \text { Male headed } \quad .343 & & \\ \text { Married, wife present } & .339 & .290 \\ \text { Working wife } & & .365 \\ \text { Non-working wife } & & .365\end{array}$

C._-By_Res idence

$\begin{array}{ll}\text { Nonfa rm } & .347 \\ \text { Fa rm } & .433\end{array}$

D.

14 to 24 years .302

25 to 34 years .291

35 to 44 years $\quad .316$

45 to 54 years .330

55 to 64 years $\quad .379$

65 years and over .471

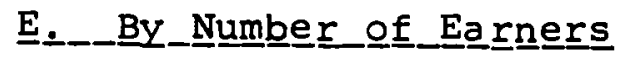

No earners $\quad .418$

One earner $\quad .361$

Two earners $\quad .297$

Three earners
or more $\quad .285$

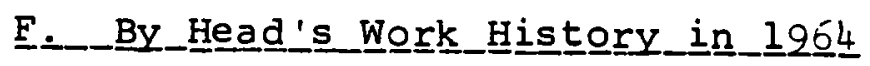

Did not work $\quad .452$

Worked .327

At full-time jobs .311

At part-time jobs .444 


\section{G._-By_Collo으}

White $\quad .349$

Nonwhite $\quad .399$

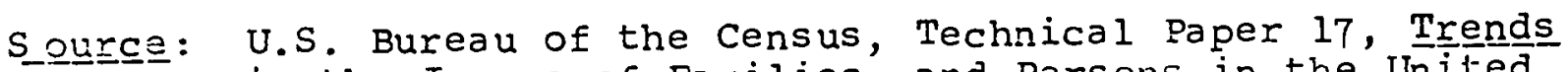
in the Income of Families and Dersons in the United States, $1947-1954$, Tables $23,2 !, 25,26,28,32$, and 33 .

a The Lorenz curves for 3 -person and 6-person families cross between the 60 th and 80 th percentiles.

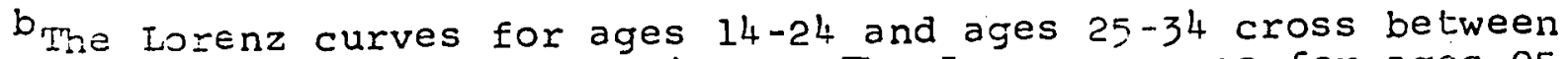
the 30 th and $95 \mathrm{th}$ percentiles. The Lorenz curves for ages $25-34$ and ages $35-44$ cross between the 4 Oth and coth percentiles. 
34.

1977.30 At the other extreme, the number of families with six or more members also drifted up slowly curing the first two postwar decades, but then took a nosedive between 1967 and 1977. Relative to 1947, we now have more childless couples, fewer families with four children or more, and fewer extended families. But since Table 16 shows that the greatest degree of inequality is found among the largest and smallest families, it is not clear that these very large demographic shifts had much influence on the trend in inequality.

The next change in family composition worthy of note is the increased incidence of female headship. The fraction of families headed by females, which fluctuated in a range around $10 \%$ from 1947 to 1967 , shot up to $14.4 \%$ by 1977 . Since female-headed families normally have lower incomes than male-headed families, and since Table 16 shows that they also typically have more unequally distributed incomes, this factor tended to retard the growth of income per family and to increase inequality.

The farm population dwindled remarkably during the postwar period. In 1947, more than one family in six lived on a farm. By 1977, this was down to one family in 26 . It is quite likely that this migration from the farm reduced income inequality because farm incomes are much more unequally distributed than nonfarm incomes (see Table 16), and because farm incomes are typically much lower than nonfarm incomes. However, there is a complication that bears mentioning. Census money income 
excludes income received in kind, which is probably far more important on farms than elsewhere. Since Census data therefore overstate the gap between farm and nonfarm incomes, they probably also overstate the equalization caused by the migration from rural areas.

The age structure of families (as measured by the age of the family head) also changed dramatically. Between 1947 and 1977, the number of young (under 25) and old (65 and over) families grew much faster than the number in the prime earning years (ages 35-64). (Table 2.) Given the facts that families at the extremes of the age distribution always have much lower incomes than those in the middle, and that the income distribution among the elderly is quite unequal (Table 16), this development pushed inequality up. 31

In summary, the changing age-sex composition of family heads pushed the distribution of income toward greater inequality while the movement off the farm pushed in the opposite direction. In addition, there were a host of other demographic changes, some of which may have had substantial effects on measured income inequality. Indeed, given the extreme sensitivity of income inequality to demography that Table 16 documents, it is somewhat amazing that the distribution of income among families changed so little during a period when the demographic structure changed so much. 


\section{Measured Inequality and the Income Concept}

It has already been mentioned that the-concept of income used by the Census Bureau is far from ideal. Two obvious questions follow. First, if we could measure income better, would inequality appear less than in the official data? Second, if we could measure income better, would a stronger trend toward equality emerge? This section answers both of these questions in the affirmative. 32

Specifically, this section deals with five potential improvements in the Census income concept: subtracting personal taxes, adding in transfers in kind, adding in other types of income in kind, including capital gains, and correcting for underreporting of income. In addition, the influence of cash transfers on inequality is examined. As in the previous section, we shall see that changes in the definition of income typically cause changes in measured inequality that exceed anything we can find in the time series.

\section{Perㅗ으믈 1 Taxes}

We can probably make sense of an income distribution that excludes both public transfer payments and taxes or one that includes both. But census income is an awkward halfway house which includes transfers but fails to deduct taxes. Thus a first step in improving the census income concept is to subtract personal taxes. 33 In practice, most studies have deducted only feederal. 
in the alleged "post-tax" income figures. 34 The federal income tax is decidedly progressive. The payroll tax, while regressive

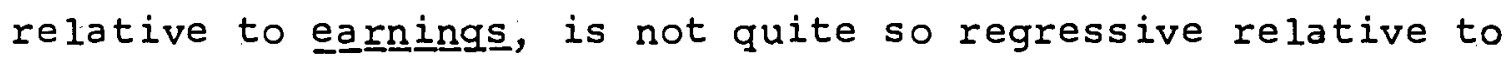
inncome because low income groups receive a large proportion of their total income in transfers. Deducting both income and

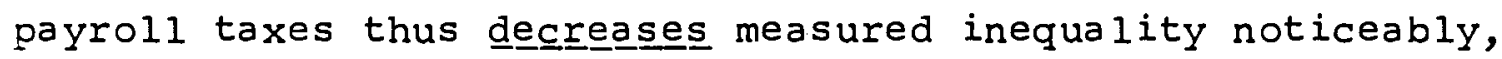
as Table 17 shows. 35

A similar study by Taussig (1973), using 1967 data and an income concept similar to census income, reported that federal personal taxes reduced the Gini coefficient from .376 to .361 . It seems unlikely that including state and local income taxes would change these figures very much, but including sales and excise taxes might. 36 I conclude that the distribution of post-tax income in any one year is moderately more equal than the distribution of pre-tax income. The difference, however, is not dramatic.

Because personal taxes have grown faster than pre-tax income (Table 5), it seems obvious that subtracting them from Census income each year would increase the trend toward equality. Yet a careful study of the 1950-1970 period by Reynolds and Smolensky ( 1977 ) contradicts this supposition. They conclude, instead, that while taxes equalized the distribution of any one year, taxes had almost no effect on the trend in inequality of after-tax income. 37 Why the discrepancy? Reynolds and 
Table 17

Effect of Federal Personal Taxes on the Distribution of Family Income, 1972

\begin{tabular}{lccc} 
Share Bef: & Beffore_Tax & Afteer_Tox & Change \\
Lowest fifth & 4.92 & 5.26 & +0.34 \\
Second fifth & 11.59 & 12.23 & +0.64 \\
Middle fifth & 17.22 & 17.69 & +0.47 \\
Fourth fifth & 23.57 & 23.87 & +0.30 \\
Highest fifth & 42.70 & 40.95 & -1.75 \\
\hline
\end{tabular}

Source : Radner (1979). 
Smolensky (1977) show that federal personal taxes became less progressive between 1950 and 1970 for several reasons, the most important of which were (a) the increasing importance of the payroll tax relative to the income tax, (b) the decreasing progressivity of the income tax.

Trans

Recent years have witnessed a sharp controversy, both in academic journals and in the popular press, over the extent to which adding transfers in kind to income would change the portrait of inequality in postwar America. The controversy is over the quanntitatative dimensions of the effect, not its qualititative direction, since no one disputes that (a) transfers in kind have grown much faster than factor incomes, 38 and $(b)$ the distribution of transfers in kind is much more pro-poor than the distribution of factor incomes. These undisputed facts are enough to conclude that more equality in any given year and a stronger trend toward equality would emerge if the distribution of income were adjusted to include transfers in kind. But how much more?

The reason for the controversy boils down to this. While it is straightforward to estimate the total volume of in-kind programs such as food stamps, public housing, public education, and medical services provided under Medicare and Medicaid, it is not quite so straightforward to distribute these 
totals among income groups. And it is even more difficult to decide how to price them out. Treating a dollar spent on a transfer in-kind as equivalent to a dollar received in cash seems inappropriate unless the transfer in kind provides precisely what the consumer would have used the extra cash to purchase. However, there are two cases in which transfers in kind are just as good as cash. 39 The first is when the government provides goods that the consumer would otherwise have purchased anyway, and provides less of them than the consumer would have bought for himself. In this case, the transfer in kind does not affect budget allocation decisions and is equivalent to a cash transfer. Food stamps come close to fitting this pattern; it is arguable whether Medicare-Medicaid do. However, it seems clear that public education and public housing are not of this character. The second case is where the good that is distributed can be resold with insubstantial transactions costs (e.g., a transferable ration coupon). It is clear, however, that few, if any, public programs fit this second model.

Apart from these exceptional cases, it is conceptually clear that transfers in kind are worth less to recipients than what they cost to provide. 40 But how much less? This question can only be answered by positing some utility function and assessing the cash equivalent (in utility terms) of each transfer in kind. An excellent recent study by Smolensky et all- (1977) did precisely this, and concluded that the cash equivalent of $\$ 1$ in either food stamps or rent supplements was 
essentially $\$ 1$, but that $\$ 1$ spent on either public housing or Medicare/Medicaid was worth substantially less than $\$ 1$ to recipients. 41

Table 18 summarizes the results of two conflicting studies of the effects of transfers in kind on the distribution of income in 1972, under the (possibly false) assumption that such transfers should be valued at full cost. The adjustment adds between 1.8 and 2.3 percentage points to the share of the poorest fifth of families, depending on whose assumptions abaut the volume and distribution of noneducational transfers we use, 42 and subtracts a like amount from the share of the richest fifth. These are substaniial changes. However, the increment to the share of the lowest fifth would be reduced by about 0.5 percentage point if transfers in kind were valued at $70 \%$ of cost instead. 43 We are thus far from agreement over how large the effect of transfers in kind has been on the postwar trend toward equality. After a series of papers by Browning (1976, 1979) and Smeeding (1979a, 1979b), airing this and a number of other issues, it appears (Smeeding, 1979b) that Browning's adjustments (including one for transfers in kind) raise the share of the lowest fifth of families in 1972 from 5.410 in the raw. data all the way to $8.5 \%$. Smeeding's corrections, by contrast, raise it only to $6.5 \%$. The difference is hardly inconsequential, though only part of it traces to their aivergent treatments of 
Table 18

Effect of Transfers In-kind on the

Distribution of Income Among Families, 1978

\begin{tabular}{|c|c|c|c|}
\hline \multirow{2}{*}{\multicolumn{2}{|c|}{ Inc요르 Concept }} & \multicolumn{2}{|c|}{ Share of: } \\
\hline & & Lowesst_Fifth & Hiqhest Eifthㅡ \\
\hline 1. & Census income & $5.40 \%$ & $41.36 \%$ \\
\hline 2 & $\begin{array}{l}\text { Census income plus } \\
\text { educational transfers }\end{array}$ & $5 \cdot 97$ & 40.22 \\
\hline \multirow[t]{3}{*}{3} & $\begin{array}{l}\text { Census income plus } \\
\text { noneducational transfe }\end{array}$ & & \\
\hline & (i) Browning & 7.29 & 40.09 \\
\hline & (ii)' Smeeding & 6.75 & 40.37 \\
\hline \multirow[t]{3}{*}{4.} & $\begin{array}{l}\text { Census income plus all } \underline{1} \\
\text { in-kind transfers }\end{array}$ & & \\
\hline & (i) Browning & $7 \cdot 70$ & 39.09 \\
\hline & (ii) Smeeding & 7.21 & 39.35 \\
\hline
\end{tabular}

Source: Calculated by author from data in Browning (1979) and Smeeding (1979a). 
transfers in kind.

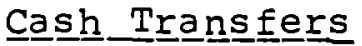

This seems an appropriate time to ask how large an equalizing effect cash h transfers have had on the distribution of income. Unlike the other concerns of this section, this does not constitute a "correction" of census income, since Census income already includes cash transfers; but the issue seems important enough to merit special attention.

By how much do cash transfers reduce income inequality in any given year? A number of studies have tried to answer this question, with relatively good agreement that cash transfers have decreased the Gini ratio by about $12 \%$ in recent years. 44 Taussig's (1973) study shows that the equalizing impact of cash transfers is much greater than that of taxes. The study by Smolensky et ㅡㅡ. ( 1977 ) enables us to compare the equalizing effects of cash and in-kind transfers with the following results:

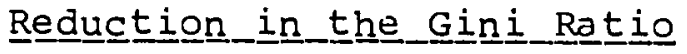

$\begin{array}{ll}\text { From cash transfers } & -.046 \\ \text { From in-kind transfers } & \\ \text { valued at full cost } & -.027 \\ & \\ \text { valued at cash } & \\ \text { equivalent } & -.016\end{array}$

Clearly cash transfers are nuch more important as equalizers, even if transfers in kind (including educational transfers) are valued on a dollar for dollar basis. If we adjust for the estimated lower value of certain transfers in $k$ ind, the predominance of cash transfers is even clearer. 
I conclude that cash transfers are a very major source of income equality--substantially more important than either personal taxes or transfers in kind. The equalization is accomplished mainly by raising the incomes of the lowest fifth. But what of the trend in inequality? As Table 4 showed, transfers have become an increasingly important source of income since 1957, and especially since 1967. We also know that the lower income strata receive a disproportionately large share of these transfers. ${ }^{45}$ Thus it is clear that cash transfers pushed the distribution of income in the direction of greater equality during the postwar period. For example, Danziger and Plotnick (1977) estimated that transfer payments reduced the Gini coefficient by .069 (or $14.4 \%$ ) in 1974 compared to only .048 (or $11 \%$ ) in 1965 .

While this is a noticeable effect over so short a period of time, it is surprising that the explosive growth of transfers did not push inequality down even faster. Three reasons suggest themselves. First, transfer payments may create disincentives for earning income that disequalize the distribution of factor income. Second, these transfer payments may have helped finance the splitting up of family units that led to increasing inequality. Third, Reynolds and Smolensky (1978) have suggested that transfers and other government programs follow a typical life cycle pattern that dulls their initial redistributive thrust. Specifically, as redistributive programs mature and reach a wider clientele, their benefits 
become less concentrated o: the poor. Thus, as the benefits from these programs grow larger in the aggregate, they simultaneously start to be distributed in a less pro-poor manner.

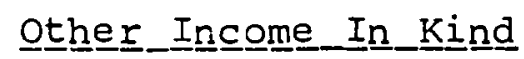

Transfers in kind have already been discussed, but some factor payments are also made in kind rather than in cash. Major items here include food and lodging consumed by farmers and farm workers, fringe benefits that are either partially or totally subsidized by employers (e.g., medical insurance, company cars), and the benefits that many self-employed individuals siphon out of their businesses (unbeknownst to the tax collector). On balance, it is quite unclear to me whether including this potpourri of items would increase or decrease measured inequality in any given year, though both Schultz (1975) and Henle (1972) have speculated that they are disequalizing. There are no studies that shed much light on this issue. 46

Nonetheless, I would still hazard a guess that, were we able to measure it, the addition of (nontransfer) income in kind to the CPS data would lead to a more disequalizing trend. One reason is that food and lodging consumed on farms (which is distributed in a pro-poor manner) has declined as a fraction of all income in kind, while fringe benefits (which are distributed in a more pro-rich pattern) have increased dramatically. Another reason was mentioned earlier: the farm/ nonfarm income differential is exaggerated by omission of income in $\mathrm{k}$ ind. 


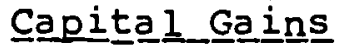

It has often been suggested that the CPS understates the degree of income inequality because it excludes capital gains--which accrue almost exclusively to the rich. And the one scrap of evidence we have on this issue supports this idea. When Smeeding (1979a) distributed an aggregate of accrued capital gains constructed by Browning (1976) among families for the year 1972,47 he found that the share of the highest fifth increased by 1.4 percentage points.

I am dubious about the value of this exercise because many, indeed most, capital gains are not gains of real purchasing power, but simply represent maintenance (or rather partial maintenance) of principle in an inflationary world. Obviously, if the inflation rate is $8 \%$ a $\$ 50$ stock must increase $\$ 4$ per year just to maintain its real value. These $\$ 4$ increments, if they occur, are not gains in real terms. A careful study by Eisner (1980) shows that over the 1946-1977 period as a whole, the more than $\$ 3$ trillion in nominal capital gains that households received failed (by a very small margin) to provide compensation for inflation. "Real" capital gains, in a word, were as often losses as gains.

Because of the extremely pro-rich pattern by which capital gains are distributed, it is clear that their inclusion would disequalize the income distribution in any year for which aggregate real gains are positive (as Smeeding and Browning found). But it is equally clear that including capital gains 
would equalizize the distribution of income in any year for which aggregate real gains are negative. Since gains were roughly zero in an "average" postwar year, I conclude that the omission of capital gains in the CPS data is not misleading on average, though it does conceal some sizeable variations in inequality from year to year.

What of the trend? Eisner's (1980, Table 33) data on real capital gains as a fraction of disposable income show violent fluctuations but absolutely no trend. 48 It is thus highly unlikely that the omission of capital gains distorts our picture of the postwar trend in income inequality.

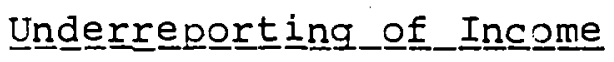

The CPS is plaguea by underreporting of all sorts of income. But the two biggest underreporting problems come at opposite ends of the income distribution: transfer payments (which are received mainly by the poor) and property income (which is received mainly by the rich). As a consequence, a correction for underreporting would raise the incomes of both the poor and the rich relative to the middle class, making it unclear whether measured inequality would rise or fall. What a series of such corrections inight do to the postwar trend in inequality is totally obscure.

\section{Suummary}

Table 19 summarizes this section by bringing together estimates, many of them admittedly dubious, of the effects on the distribution of income of all the adjustments discussed here. 49 The overall conclusion seems to be that patching up the census income concept probably would lead to a distribution 
of income with noticeably more equality in any one year, but only a sliqihtly stronger trend toward equality over the postwar period as a whole.

While there is a good deal of guessinork involved, it is conceivable that all the adjustments together might reduce the level of the Gini ratio by about .050 in any one year--a change which exceeds by far the difference between the highest and lowest Gini ratios recorded in Table 14 . For the share of. the poorest fifth of families, it is clear that transfers in kind are the most important adjustment, though personal taxes and underreporting also matter. For the share of the richest fifth of families, transfers in kind, personal taxes, and (in some years) capital gains, are all quite important.

Where the trend in inequality is concerned, all the adjustments together seem likely to lead to more equalization through time, mainly because of transfers in kind. However, the effects of improving the income definition seem unlikely to be as strong as the effects of the demographic changes discussed in the previous section.

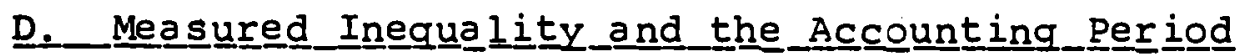

It is clear that the distribution of income would look

more equal if income were measured over an accounting period longer than a year because:

(a) some year-to-year fluctuations would be

"smoothed out"; 
Table 19

Effects of Adjustments in the Income

Concept on the Distribution of Income

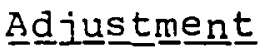

1. Subtract personal taxes
Effect on Giniㅛ Raaㅡㅁㅡo

$$
-.015^{b}
$$

2. Add in-kind transfers

\section{Effect of Share on:}

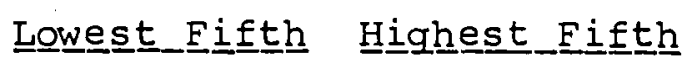

$+0.3^{c}$

$-1.7^{c}$
Effect on Trend

Toward

Equa $\underline{1}$ ityy.$$
-.027^{d}
$$$$
-.016^{\mathrm{d}}
$$
At $70 \%$ value
At full value
$+2.0^{e}$
$-2.1^{e}$
$+1.5^{e}$
$-1.6^{e}$

$+$

3. Add other income in $\mathrm{kind}$

$?$

0

NA

4. Add capital gains

5. Adjust for underreporting

0 $=$

$N A=$ Not available.

$a_{A} "+"$ sign means the correction would increase the trend toward equal lity. A "-" sign means the correction would deccrease the trend toward equality. A zero means approximately no effect.

${ }^{b}$ From Taussiq $(1973)$.

Crom Radner ( 1979 ).

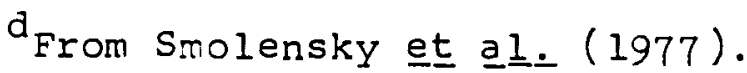

e Computed by author from data in Smeeding (1979a) and Browning (1979). Both educational and noneducational $i_{n-k}$ ind transfers are included. Since the two sources disagree on the latter, their estimates have been averaged.

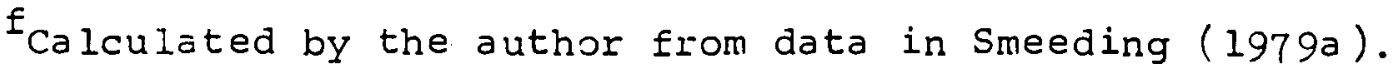


(b) part of the inequality in any one year's income distribution is due to the fact that people are at different stages of their life cycles, and income varies systematically by age.

It is not obvious, however, that these considerations have much bearing on the treend in inequality. The fact that there are transitory income fluctuations will distort our picture of the trend only if the variability of income has increased or decreased systematically over time. It is far from evident that this is true. Similarly, the fact that life cycle influences contribute to measured inequality, will alter the trend only if these life cycle influences have grown more (or less) important over time. Here, however, it has been claimed that this is in fact the case--that the gap between annnua income inequality and lifetime income inequality has increased over the postwar period.50 An examination of this controversy is the major task of this section.

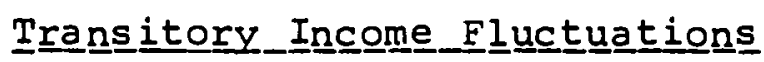

The natural approach to correcting for transitory fluctuations in income is to follow households through time and average their incomes over multi-year periods. Up until quite recently, there was a dearth of data with which to do this. Kravis ( 1962 ) had studied a panel of households for five years between 1949 and 1954, finding inequality (as measured by the Gini ratio) over 5 years to be about $10 \%$ less than inequality in a single year. He had also examined 12 years of Delaware tax returns (1925-1936), and found the $12-y e a r$ Gini ratio to be $8 \%$ lower than the average of the 1 -year Gini 
ratios.

The availability of several panel studies in the U.S. in recent years has verified Kravis' findings. Various sets of panel data have been used by Benus and Morgan (1975), Kohen, Parnes and Shea (1975), Hoffman and Podder (1976), David and Menchik (1979) and others to reach the following general conclusions.

1. Gini ratios for income over 3 years generally are about 3-5\% lower than Gini ratios for 1 -year, 51 though reductions as large as $10 \%$ have been found. 52

2. If we stretch the accounting period to 7 years, the drop in the Gini ratio increases to $9 \%$, even if we resticict attention to families with the same head throughout the period. 53

3. Because of the specific way it weights reductions in inequality at various points on the Lorenz curve, the Gini ratio seems to decline less as the accounting period is lengthened than do other measures of inequality. 54

If these sound like small adjustments, it should be remembered that a $10 \%$ decline in the Gini ratio (e.g., from .360 to .324) is absolutely collossal compared to anything we can find in the time series data (see Table 14 ).

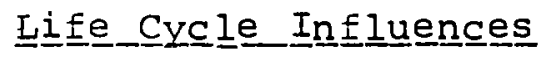

It is clear that inequality over the lifetime is lower than inequality in any one year, but here the absence of hard 
data make it necessary to resort to simulation and estimation techniques.

My simulation study (Blinder, 1974) "guesstimated" that inequality in lifetime income was about $30 \%$ lower than inequality in a single year if the Gini measure was used, but about $40-45 \%$ lower if the coefficient of variation was used to measure inequality. 55 Lillard (1977) estimated that the Gini ratio for lifetime earnings was about $45 \%$ less than that for annual earnings in a very special group of American men. Gordon (1976) estimated that for a sample of white male heads of households between 30 and 55 years of age, the share of the lowest fifth in 1 ifetime income was $8.7 \%$, compared to $6.7 \%$ in annual income. Without actual data, it is hard to know how accurate these estimates are. 56

Our best guess is thus that the difference between lifetime inequality and annual inequality is very great. But is this important for interpreting the postwar trend in inequality? To answer this, think of a population composed of different age groups. Inequality can increase if: 57

1. Inequality within age groups increases.

2. The distribution of families across age groups shifts toward groups with greater inequality.

3. Income differences by age become more pronounced. What do the data tell us about each of these factors? 1. Data covering 1947-1964 reveal only weak downward trends in age-specific Gini ratios. ${ }^{58}$. Danziger et al 1 . (1977) found that if all age-specific Gini ratios had been constant at their 1965 levels, the Gini ratio for 1972 would have been 
(very slightly) lower than it was. Thus it seems that factor I was operative, but very weak.

2. As noted earlier (see page ___ and Table 2), changes in the age structure of families were substantial and disequalizing. Over 1965-1972, Danziger et al. (1977) found that the shifting age distribution added .011 to the Gini coefficient (which increased in total by .016). Blinder and Esaki (1978) created a time series of hypothetical income distributions covering 1947-1974 on the counterfactual assumption that the age distribution did not change. They found that the effect of the shifting age distribution on quintile shares, while disequalizing, was very moäest.

3. The data do show an increased arching in the ageincome profile, as Figure 3 illustrates. 59 Danziger et al (1977) attributed a .005 increase in the Gini ratio between 1965 and 1972 to this factor. We lack a study of this factor over a longer period of time.

On balance, it seems clear that the shifting age distribution and the increased curvature of the age-income profile have caused income inequality to increase during the postwar period, despite small declines in age-specific inequality. But the magnitude of the effect seems modest.

Yet, in a controversial paper, Paglin (1975) claimed that the shifting age distribution counteracted what would otherwise have been a very strong trend toward greater income 
Relative Mean Income

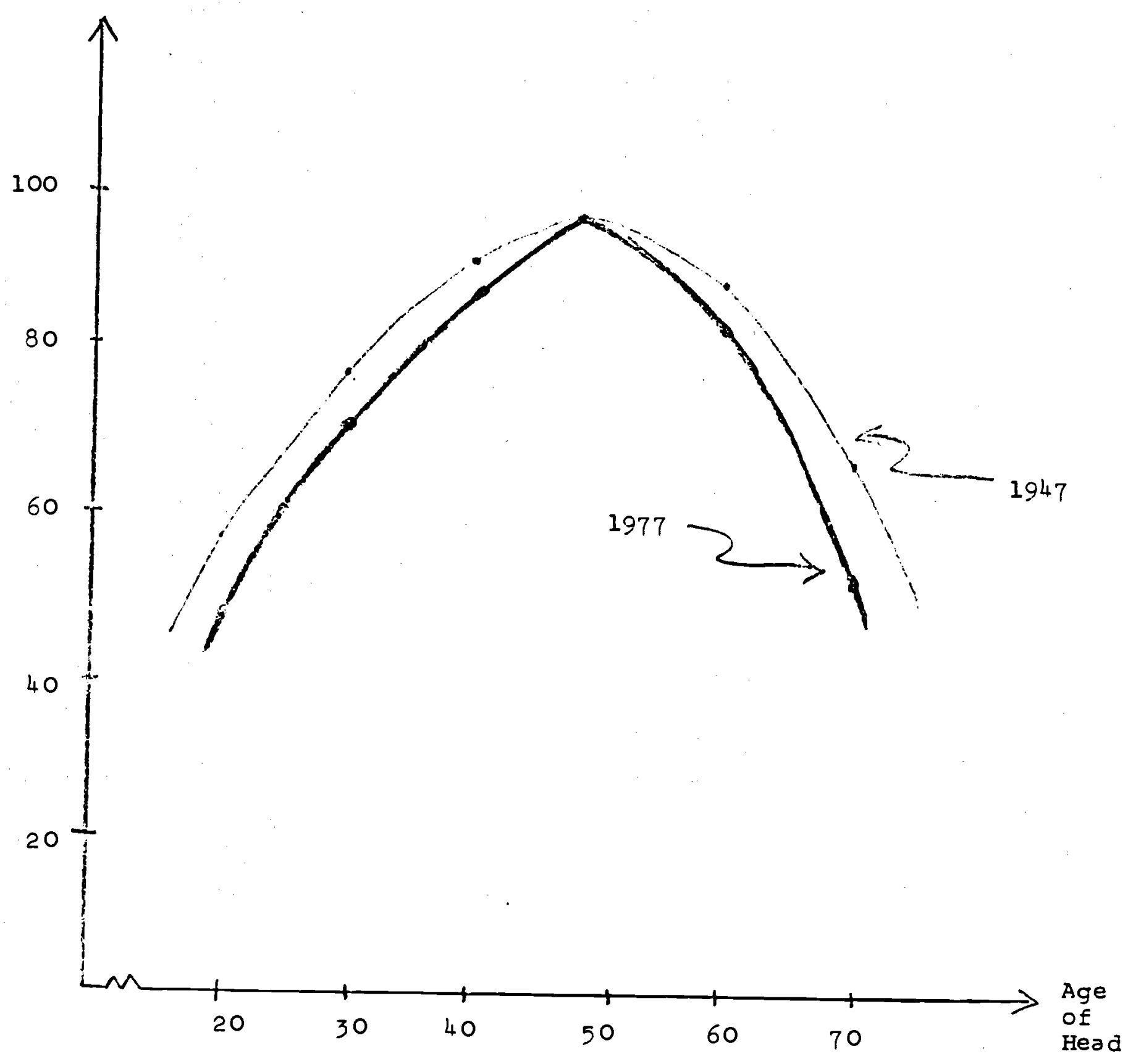

Figure 3

Age-Income Profiles for Families 
equality among families. Whereas the raw data (see Table 14) show rather little downward trend in income inequality between 1947 and 1972 (a $4 \%$ decline in the Gini ratio), Gini ratios that Paglin (1975) presented as "corrected" for age factors exhibit a very strong downward trend (dropping $21 \%$ ). It behooves us to examine Paglin's calculations. Is his method a valid way to "remove" the influence of the changing age structure from the data?

Paglin's technique for decomposing the Gini ratio is straightforward. Begin by constructing a hypothetical Lorenz curve on the assumption that all families of the same age (as defined by the family head) have the same income, and use the area between this hypothetical Lorenz curve and the actual Lorenz curve (shaded in Figure 4 ) as a measure of inequality due to factors other than the life cycle. This simple decomposition seems appealing at first, but does not survive closer examination. 60

Pyatt (1976), and before him Bhattacharya and Mahalanobis (1967), have shown that the Gini ratio can be decomposed into thriee components (not two): (a) a weighted-average of the agespecific Gini ratios (or of any other desired grouping), (b) a part dependent on the differences in average incomes across age groups, and (c) a part due to the overlapping of the groups. 61 Paglin is presumably interested in isolating (a) above; but by subtracting term (b), he is actually left with parts (a) and (c). Since part (c) has no intuitive interpretation, the Paglin measure of age-corrected inequality 
Percentage of

All Income

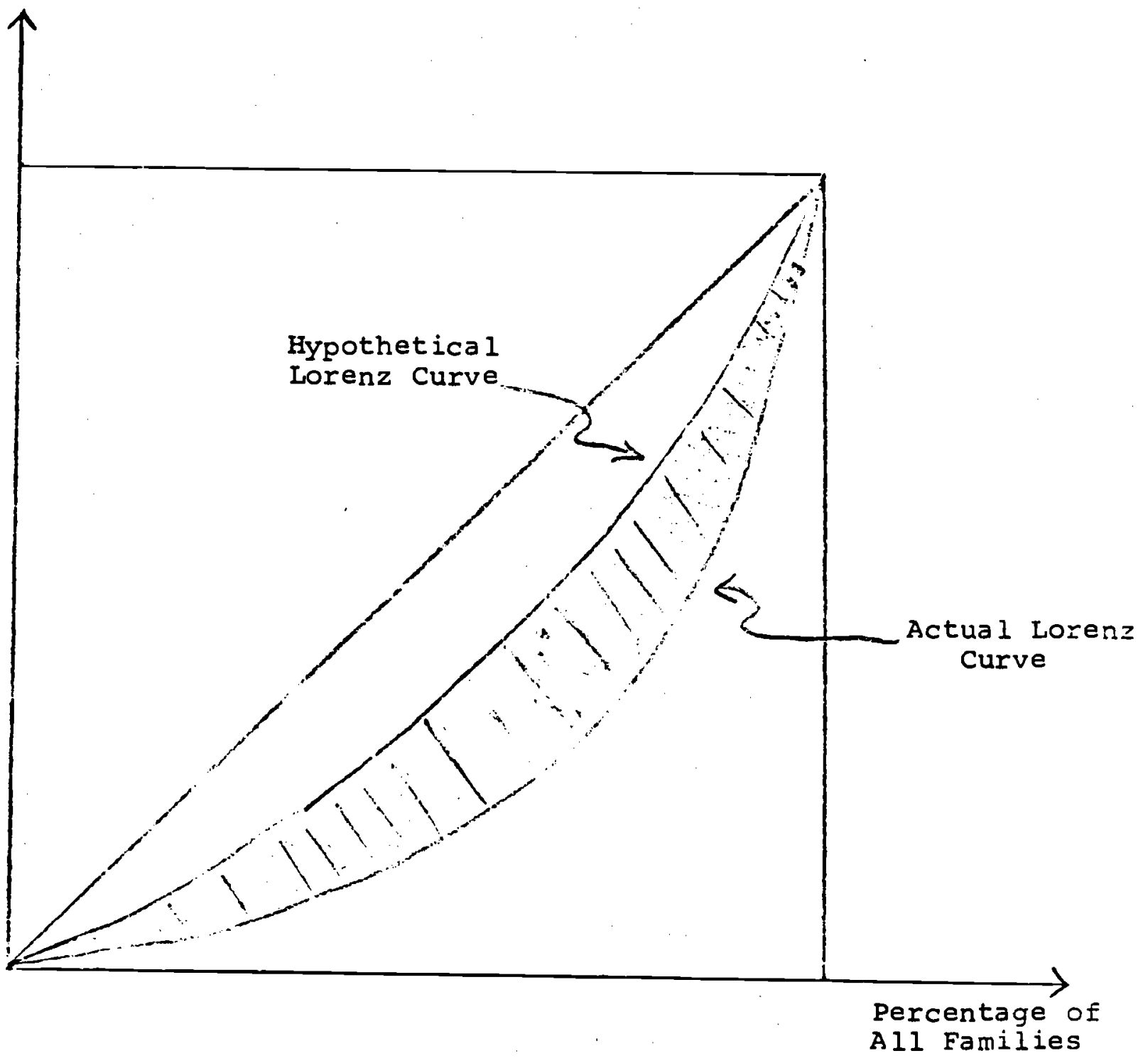

Figure 4

Paglin's Decomposition of the Gini Ratio 
can exhibit strange behavior, as Danziger, Haveman, and Smolensky (1977) have shown. In terms of the three age-related factors enumerated on page _-_, Paglin's procedure does not succeed in isolating factor 1 .

I conclude that while Paglin's basic point--that postwar changes in life cycle influences on income distribution have masked some of the trend toward equality--is correct, he has probably exaggerated its quantitative significance.

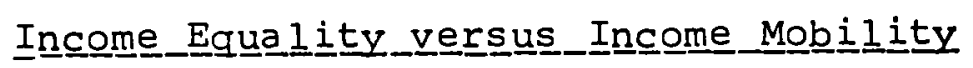

A related point should be dealt with here. There is considerable churning within the income distribution from year to year. The same families do not always populate the bottom fifth, the top $5 \%$, etc. If our real concern (for welfare purposes) is with income inequality over some lengthy period of time, then it is clear that we can get a good degree of equality in either of two ways:

1. Families could occupy essentially the same relative positions year after year, but the annual distribution (and hence the multi-year distribution) could be quite equal.

2. The annual distribution of income could be quite unequal, but families could move around within the distribution so much that the multi-year distribution of income was quite equa 1 .

In this sense, income equali $\underline{\text { ity }}$ and income mob $\underline{\text { il }}$ ity are substitutes for one another. 62 In fact, I am certainly not the first to speculate that mobility occupies a more exalted 
place in the American constellation of value judgments than does equality. Americans seem quite willing to tolerate gross disparities in incomes so lang as there is a reasonable chance that low-income families in one year can become high-income families in another year. Wi.th very little mobility, on the other hand, even a Gini ratio of .300 might be considered intolerable.

The studies cited earlier, and several others as well, seem to suggest a good deal of mobility in the U.S. income distribution--especially near the bottom of the distribution 63 and among the young. 64 To cite just one summary statistic, Lane and Morgan (1975) found that the rank correlation for family money income between years 1 and 6 of the Panel. Study of Income Dynamics was only .47 (or .64 among families with the same head in the two years). While ghetto dwellers rarely trade places with Rockefellers, ours is not a stratified society.

\section{5-_Special l_Aspects of Income Inequablity}

Social scientists and philosophers have long been intrigued by issues relating to equality in the abstract. Layman and political figures, by contrast, have shown rather less interest in equality than in such related (and more concrete) issues as the plight of the poor, income differentials by race, and income differentials by sex. Each of these special aspects of income inequality has been the focus of a major public policy initiative during the postwar period. For these reasons, 
each of them merits special attention.

\section{A. The Speccialal_Probolem_of 으 Poverty}

As just noted, the revealed political preferences of the American public show much less concern with inequality than with the plight of the inhabitants of lower tail of the distribution--the poor. As Lampman (1973) has remarked, this country has never set a target for the Gini ratio. It has, however, declared war on poverty and set specific targets for its reduction. Who is winning the War on Poverty?

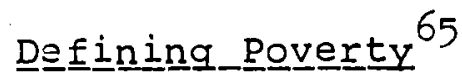

It turns out, however, not to be so easy to separate the specific problem of poverty from the more general problem of income inequality. The reason is clear enough. Income is a continuous variable, whose distribution can be estimated. Poverty, however, is a dichotomous variable: a family is either poor or it is nonpoor. To decide who is poor, we must place a "poveryy line" somewhere in the income distribution, as depicted in Figure 5, and count how many families (or people) fall below it. Unfortunately, there are many ways to place the line.

At one extreme, we could base our poverty line on a

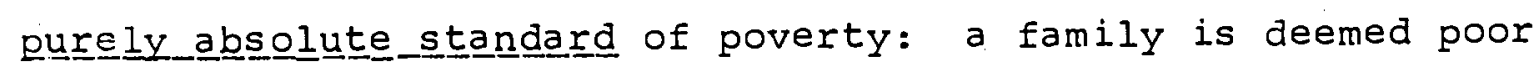
if and only if its income is insufficient to purchase a prescribed bundle of goods and services. Since the bundle is fixed, the poverty line is increased only to adjust for inflation. This concept of poverty, which underlies the official poverty counts of the U.S. government, has been criticized on many grounds. 
Density of Population

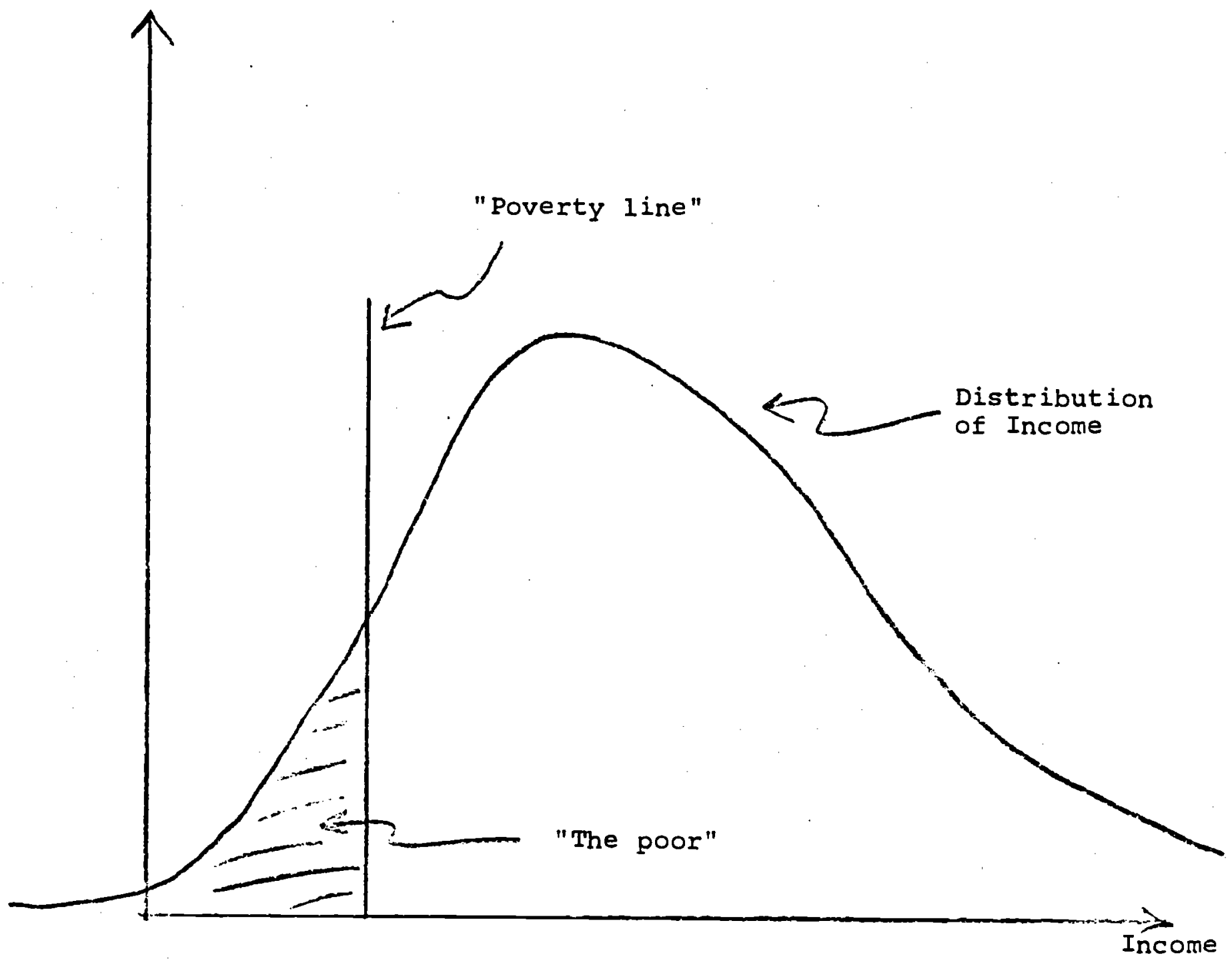

Figure 5

Defining the Poverty Population 
1. It seems to contradict public notions of what constitutes poverty. This point is obvious when we consider long periods of time: the rich of centuries ago lacked many of the conveniences that today's poor routinely have. But Section 3 showed how dramatic changes in the standard of living have been even over a period as short as 30 years. It would be surprising indeed if the concept of poverty had not changed accordingly, and evidence from public opinion polls and elsewhere suggests that it has. 66

2. The bundle of goods and services is inherently arbitrary. Who knows what items every family must have if it is not to be deemed "poor?" Answers to this question are arbitrary at best. Official definitions of poverty in the United States are essentially obtained by defining a food budget and tripling it. 67

3. It is clear that economic growth will eventually pull almost everyone above any purely absolute poverty line. Contrary to the Bible, there would be no meek left to inherit the earth: This definition seems to make the war on Poverty too easy to win.

The unexceptionable idea that what constitutes poverty is culturally, not biologically, determined leads us away from a purely absolute standard of poverty. But where do we stop? We could go all the way to a pure the poor as the lowest $20 \%$ of the income distribution. Under this definition, the "War on Poverty" would be unwinnable by 
deféfinition; and the Bible would be literally correct: ye have the poor always with you. Personally, I find this to be not an unattractive definition of poverty. However, it does require that we amend the poverty-reduction goal. Counting the poor will no longer do; instead, it is natural to study trends in the share of total income received by the lowest $20 \%$. This, of course, has been done at length in this chapter. By this definition, the "special" problem of poverty has already been considered, with the conclusion that poverty has been eroding--but slowly.

There are, of course, intermediate grounds between purely absolute and purely relative standards of poverty. Poverty lines based on "minimum decency" budgets recognize psychological as well as physical needs, and are periodically adjusted to reflect changing norms and mores. Between adjustments, of course, they function just like fixed budgets, and so are close cousins to strictly absolute definitions of poverty. They also share the arbitrariness of the fixed budget standard. 68

A different intermediate choice comes much closer to the purely relative concept of poverty: define the poor as those families with incomes below $x^{\%}$ of the median. Fuchs (1967) suggested such a standard with $x=50$. While this definition allows the poverty population to shrink or expand in principle, in practice it has amounted to defining the poor as the lowest $20 \%{ }^{69}$ Thus no definition of poverty is unobjectionable. 


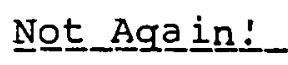

A related set of points is worth making here. If we are to enumerate the poor, we must decide what types of recipient units to count (families? persons?), we must select a definition of income, and we must pick an accounting period. This all sounds familiar. The issues and problems are exactly the same as in our lengthy discussion of income inequality--and so is the sensitivity of the poverty count to the choices we make. Official poverty counts, it should be noted, are based on Census income--a concept which, we have seen, apparently hides an upward trend (of uncertain amount) in the share of the bottom fifth. The demographic shifts studied earlier are also worth recalling, since many of them have served to increase the poverty population under official definitions. Finally there is the accounting period. Official poverty counts make no attempt to distinguish those who are permanently poor from those who are temporarily poor (owing, for example, to a large capital loss). $7^{\circ}$ Given the amount of mobility that has been found at the lower end of the income distribution, this may be an important problem.

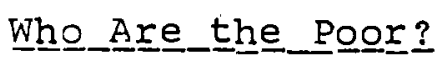

Having said all this, let us see who the official data classify as poor. According to the latest data (for 1977), $9.3 \%$ of a 11 families and $22.6 \%$ of all unrelated individuals fell below official poverty lines. Persons in families constituted about $80 \%$ of the poor, and almost half of these were in families 
headed by a female--a female headship ratio far higher than that for the population as a whole. The poverty rate was only $5.5 \%$ for male-headed families, but $32 \%$ for female-headed families. Among poor unrelated individuals, almost two-thirds were female.71 Relative to the population as a whole, the poor were also more frequently black, less educated, and lived in larger families. 72

Alternative definitions of income or concepts of poverty give rather different poverty counts, however. Table 20 , for example, shows how the fraction of persons classified as poor changes as we adjust either the income concept or the definition of poverty. The upper lefthand entry is the official poverty count for 1976: just linder 12 percent of all persons were considered poor. A relative poverty definition 73 raises the count to $15.4 \%$ of the population--a $30 \%$ increase in the number of poor people. Altering the definition of income by deducting direct taxes, adding income in kind, and correcting for underreporting (which, we know, is very serious for transfer income) cuts the poverty count drastically--to only $61 / 2 \%$. Trengis in Poverty Counts

How has the poverty count behaved through time? Figure 6 plots four different estimates. The official data, using census income and an absolute definition of poverty, show rapid progress against poverty from 1959 (when the data begin) until about 1969. Thereafter, the fraction of families who are classified as poor almost levels off (it is $9.7 \%$ in 
Table 20

The Poverty Count for 1976,

by Different Definitions

(percent of all persons)

\begin{tabular}{|c|c|c|c|}
\hline & $\begin{array}{l}\text { Census } \\
\text { Incoㅡㄹㅡ }\end{array}$ & $\begin{array}{l}\text { Census Income } \\
\text { Adjustéd }\end{array}$ & 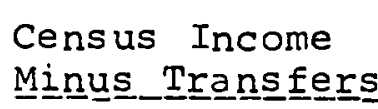 \\
\hline Official poverty lines & 11.8 & 6.5 & 21.0 \\
\hline $\begin{array}{l}\text { Relative poverty } \\
\text { standard b }\end{array}$ & 15.4 & NA & 24.1 \\
\hline
\end{tabular}

Soluxㅗㅌㅡ: Danziger, Haveman, and Plotnick (1979), Table 5, p. 31.

adjusted for income in kind (both transfers and otherwise), direct taxes, and underreporting by Smeeding (1977).

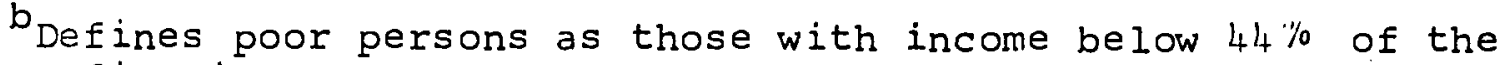
median income. 


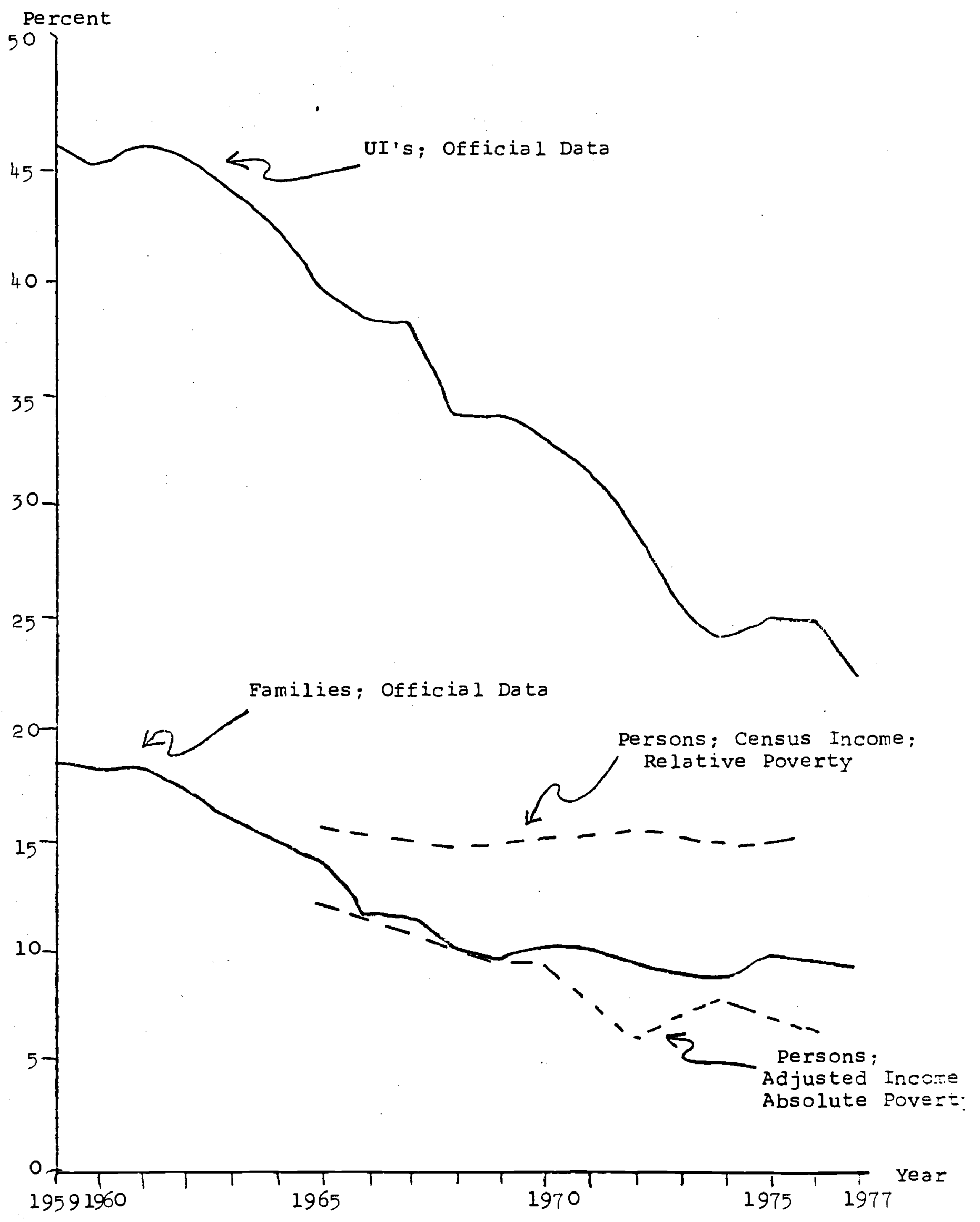

Figure 6

Trends in Poverty 


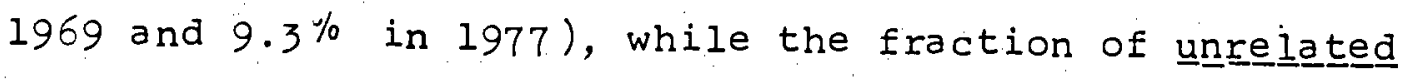

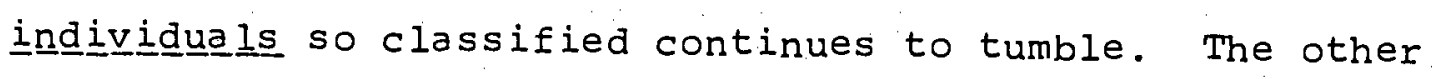
two series use persons as the recipient unit, and are available only since 1965 (and not for every year). There is no discernible trend in relative poverty based on Census money income. Absolute poverty based on income adjusted for taxes, in-kind income, and underreporting does show a downward trend, though fluctuations are severe. 74

The conclusion, then, seems to run something like this. The official poverty count declined smartly through the 1960 , but has been stagnant since then. This constancy, however, is due to the dominant position of families in the aggregate; the incidence of poverty among unrelated individuals continued to fall. If we fix up some of the pitfalls with census income, there appears to have been cunsiderably more progress in the War on Poverty. But if we adopt a relative poverty concept rather than the official poverty lines, there has been much less.

One final word seems in order. Whether we use official poverty lines or a relative poverty concept, Table 20 shows that many fewer people are poor after (cash) transfers than before transfers. The trends in pre-and post-transfer poverty are also quite different. By official definitions, the poverty rate for all persons declined 24,4\% between 1965 and 1976. But, there is almost no trend in the poverty rate based on income minus (cash) transfers. ${ }^{75}$ Transfers, in a word, have been the chief weapon in the war on Poverty. 
60.

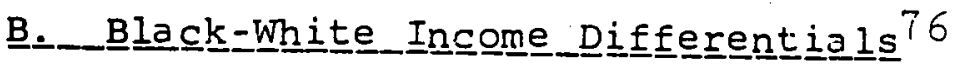

It is, of course, well-known that nonwhite individuals and families typically have lower incomes than whites. For example, the ratio of mean income among nonwhite families and unrelated individuals (UI's) to that among whites averaged .589 (with standard deviation .057) for the postwar period as a whole.

However, there was a substantial narrowing of the differential during the period. Figure 7 charts the behavior of the nonwhite/white income ratio since 1947 , for families and UI's pooled. The upward trend from .52 in 1947 to .68 in 1975 is clear and unmistakable, though there has been some slippage since tinen. The gains scored by blacks between 1965 and 1968 are particularly impressive. 77 The economic position of blacks relative to whites is far from uniform across different demographic groups. In 1977 , for example, the black/white mean income ratio was .63 when averaged over all families. But for families with a head aged 18-24, it was .97 while for families headed by a 55-64 year old it was .57. Similarly, the ratio was .76 for male-headed families versus .64 for female-headed families.

Several demographic forces limited the economic gains achieved by blacks, however. First, there was a substantial increase in the fraction of families headed by females--which rose from $28 \%$ in 1967 to $37 \%$ by 1976.78 second, the labor force participation rate of black men declined somewhat--from 
Figure 7

$$
\text { F }
$$

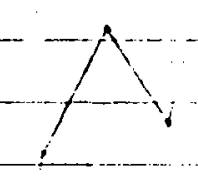


$85 \%$ in 1954 to $71 \%$ in 1977 , with much of the drop accounted for by the elderly. ${ }^{79}$ This occurred despite an increase in black earning rates relative to those of whites. However, relative earnings gains were greater for women than for men. Indeed, something close to full parity between the races was achieved among females working full-time full-year. The black/ white earnings ratio for such workers rose from .56 in 1955 to .93 in 1977.80

Thus the improvement in the black/white income ratio was the net result of a confluence of forces, some of which were equalizing and some of which were disequalizing. On balance, however, there can be no question that the relative economic position of blacks improved substantially during the postwar years. Equally clear is the fact that-except in isolated instances--parity has not yet been achieved.

C.

When we come to consider income differentials between men and women (or between male- and female-headed families) a rather different picture emerges. As Figure 8 shows, the ratio of female to male incomes dropped from $48 \%$ just after World War II to only $40 \%$ by 1950 , hovered in a narrow range between $40 \%$ and $41 \%$ between 1960 and 1969, and rose in recent years to $44 \%$.

Part of this huge income differential-which is wider than that between blacks and whites--is due to the fact that more women than men work part time or for only part of each year. 


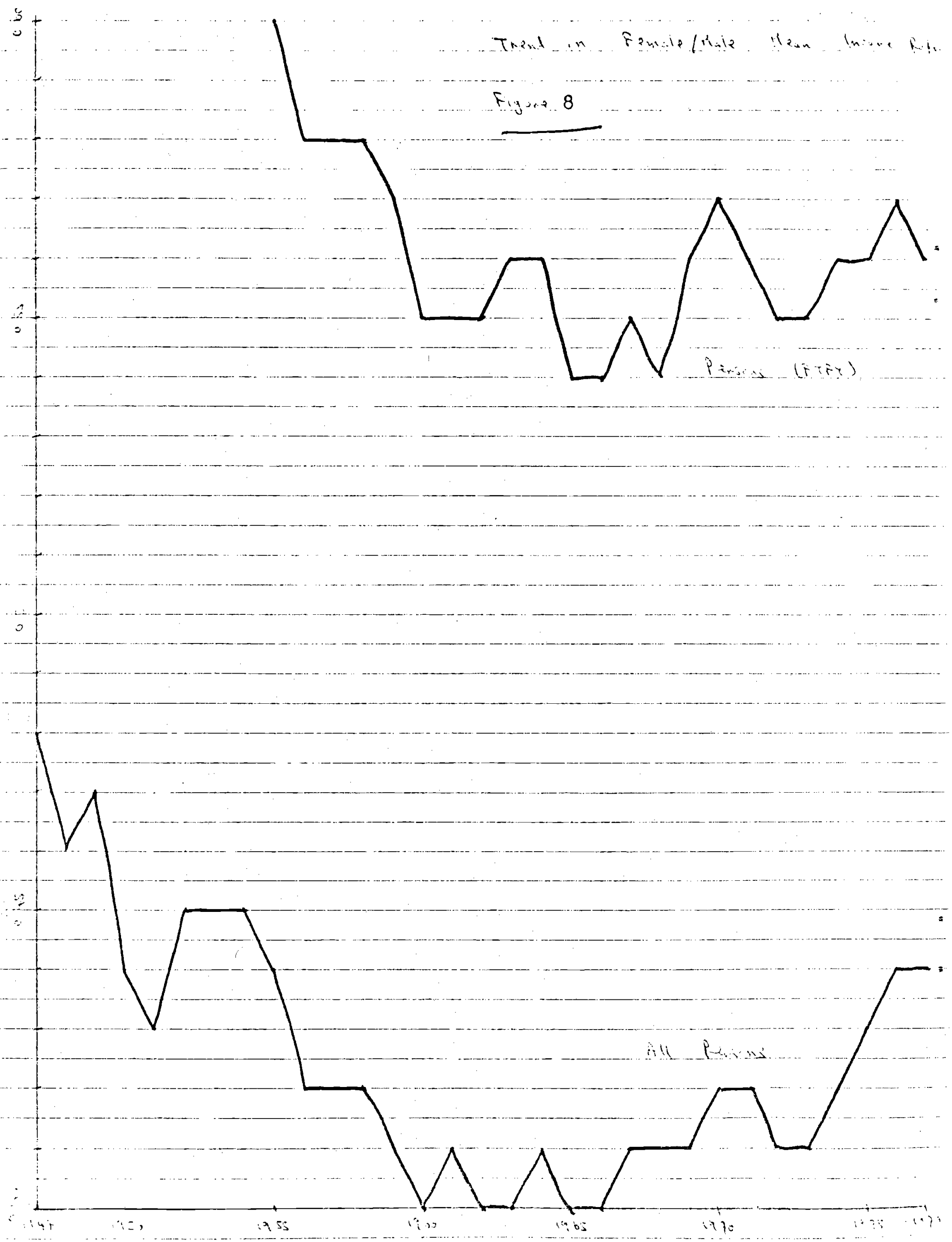


But Figure 8 shows that even women who worked full time for a full year typically had incomes only about $55 \%$ as large as those of their male counterparts. (Earnings differentials show much the same pattern.) Differentials in incomes between male- and female-headed families paint an even more pessimistic picture. Female-headed families averaged $73 \%$ of the income of male-headed families in 1947, but only 50\% in 1977. Indeed, as Lampman (1977) has remarked, the lack of progress in narrowing male-female differentials is almost unique in a period when black-white, North-South and other differentials were being reduced. The sharp increase in female labor force participation rates suggests itself as the leading explanation of this lack of progress, although that just raises another question: why did female participation rates rise so much? 81

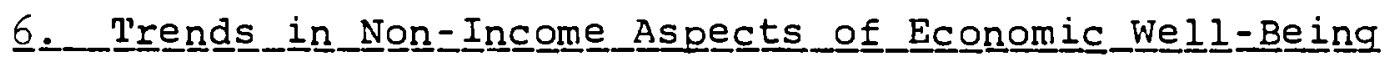

This section seeks to remedy some of the omissions caused by the myopic concentration thus far on incomene as the measure of well-being. The discussion is necessarily less systematic, less quantitative, and more impressionistic than the discussion of income.

\section{A. Leisure}

When an economist is asked to go beyond income as a measure of economic well-being, the first thing he thinks of is leisure. (Indeed, this is often also the last thing he 
thinks of.) It would seem that if two individuals have the same wage rate 82 but earn different incomes because they voluntarily work different hours, then the best first guess is that they are equally well off. Income inequality that arises from voluntary choices between work and leisure, then, is not to be considered a social "bad." 83

Leisure time can be expanded in several ways. The number of hours worked per week can shrink. 84 The number of (fulltime equivalent) weeks per year can decline because of longer vacations and more paid holidays. Or the number of years of retirement can be increased. As we shall see, each of these factors has been operative during the postwar period. I begin with hours of work.

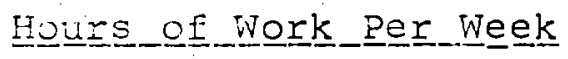

It is, of course, well known that the work week has shrunk over the long sweep of history. Indeed, the extent of this shrinkage is often exaggerated. We have probably all heard stories about how a work week of six or sever. 12 -hour days was "typical" around the turn of the century. But the data belie these grisly tales. The average manufacturing worker at the turn of the century apparently worked about six 10-hour days per week--an average work week of 59 hours. 85 Hours outside of manufacturing were typically shorter yet, so the average worker in all industries worked only 53 hours. 86 From 1900 to 1947 . there was a steady downward trend in the average work week among manufacturing workers, which reached 40.4 hours by $19+7.87$ 
It is often claimed that the decline in the typical work week ended around World War II, and that since then American workers have taken their increased leisure in the form of fewer weeks per year. This widely-held view derives from

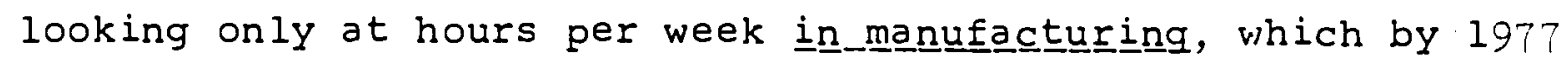
accounted for just $24 \%$ of total employment. Here the decline in the work week did indeed halt: it was 40.3 hours long in 1977. But more than three-quarters of the U.S. labor force works in other industries; and in these industries the decline in the average work week has continued throughout the postwar period (see Table 21). I conclude that American workers decreased the ir average work week by about $10 \%$ during the postwar period. Manufacturing workers (a shrinking minority) were a notable exception.

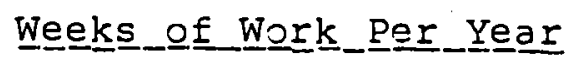

Data are scarcer for the number of work weeks (or days) in a year. Lebergott (1976, p. 91) reports that the percent of nonfarm workers taking vacations increased from nearly zero in 1930 to $60 \%$ in 1950 and $80 \%$ in 1970 . He also cites BLS data that the typical American worker had 7 paid holidays. While we do not know this for a fact, it is not hard to imagine that the spreading incidence of vacations and paid holidays may have reduced the typical work year by 2 weeks (about $4 \%$ ) or more. 
Table 21

Average Weekly Fous in Selected

Industries, I:- to 197 ?

A11 Private

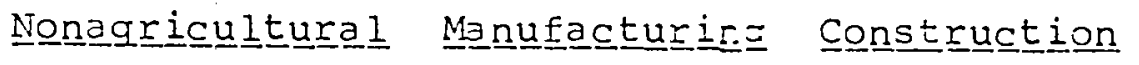

Wholesale and

$19 \div 7$

40.3

40.4

38.2

Retaiㅡ늠ade

1977

36.0

40.3

36.6

40.5

32.8

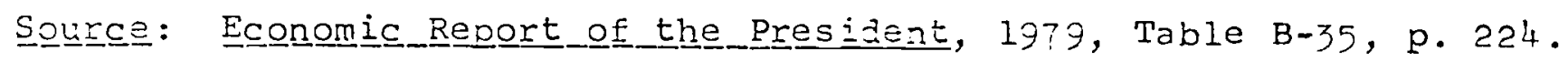




\section{Incㄷidenence of 0 f Ret}

Another remarkable development of the postwar period has been the increasing prevalence of retirement, especially for men. 88 The labor force participation rate for men 65 years of age and older fell from $47.8 \%$ in 1947 to only $20.1 \%$ in 1977; for men aged 55-64, the decline was from $89.6 \%$ to $74 \%$. 89 Reimers ( 1976 ) compared men who reached age 65 around 1933 with men who reached age 65 around 1963 and concluded that the younger generation devoted about 2 percent fewer years of its life to work than did the older generation.

It takes more than a little chutzzpah to combine this guesstimate with my seat-of-the-pants estimate that more vacations decreased the work year by about $4 \%$, and with data showing a $10 \%$ decline in the average work week. But, if we do all this, we are led to conclude that working time over a typical career has decreased about $16 \%$ during the postwar period. While this is a substantial amount, it probably means that leisure time expanded more slowly than the consumption of market goods and services. 90 Evidence that leisure time is a luxury good is lacking.

H으므트느으토

There is, however, one other important aspect of declining work effort that ought not escape our attention. Lebergott (1976) has estimated that the typical housewife spent about 12 hours on housework per day in 1900, but only 5 hours 
in 1966. Stafford and Duncan (1977) cite data from time diaries showing that married women spent about 27 hours per week on work in the home. How much of this decline in the housewife's work day took place since World. War II is not known. But if we attribute half of the 8-hour-per-day decline to the postwar period, then the postwar decline in the work day for housewives would be about 50\%. This may be an overestimate, 91 but it does seem that housewives have improved their lot relative to paid workers in the pcstwar period. 92 Family leisure thus probably increased faster than leisure time of the principal breadwinner. 93

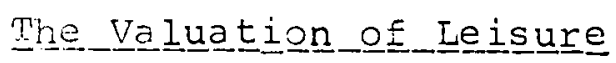

How much is this increasing leisure worth? There seem to be two basic approaches to the valuation of leisure time, though each has many variants. The first approach tacitly or explicitly posits a utility function that combines both income (or consumption) and leisure time into a composite measure of well-being. The major alternative is to convert leisure time into money by using the market wage. While the utility-function approach is obviously conceptually superior, it faces one (insurmountable?) problem: who knows what the right utility function is?

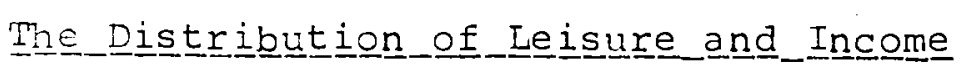
What of the distribution of leisure time? Morgan and Smith (1969'), using data from the Panel study of Income Dynamics, 
found a slight negative correlation between leisure and income, but a slight positive correlation between leisure and the ratio of income to "needs." Sirageldin (1969) constructed a distribution of economic well-being based on leisure and the ratio of income to "needs" for data from the Productive Americans Survey. He found that well-being so defined was distributed more equally than income. Taussig (1973) valued leisure at the wage, using data from the Survey of Economic Opportunity, and obtained very similar results. "Full income" was slightly more equally distributed than money income. Browning (1976) and Browning and Johnson (forthcoming) made two different adjustments for non-working time, and found very substantial equalizing effects. The conclusions seem to be, therefore, that (a) leisure is distributed somewhat more equally than income;

(b) leisure has a slight negative correlation with income ;

(c) more comprehensive measures of economic well-being that include both leisure and income are distributed more equally than income alone.

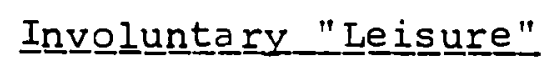

Having said this, we must not ignore the fact that not all "leisure" time is taken voluntarily. A person who is disabled or involuntarily unemployed does not want to "buy" 
all the leisure he gets at the going wage rate. For him, the wage clearly overestimates the marginal value of leisure time. While there is no satisfactory way at present to decompose unemployment time into "voluntary" and "involuntary" components, 94 it is at least worth pointing out that the incidence of total unemployment is highly uneven. The young, the black, and the female suffer most from unemployment. Involuntary leisure seems concentrated at the lower end of the income distribution. It is hard (for me at least) to imagine that this pattern is entirely the result of free choice.

\section{B. - W Wea It $h$}

In purchasing the goods and services from which they derive satisfaction, people are not restricted to their current income if they have accumulated wealth on which they can draw. So, if our real concern is with the distribution of economic w이기트름, data on the distribution of wealth are a valuable supplement to data on the distribution of income. 95

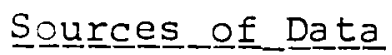

We know far less about the distribution of wealth in the United States than about the distribution of income. certainly nothing comparable to the annual cPs exists for wealth. What meager knowledge of the wealth distribution we have comes from three sources.

First, there have been a few surveys of wealthholding, of which the Survey of Financial Characteristics of Consumers (SFCC) for 1962 (Projector and Weiss, 1966) is undoubtedly the best. But these surveys have been sporadic, scattered through 
time, and noncomparable; so they tell us little about trends in wealth inequality. In addition, it is apparently very hard to elicit accurate data on wealth holding from survey respondents: even the assiduously planned and executed SFCC was plagued by underreporting. 96 Nonetheless, the SFCC data on the wealth distribution in 1962 is undoubtedly the best "snapshot" information we have.

Second, estimates of the wealth distribution have been made by the estate multiplier method. Briefly, this method involves treating individuals who die in a particular year as a random sample (perhaps after some adjustments) of those who were living in that year. Then estate tax records on the wealth of decedents can be used to infer the distribution of wealth among the living. 97 However, since only estates above a certain amount (which for many years was $\$ 60,000$ ) are required to file tax returns, the estate multiplier method can yield information only about the extreme upper tail of the wealth distribution.

Finally, a clever investigator can piece together scraps of information from which he can create an estimate of the distribution of wealth (Lebergott, 1976). While this technique may be promising, it involves considerable judgment and perhaps some guesswork in piecing together disparate pieces of information, making time series comparisons very difficult. 


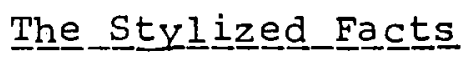

The stylized facts of the wealth distribution in the postwar United States are allegedly as follows:

1. Inequality in the wealth distribution far exceeds that in the income distribution.

2. There is no noticeable trend in wealth inequality. Qualitatively, fact 1 rests on a fairly secure base; but we remain uncertain of its quantitative dimensionsowing to the paucity of data. The SFCC found the Gini coefficient for wealth to be .76 , as compared to a Gini ratio for income in the same population of .43.98 Lansing and Sonquist (1969, p. 50) reported Gini ratios for wealth within age cohorts in the 1953 and 1962 Surveys of Consumer Finances ranging from .62 to .69.99 Feldstein (1976), however, has pointed out that these wealth data exclude an important source of wealth which is both very large in the aggregate and very equally distributed: the discounted present value of future social security benefits. When he added estimates of this "social security wealth" to the fungible wealth of those consumer units in the SFCC with heads between 35 and 64 years of age, the Gini ratio dropped from .72 to .51 . The top $1 \%$ of wealthholders held $28.4 \%$ of fungible wealth, but only $18.9 \%$ of total wealth. This adjustment, as dramatic as it is, does not overturn the conclusion that wealth is more unequally distributed than income. George stigler (1973) once asked in another context, "Is this fact in fact a fact?" Our second "fact" may not be. 
What we know from estate multiplier estimates by Lampman (1962) and Smith and Franklin (1974) is that the share of the very, very wealthy fell somewhat between the $192 \mathrm{Os}$ and the $194 \mathrm{Os}$, and has been relatively constant since then. Thus the alleged stability of the wealth distribution is based on the experience of the toop $1 / 2 \%$ ( or at best the top $1 \%$ ). It hardly needs to be stated that the lower $991 / 2 \%$ might have had a different experience. Furthermore, Feldstein (1976) has pointed out that the explosive growth of (very equally distributed) social security wealth doubtless imparted some equalizing trend to the wealth distribution.

Cómbinining Wea 1 th $h$ and Income

This look at the wealth distribution was motivated by a need to supplement information on income inequality. For this purpose, however, we need to know the joint distribution of income and wealth across individuals. Only survey data can give us this information. The SFCC data show a strong positive correlation between income and wealth, 100 which can hardly be considered surprising.

The most natural way to combine the distributions of wealth (a stock) and income (a flow) is to add the annuity value of net worth to Census money income, and then subtract current property income to avoid double-counting. Weisbrod and Hansen (1968) did approximately this in combining the SFCC with the 1962 CPS, but were forced to merge the two data sources in a very crude way. They found that the Gini ratio of .37 for Census income became .42 when the annuity value of net worth was added at a $4 \%$ interest rate and .47 when a $10 \%$ 
interest rate was used. Taussig (1973) combined income and net worth information from the same data source, using a $6 \%$ interest rate, and found that the Gini ratio was almost unchanged unless substantial corrections were made for underreporting of net worth. After those corrections, the Gini ratio rose from .361 to .393 . Taking account of the distribution of wealth thus seems to increase the degree of inequality.

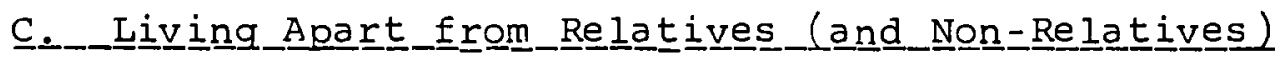
Whatever benefits the extended family may have brought to its members, they came at a cost of increasing household congestion and loss of privacy. And, apparently, Americans in the postwar period prized the reduced congestion and increased privacy more than the benefits of the extended family. Data on the rapid growth of the number of unrelated individuals-especially young and old people living alone-were cited earlier in this chapter (see pages 00-00). Table 22 offers further data on this subject.

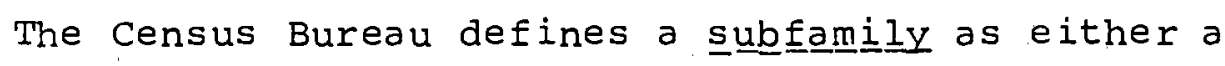
married couple (with or without children), or a single parent with one or more unmarried children, living in the same household as another family to which they are related. The number of subfamilies so defined thus seems a good indicator of the number of extended families, though single grandparents would not be counted as subfamilies. Part $A$ of Table 22 shows that the absolute number of subfamilies fell by almost two-thirds between 1947 and $197 \% 101$ In 1947 , almost $9 \%$ of primary families had 
Table 22

Selected Data on Living Apart

and Privacy, 1940-1970

A. Data on Subfamilies ${ }^{a}$

Number of Subfamilies (millions)

Year All Husband-Wife Other

Ratio of Subfamilies

1940

2.06

1.55

0.52

too Primary Families

1947

3.12

2.33

0.79

.065

1977

1.18

0.51

0.67

.089

$.0<1$

B. Data on Married Couples without Own Household

Year Number (millions) Eraction of all Married Couples

$\begin{array}{lll}1940 & 1.95 & .068\end{array}$

$1947 \quad 2.93 \quad .087$

$19770.53 \quad .011$

C. Data on Secondarv Eamilies ${ }^{b}$

Number of Secondary Families (millions)

Year All Husband-Wife other

Ratio of Secondary Familia

$1940 \quad 0.68$

0.40

0.28

.021

1947

0.83

0.60

0.23

.024

1977

0. 14

0.03

0.21

.004

Sources: Historical statistics, p. 41 , series A288-A319; Current

Populatilion_Reports, Series P-20, No. 313, Table 5 .

aefined as "a married couple with or without children, or one parent with one or more unmarried children under 18 years old, living in a household and related to, but not including, the head of the househole or his wife."

b Defined as "two or more persons such as guests, lodgers, or resident employees and their relatives, living in a household and related to each other." 
another related family living with them. By 1977, this fraction was down to barely over $2 \%$. Furthermore, about three-quarters of these subfamilies in 1947 included both parents, whereas by 1977 less than half of all subfamilies had two parents. Data in Part $B$ on the number and frequency of married couples living in the household of some other family (not necessarily a related family) tell a similar story.

A phenomenon related to living apart from relatives is the decline in the number of boarders and lodgers in American households -living apart from non-relatives. According to data put together by Lebergott (1976), the percentage of urban households with a boarder or lodger decreased from $23 \%$ in 1900 to $14 \%$ in 1941 and to only $2 \%$ in 1970. The lodger, in other words, almost disappeared from the scene during the postwar period.

Data germane to this phenomenon appear in Part C of Table 22 The Census defines a "secondary family" as two or more persons related to one another but not related to the primary family. This category includes guests, lodgers, or resident employees; but since single individuals are not counted as secondary families, most lodgers are excluded in this count. Nonetheless, as many as $21 / 2 \%$ of primary families shared their homes with such an unrelated secondary family in 1947. Almost none did by 1970. D.

It will not be considered heretical to assert that, at equal levels of consumption and leisure, healthier people are better off. And it is quite ciear that the health of the American people has inproved considerably during the postwar period. ." 
Perhaps the most useful summary statistic representing the state of health is life expectancy. Table 23 displays data on life expectancies at birth and at age 20 . The increase in life expectancy at birth was quite dramatic over the three decades, though progress in this regard for men ceased around 1955. However, as Part B suggests, a good deal of the improvement for men came in the reduction of infant and child mortality. The life expectancy of a man reaching adulcnood increased only 2 I/z years from 1940 to 1970 and has been virtually unchanged since 1955. (For women, however, life expectancies have continued to improve..$^{102}$ By contrast, infant mortality in 1970 was less than hali what it was in 1940.103 Mortality and morbundity from many, but not all, serious diseases has also fallen dramatically in the postwar period, as Table 24 shows.

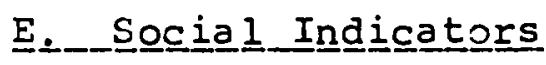

Not all indicators of well-being are pointing upward. As Table 29 shows, the postwar period has witnessed a stunning increase in the incidence of illegitimate children, a surge in the divorce rate, and little or no progress against suicide. Furthermore, crime has been one of our biggest growth industries. There is little cause for cheer in any of this. E.

"Early to bed, early to rise, makes a man health, wealthy, and wise." This rhyme, I suppose, is meant to be a formula for happiness. Americans, we have seen, are indeed considerably 
Table 23

Changes in Life Expectancy, a 1940-1970

A. Lifife Expectancy at Birth (in years)

Yea

$\begin{array}{lll}1940 & 60.8 & 65.2\end{array}$

$1955 \quad 66.7 \quad 72.3$.

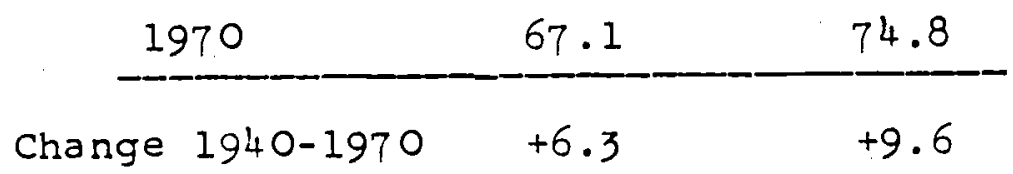

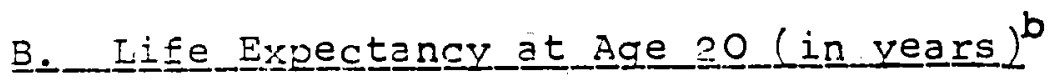

Year. Males Eemales

$\begin{array}{lll}1939-41 & 47.8 & 51.4\end{array}$

$\begin{array}{lll}1955 & 50.1 & 55.8\end{array}$

$1970 \quad 50.3 \quad 57.4$

Change 1940-1970 +2.5 +6.0

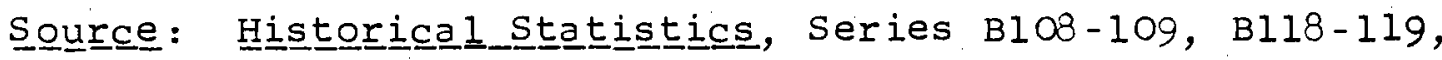
pp. $55-56$.

${ }^{a}$ Expected years of 1 ife remaining.

$\mathrm{b}_{\text {Whites only. }}$ 
Table 24

Selected Data on Iilness and

Disease, 1940-19-0

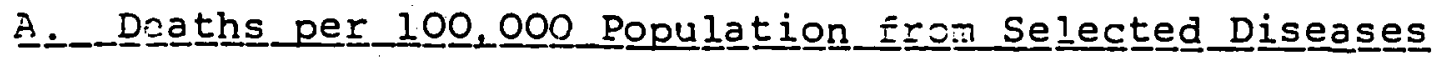

\begin{tabular}{|c|c|c|c|c|c|c|}
\hline$\underline{\underline{Y}} \underline{\underline{a}} \underline{\underline{r}}$ & Túbercu lossis & Syphi1is & $\begin{array}{l}\text { Influenza } \\
\underline{E} \text { Pneunonia }\end{array}$ & Diabetes & $\begin{array}{l}\text { Ma lignant } \\
\text { Neoplasms }\end{array}$ & $\begin{array}{l}\text { Cardiovascul } \\
\text { Renal.Diseas }\end{array}$ \\
\hline $19 \div 0$ & $45 \cdot 9$ & 14.4 & 70.3 & 26.6 & 120.3 & 485.7 \\
\hline 1970 & 2.6 & 0.2 & 30.9 & 18.9 & 162.8 & 496.0 \\
\hline
\end{tabular}

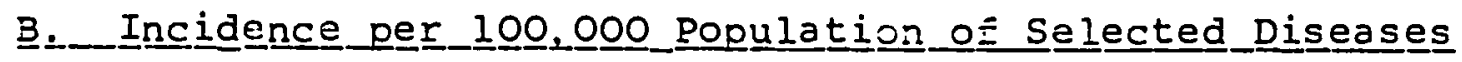

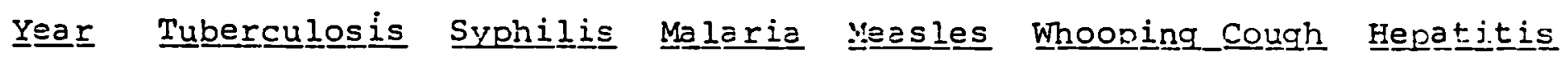

$\begin{array}{lllllll}1940 & 78.0 & 359.7 & 59.2 & 220.7 & 139.6 & 2.5^{a}\end{array}$

$\begin{array}{lllllll}1970 & 18.3 & 43.8 & 1.5 & 23.2 & 2.1 & 32.0\end{array}$

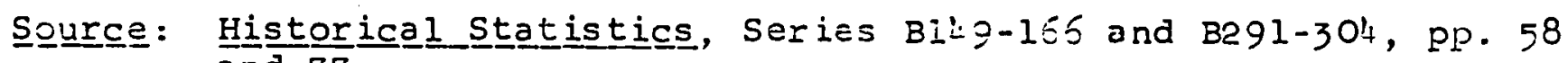
and 77 .

a Data pertain to 1950. 
Table 25

Changes in Selected Social Indicators

\begin{tabular}{ccccc} 
Year & $\begin{array}{c}\text { Illegitimate } \\
\text { Birth_Rate }\end{array}$ & $\begin{array}{c}\text { Divorce } \\
\text { Rateb }\end{array}$ & $\begin{array}{c}\text { Suicide } \\
\text { Ratec }\end{array}$ & $\begin{array}{c}\text { Crime } \\
\text { Rate }\end{array}$ \\
1940 & 7.1 & 8.8 & 14.4 & 88.9 \\
1955 & 19.3 & 9.3 & 10.2 & $79.8 / 83.5$ \\
1970 & 26.4 & 14.9 & 11.6 & 274.7 \\
\hline
\end{tabular}

allegitimate live births per 1,000 married females. Source: Historical Statistics, Series B29, p. 52 .

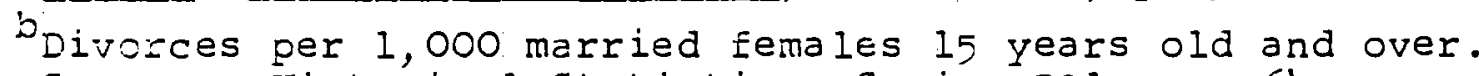

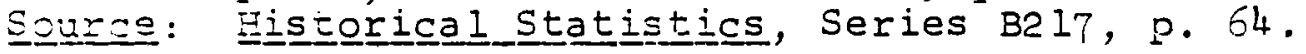

$C_{\text {Suicides }}$ per 100,000 population. Source: Historical Statistics, Series Bl66, p. 58 .

dCrimes known to police per 1,000, 000 population. Two series are spliced here. The righthand series pertains to the entire U.S., and the number reported for 1955 is actually for 1957 . The le thiand series pertains to urban areas only and is constructed by the author from separate data on urban crimes and urban population. (Urban population for 1955 is interpolated between the 1950 and 1960 censuses.) Source: Historical Series H952 and H962, p. 413 and Series A57, p. II. 
wealthier and healthier than they were 30 years ago. They are also better educated. 104 Are they happier?

This is not the sort of question an economist feels comfortable with--and with good reason. Nonetheless, a provocative paper by Easterlin (1974) attempted to answer this question by studying opinion-poll data on people's self-proclaimed happiness. Easterlin's findings for the United States are easily summarized. At a given point in time, happiness seems clearly to increase with economic status. However, as we look over time, there is little if any upward trend in happiness despite noticeable improvements in the average standard of living.

These findings suggest one of two things. Either "happiness" is a relative concept which depends (only) on each person's situation relative to his peers, or that, regardless of how happy people really are in an absolute sense, they tend to answer a survey question like this by rating their happiness relative to their contemporaries. There is probably no operational way of distinguishing between these two competing hypotheses, though they are different. For example, if we compare a family with income of $\$ 18,264$ in 1977 and one with $\$ 3,546$ in 1947 (the means for the two years), the first hypothesis states that they are equally happy while the second hypothes is states that the 1977 family is happier on an absolute scale, but no more happy on a relative scale--and responds to the questioner by reporting on relative happiness. I personally find the latter interpretation more appealing. 


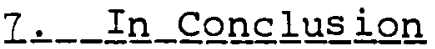

"When I use a word... it means just what I choose it to mean--neither more nor less."

--Lewis Carroll

We have seen in this essay that, according to the official data, average incomes generally have been risising during the postwar period while income inequality has been relatively constant What welfare implications, if any, follow from them?

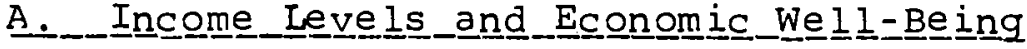

The data show that per capita income and consumption increased roughly $80 \%$ in real terms between $19 \% 7$ and 1977 . In addition to consuming more of most goods and services, Americans changed their patterns of consumption markedly. For the most part, these redirections of spending seem recognizable as improvements in the quality of life. In addition, longevity and health improved, leisure time expanded, and privacy increased. Yet over the same period a number of social indicators (e.g., divorce, illegitimacy, crime) signal a deterioration in the quality of life, and people report themselves no happier than 30 years ago. What are we to make of all this? Must we abandon the use of income as a measure of well-being?

My own impression is that we need not. For one thing, our main use of income as a guage of well-being is crosssectional, and it still seems reasonable to view people with higher incomes as "better off" at any moment in time--despite 
some anamolies. Second, even looking across time, my guess is that $r$ ising average income does indeed improve the human lot--though perhaps not by as much as the data suggest. Various non-income aspects of well being, such as leisure time and health, may not grow as rapidly as material consumption; growth may produce a variety of well-known disamenities (pollution, congestion, etc.); and we should not entirely ignore the message that "happiness" is perhaps a relativistic concept. While it would be presumptuous to concl ude that people are $80 \%$ "better off" now than they were in 1947, it seems preposterous to conclude that they are no better off.

\section{B.-Income Inequality and Economic Wellize Being}

Things get quite a bit murkier when we turn our attention to the trend (or lack thereof) in income inequality. During the postwar period, a number of strong, and seemingly autonomous, forces pushed income inequality higher. ${ }^{105}$ These include:

*a shifting age distribution that left the 1977 economy with relatively more old and young (and thus lower-paid) members than the 1947 economy; families $; 06$

*an increasing incidence of female headship of * changes in living arrangements that produced more low-income units as extended families broke up, fewer families took in lodgers and boarders, and more young and old people formed their own households. 
In brief, when we look at the U.S. economy from 1947 to 1977 , we are not looking at a society unchanging in composition by age, sex, and family structure. And most of the demographic changes that occurred were the sort that produce greater inequality, given our measurement procedures. Two conclusions follow. First, if we could measure the income distribution at fixed demography, a trend toward equality would emerge--a trend that the official data mask. Second, most of the factors that served to increase inequality during the postwar period do not signify deteriorations in economic well-being. Indeed, the opposite seems more likely. Measured income inequality thus seems an unreliable indicator of economic welfare.

Despite these and other disequalizing factors, the overall income distribution--as measured--did not become more unequal. The main reasons seem to have been a variety of government redistributive activities, including:

* the rapid growth of cash transfers which, we have seen, have been the principal weapon in the War on Poverty; * the equally rapid growth of transfers in kind, which are not included in the official data (another reason why the official data understate the trend toward equality); *other programs such as affirmative action guidelines, equal opportunity and anti-discrimination laws, and the like. These programs have not been dealt with in this chapter because we lack estimates of their effects on income inequality. 107 
But I would be remiss not to suggest a possible link between these governmental activities and the observed narrowing of black/white income differentials.

It appears that, on balance, these competing sets of factors--demography versus government--battled to a standoff. Income inequality, as measured in the official data, was urchanged between 1947 and 1977. But I would not want to push the analogy to a tug-of-war too far, because there is reason to suspect that the two sides were not independent. Specifically, government programs designed to equalize post-tax post-transfer incomes may well have helped disequalize pre-tax pre-transfer incomes. For example:

* It has often been suggested that redistributive tax and transaer schemes have disincentive effects that, e.g., discourage labor supply among beneficiaries (the poor, the elderly, etc.). 108

* It is conceivable, though here we know much less, that transfer programs such as AFDC and social security may have contributed to some of the changes in family structure and living arrangements that were just labeled as disequalizing factors (e.g., increases in female headship, more elderly people living alone, etc.).

* It is quite possible that expenditures on public education (an apparently "equalizing" transfer in kind) were among the factors leading to the more pronounced age-income profile--thus contributing to a growing gap between annual and lifetime inequality. 
80.

No wonder, then, that in the wonderland of inequality:

...it takes all the running you can do, to keep in the same place. If you want to get somewhere else, you must run at least twice as fast as that: 
$\mathbf{F}-1$.

FOOTNOTES

${ }^{1}$ For a detailed treatment of postwar demographic changes, see the chapter by Richard Easterlin in this volume.

${ }^{2}$ For an extensive discussion of opportunity sets, see Gordon ( 1977 ).

3 Conversely, two people with equal incomes may have gotten there from very different opportunity sets.

${ }^{4}$ Even the CPS data are not perfectly consistent over time. Minor changes in definitions, survey techniques, etc. have been made. For a more detailed discussion and critique of the Census income concept, see Taussig (1977).

5 On this, see Lebergott (1976, pp. 11-12) or Riviin (1975).

${ }^{6}$ For more detailed technical discussions of this issue, the interested reader is referred to Atkinson (1970), Sen (1973), or Rothschild and Stiglitz (1973).

7 Readers familiar with the Gini ratio may skip the rest of this section, which is a nontechnical explanation for lay readers.

${ }^{8}$ By tine formula for the area of a triangle, this area is a lways $1 / 2$.

${ }^{9}$ But not all, as a weli-known paper by Budd (1970) established. 
$10_{A}$ full account of these recessions can be found in the paper by Robert Gordon in this volume.

${ }^{11}$ Defined specifically as personal income plus retained earnings plus contributions for social insurance (both employee's and enployer's shares).

12 Defined specifically as disposable income (as in the $N I A)$ plus retained earnings, or alternatively as augmented personal income minus contributions for social insurance minus personal tax and nontax payments.

${ }^{13}$ All deflation is done using the implicit deflator for personal consumption expenditures.

${ }^{14}$ It hardly needs pointing out that the national income accounts measure nominal interest, not real interest. The share of interest has risen mainly because there is trend in the inflation rate.

${ }^{15}$ Age of the housing stock refers to private nonfarm residertial structures containing from 1 to 4 units. The increase in the incidence of running water and flush toilets came largely in rural areas.

\section{${ }^{16}$ Absolute prices rose only $15 \%$ over 30 years, which} implies that relative prices fell $57 \%$.

17 In 1940, there were 2, 412, 000 private household workers and $3-.2-9$, 000 households. By 1970, the number of private household workers had fallen slightly to $2,347,000$, while the number of 
households had risen to $63,401,000$. Sour Series $D-567$ and $A-288$.

${ }^{18}$ A procedure the commerce Department does not follow. I have taken several liberties with their way of organizing the data.

${ }^{19}$ This category also includes radios, musical instruments, and records.

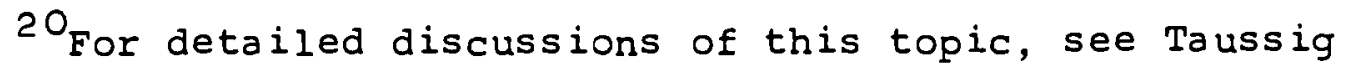
(1977) and Danziger ( 1977 ).

$2 l_{\text {The income concept underlying this table differs from }}$ census income, and so these distributions are not directly comparable to those in Table 9 .

${ }^{22}$ Table 11 pertains to families, and excludes unrelated individuals.

${ }^{23}$ A similar calculation comparing the richest tenth and the poorest tenth brings an apparent $15: 1$ ratio in the raw data down to only $2.8: 1$.

${ }^{24}$ This issue has been stressed by Kuznets (1974), among others.

${ }^{25}$ My discussion of this point is deliberately sketchy. For further details, see the chapter by Richard Easterlin in this volume.

${ }^{26}$ Blinder and Esaki (1978) report detecting a statistically significant break in the trend for several percentile shares around 1958 . 
27 A regression was run with the Gini ratio as the dependent variable, and the following independent variables: the unemployment rate, a constant, a dummy variable which is 1 starting in 1958, time, and the interaction of time with the dummy. The coefficient of time was -.0022 (with standard error .0004). The sum of the coefficients of time and the interaction term, which is the post-1958 time trend, was -.0004 (with standard error .0017).

28 In a regression identical to that reported in the previous footnote, the estimated time trend in the Gini ratio among unrelated individuals was -.0014 (standard error $=.0013$ ) until iz: and -.00Lo (standard error .0017) thereafter.

29 Table 16 summarizes the whole aistribution by the Gini ratio only to keep the volume of data manageable. Inspection of the underlying distributions reveals, fortunately, that there are hardiy any instances of crossing Lorenz curves-the circumstance that would render the Gini ratio potentially misleading. The few Lorenz curve crossings that occur are indicated in footnotes to Table IE. The year 1964 was selected for this table because it comes closest to being a "typical" postwar year.

${ }^{30}$ The reader is reminded that, by census definitions, there are no one-person families.

${ }^{31}$ I will have more to say on the subject of age and the income sistribution when I discuss the accounting period, since the proilems arise largely from measuring income in a particular year ratier than over the lifetime. 
32 The section is limited to the family income distribution both to save space and because most of the literature does the same.

${ }^{33}$ Let us be clear about what this simple adjustment doeㅗ

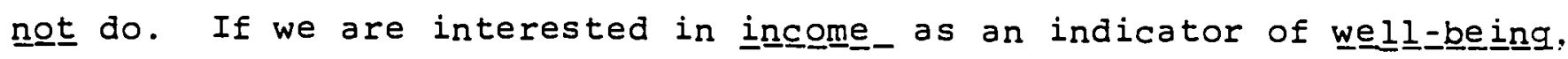
as we are, then a proper "adjustment" for taxes and transfers really requires resolution of every complex and controversial issue in tax incidence theory. What portion of the value of any transfer payment actually accrues to the recipient? What part of the burden of a sales tax falls on the consumer of the product? Can the income tax be shifted? It hardly needs saying that questions like these are well beyond the scope of this chapter, and indeed probably also beyond the scope of current economic knowledge. My aim here is much more modest: to get the bookkeeping straight. Specifically, subtraction of individual. income tax payments and the employee's share of the payroll tax from census income (the employer's share is already excluded), is not meant to imply that the burden of these taxes falls entirely on those who pay them. Nor does the absence of any deduction for indirect taxes imply that they are totally borne by firms.

${ }^{34} \mathrm{An}$ exception is Smeeding (1979a), who also deducts indirect taxes.

${ }^{35}$ This table is drawn from a detailed study of the 1972 distribution using micro data and the OBE income concept. The findings correspond closely to those reported earlier by Budd 
(1967) for 1962. Table 17 shows much less redistribution than that implied by the data in Browning (1976).

\section{6 on this, see smeeding (1979a). Sales taxes are}

usually viewed as regressive, but Browning (1978) argues that they should be considered as progressive. Smeeding (1979c) disagrees.

37 Browning (1976) reaches a similar conclusion. ${ }^{38}$ According to Browning (1976), transfers in kind (including public education) increased from $7.2 \%$ of census income in 1952 to $9 \%$ in 1962 and $14.6 \%$ in 1972 .

39 For further discussion, see smolensky et._al. (1977).

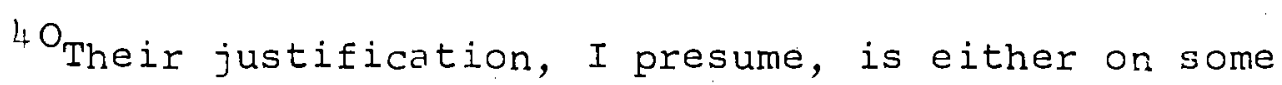
externality argument or on grounds of paternalism.

${ }^{4}{ }^{1}$ Smolensky, ett_all- $(1977)$ did not try to price out public education by this method, which is difficult because the market for private education is so thin and because public and private education seem to be diffirent products.

${ }^{4} 2$ The volume and distribution of educational transfers are apparently not in dispute.

$$
\begin{aligned}
& { }^{43} \text { See smeeding }(1979 a, p .941) \text {. } \\
& 44 \text { Lorenz curves for income before and after cash }
\end{aligned}
$$$$
\text { transfers do not cross, so the Gini ratio is probably a }
$$
satisfactory summary statistic. Studies alluded to include Danziger and Plotnick (1977), Taussig (1973), Smolensky et. 
(1977), and Garfinkel and Haveman (1978), and cover years ranging from 1965 to 1974 .

45 According to Browning and Johns on (fortheoming, Table 1), in 1976 the lowest fifth of families (ranked by total income) received $63 \%$ of its income in the form of transfers. ${ }^{46}$ Smeeding (1979a) attempted an adjustment for employer pension contributions but, as Browning (1979) pointed out, was guilty of double-counting since census income includes income from pensions. In principle, we might want to include eithener pension contributions when made or pension income when received, but not both.

${ }^{47}$ His distribution assigned $68 \%$ of the gains to the top fifth and $3 \%$ to the bottom fifth.

48 Real capital gains as a percentage of disposable income varied from $+38 \%$ in 1958 to $-54 \%$ in 1946. A regression of this ratio against time produced a coefficient that was essentially zero.

${ }^{49}$ A similar analysis can be found in Danziger (1977). $50_{\text {Paglin }}(1975)$.

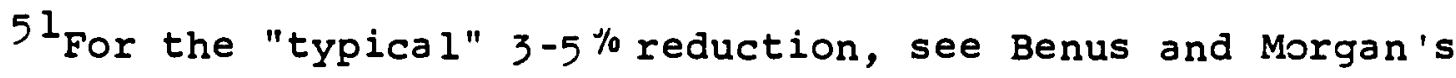
(1975) calculations for a 1968-1972 Office of Economic Opportunity panel and for a special panel designed to study the impact of the 1964 income tax cuts; and Kohen, Parnes, and Shea's (1975) results with the National Longitudinal Survey (NLS) of mature men. Earlier, Vandome (1958) had reported similar results for the U.K. 
52 Benus and Morgan (1975) reported a $9 \%$ reduction in the Gini coefficient in a 1967-1970 panel study of purchases of durable goods, and Kohen et_al. (1975) found a 10\% reduction among the NLS young men.

$$
\begin{aligned}
& 53 \text { Hoffman and Podder ( } 1976) \text {. } \\
& 54 \text { Again, see Hoffman and Podder (1976), who report }
\end{aligned}
$$
declines in several measures of inequality ranging from $13 \%$ to $21 \%$ when the accounting period is lengthened from one year to seven years. David and Menchik (1979) find an even stronger effect: the coefficient of variation declines $14 \%$ when income over 3 years is used instead of annual income.

${ }^{55}$ The coefficient of variation, a common measure of dispersion, is the ratio of the standard deviation to the mean. 56 Soltow's (1965) study of the distributional history of the town of Sarpsborg, Norway from 1928 to 1960 found that the 33 -year Gini ratio was $27 \%$ lower than the average of the 1-year Gini ratios. Blonquist (1976) estimated that the Gini ratio for lifetime income among employed males in Sweden was about half as large as the Gini ratio for annual income.

57 This classification follows Danziger, Haveman, and Smolensky (1977).

58 The data are from U.S. Bureau of the Census, Technical Report No. 17 , and are not reproduced here. 
${ }^{59}$ Figure 3 shows smooth curves fitted (by eye) to grouped data. Each mean income is expressed as a fraction of the income of families headed by a 45-54 year old. ${ }^{60}$ For criticisms of Paglin's method, see Danziger, Haveman, and Smolensky (1977) and Minarik (1977).

$61_{\text {The third part arises from the fact that the upper }}$ part of the low-income groups have higher incomes than the lower parts of the high-income groups. For a lucid explanation of Pyatt's decomposition and a discussion of how it relates to Paglin's technique, see Murray (1978).

62 For further discussion see Shorrocks (1978) or Blinder $(1976)$.

$$
\begin{aligned}
& { }^{63} \text { Mirer }(1975) \text {, Benus }(1974) . \\
& { }^{64} \text { Kohen et_a․ }(1975) . \\
& { }^{65} \text { For a fuller discussion, see Weinstein and Smolensky }
\end{aligned}
$$
$(1976)$

${ }^{66}$ Kilpatrick ( 1973 ) used Gallup poll surveys of minimaI income needs to argue that the man on the street's concept of the poverty line rises with average income, though less than in strict proportion. Lebergott (1976, pp. 53-60) collected data showing that payments to poor on relief remained about $30 \%$ of the wage for common labor for more than a century. See also Rainwater $(1974)$, esp. Chapters 3 and 5 . 
67 Based on the work of Orshansky (1965).

${ }^{68}$ Lebergott ( 1976 ,pp. $70-76$ ) has objected eloquently to the "scientific" budgets that underly the minimum decency standard.

${ }^{69}$ See Fuchs $(1967)$, p. 89.

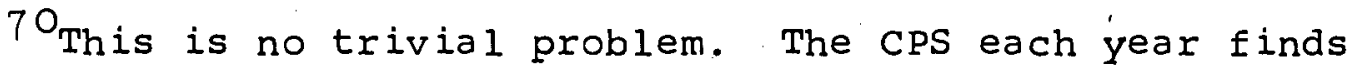
a number of families with nequative income (and Census income

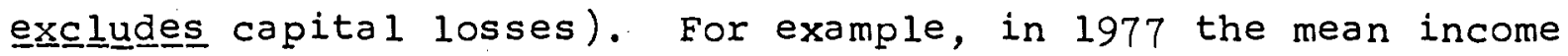
among the $2 \%$ of families with incomes below $\$ 2$, 000 was $-\$ 1700$. One wonders how many families with negative incore are "poor" in any meaningful sense.

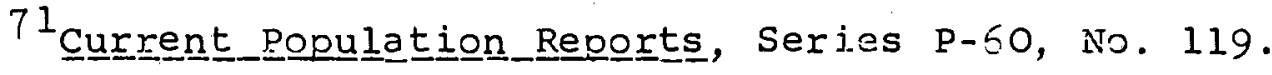

72 Non-whites constituted $34 \%$ of a 11 poor persons; among heads of poor families, $63 \%$ had not finished high school; the

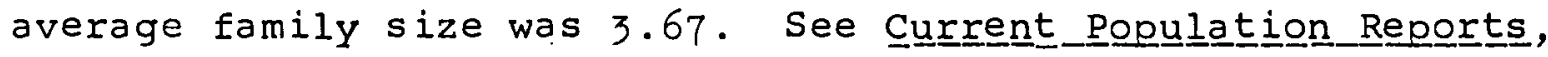
Series $\mathrm{P}-60$, No. 119.

73 The poor are those below $44 \%$ of the median income.

74 These fluctuations may be due to inconsistencies in estimation methods over time. See plotnick and Smeeding (1979), footnote 16 .

75 Danziger, Haveman, and Plotnick (1979), Table 5, p. 31.

${ }^{76}$ For data on black-white earniㅡ몽 differentials, see the chapter by Richard Freeman in this volume. 
77 The data pertain to "nonwhites," rather than to blacks. However, blacks predominate in this group.

${ }^{78}$ Versus $9 \%$ and $11 \%$ for white families in the two years. Data are from Danziger and Lampman (1978).

${ }^{79}$ see the chapter by Richard Freeman.

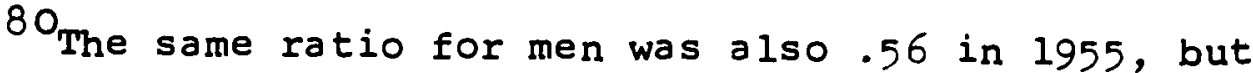
improved only to .69 in 1977. See Thurow (1979).

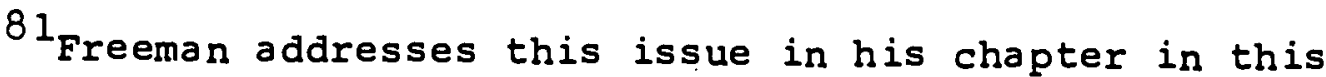
volume.

${ }^{82}$ And the same wealth. More on wealth later.

${ }^{83}$ The crucial words in these last two sentences, of course, are "voluntarily" and "voluntary." Not all interpersonal differences in hours of work are voluntary. More on this below.

${ }^{84}$ or there can be more leisure time on the job. On this, see Stafford and Duncan (1977).

${ }^{85}$ Historical statistics. The work week comes from series $D-765$, p. 168 ; the work day is reported as 9.89 hours in Series D-847, p. 172 .

${ }^{86}$ Moore and Hedges ( 1971 ).

87 The older and newer hours series are not entirely comparable, though both display downward trends. The data series cited in footnote 85 ends in 1926, when average weekly hours are 50.3. The newer series used for postwar comparisons records a value of 45 for that same year. 


\section{${ }^{88}$ Gordon and Blinder (1979) explore reasons for}

this phenomenon.

${ }^{89}$ Reimers ( 1976 ) shows that these data need not imply

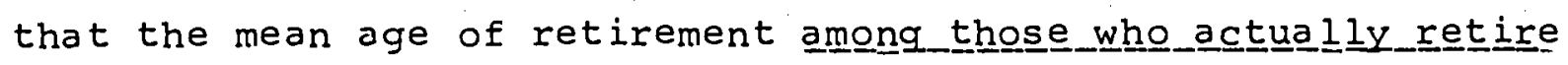
has decreased; and she estimates that it has been fairly constant at around 65 years. The reason is that there are fewer and fewer people who never retire.

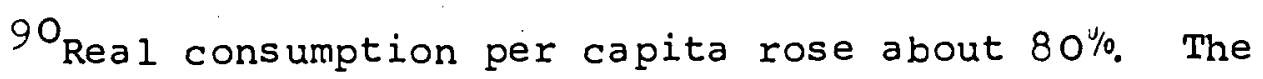
percentage increeㅗㅇㅡ in leisure is the percentage deccrease in working time multiplied by the initial ratio of work to leisure. If that initial ratio was two, for example, then leisure time rose $32 \%$.

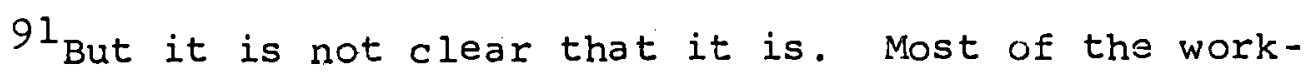
saving machinery that has helped the housewife became widespread only after World war II.

92 It should be noted, however, that housewives were more overworked in 1900 than were paid workers. Housewives, it seems, really did work the proverbial six or seven 12 -hour days.

${ }^{93}$ Yet one more qualification. Women are spending far more time in the paid work force than they used to. So the reduction in housework often may not represent more leisure time. 94 Taussig (1973) makes an attempt at this. Browning (1976) and Browning and Johnson (forthcoming) treat all non-working time as voluntary leisure. 
95 Were the lifetime used as the interval for measuring income, there would be little need for separate data on wealth. The present value of income would differ from (human plus nonhuman) wealth only to the extent that inheritances differ (in present value) from bequests.

$$
{ }^{96} \text { Projector and We iss (1966, p.61-62); Lebergott (1976, }
$$
pp. $217 \mathrm{ff.}$.).

97 For a discussion of the method, and examples of its use, see Lampman (1962) or Smith (1974).

98 Projector and weiss $(1966)$, p. 30 .

${ }^{99}$ Since Gini coefficients within these age cohorts were .70-.71 in the SFCC, the agreement between the two sources is close.

100 Projector and weiss (1966), pp. 6-7.

101 The year 1940 is included also to show the increase in living together brought about by the war.

${ }^{102}$ The extent to which longevity has increased is often exaggerated. Life expectancy at age 60 for males increased only 1.1 years over the entire 30 -year period, and only 0.2 years from 1955 to 1970. Life expectancy for 60-year-old females, however, increased by 4 years between $1939-41$ and 1970 .

${ }^{103} 20$ deaths per 1000 live births in 1970 versus 47 in 1940 . 


$$
\text { F-14. }
$$

$$
{ }^{104} \text { I resist the temptation to equate education with }
$$

wisdom.

$$
105
$$

The word "autonomous" needs some explanation. I do not mean to imply that these forces were God-given or exogenous in some ultimate sense, but only that they probably were not themselves effects of the changing income distribution.

$$
{ }^{106} \text { Among the many factors contributing toward this }
$$

development were higher divorce rates, more illegitimate births, and changing social mores regarding the role of women. For a full discussion, see Ross and Sawhill (1975).

$$
{ }^{10} 7 \text { They are dealt with in the chapter by Richard Freeman }
$$
on the labor market.

$$
{ }^{108} \mathrm{~A} \text { possible counterweight to this is that withdrawal }
$$
of labor supply may push up the relative wages of these groups. 


\section{References}

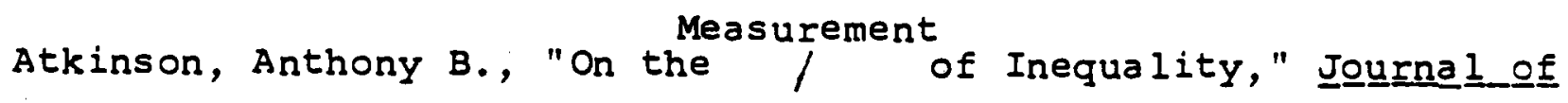
Economic Theory, 2, September 1970, pp. $244-263$. Benus, Jacob, "Income Instability," in J. N. Morgan et ąl., 互诸 Thousand American Families, Vol. I (Ann Arbor: Institute for Social Research), 1974.

Benus, Jacob and James N. Morgan, "Time Period, Unit of Analysis, and Income concept in the Analysis of Income Distribution," in James D. Smith (ed.), The Personal Distribution_of_Income and Weal $\underline{\underline{t}} \underline{h}$, National Bureau of Economic Research Studies in Income and Wealth, Vol. 39 (New York: Columbia University Press), 1975, pp. $209-224$.

Bhattachorya, N. and B. Mahalanobis, "Regional Disparities in Household Consumption in India," Journal of the Amereriçan Statistical Association, vol. 62, March 1967 .

Blinder, Alan S., Toward an Economic_Theory of Income_Distributín (Cambridge, Mass.: MIT Press), 1974. Blinder, Alan S., "Inequality and Mobility in the Distribution of Wealth," Kyklos, Vol. 29, Fasc. 4, 1976, pp. $607-638$. Blinder, Alan S., and Howard Y. Esaki, "Macroeconomic Activity and Income Distribution in the Postwar United States," Review of Economics and statistics, November 1976, pp. 604-609. 


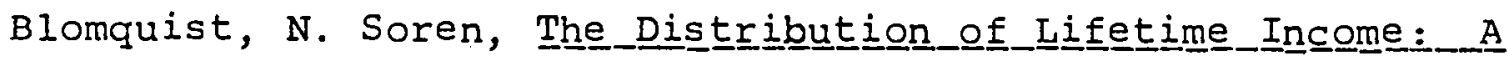

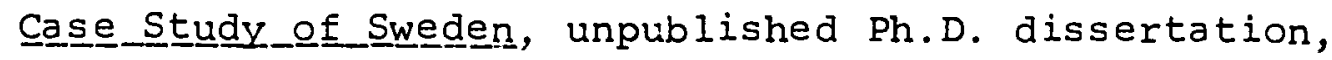
Princeton University, 1976.

Browning, Edgar K., "The Trend Toward Equality in the Distribution of Net Income," Southern_Economic Journal, 1975, pp. 912-923. Browning, Edgar K., "The Burden of Taxation," Jourrnal_of Politicical Economy, Vol. 86, No. 4, 1978, pp. 649-671.

Browning, Edgar K., "On the Distribution of Net Income: Reply,"

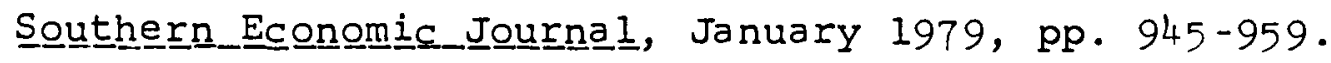
Browning, Edgar K. and William R. Johnson, "Taxes, Transfers, and Income Inequality," in Gary Walton (ed.), Requulatory

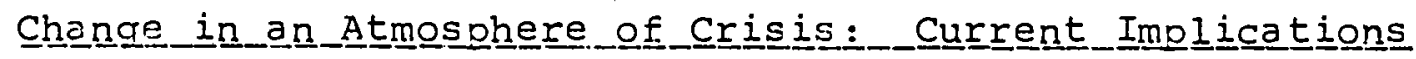

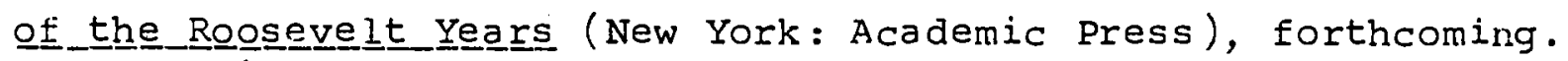

3ucd: Edward c., Inequalitity and_poverty (New York: Norton), 1967. Budd, Edward C., "Postwor Changes in the Size Distribution of Income

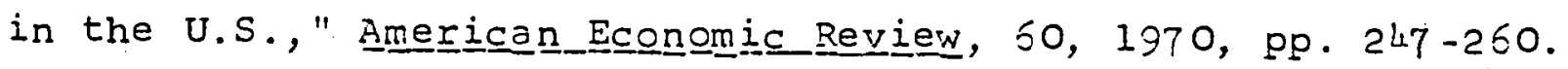
Denziger, Sheldon, "Conference Overview: Conceptual Issues, Data Issues, and Policy Implications," Conferencee_on thhe Tre Income_Inequality in the U.S. (Madison, wisconsin: Institute for Research on Poverty), 1977.

Dònziger, Sheldon, Robert Haveman, and Robert Plotnick, "Income Transfer Programs in the United States: An Analysis of their Structure and. Impàcts," Prepared for the Joint Economic Committee of the U.S., Special Study on Econcmic Change, May 1979. 
Danziger, Sheldon, Robert Haveman, and Eugene Smolensky, "The Measurement and Trend of Inequality: Comment," American_Economic_Reviev. Vol. 67, No. 3, June 1977, pp. 505-512.

Danziger, Sheldon H. ;/Robert J. Lampman, "Getting and Spending,"

The Annals of the American Academy of Political and Social

Science, Vol. 435, January 1978, pp.23-39.

Danziger, Sheldon and Robert Plotnick, "Demographic Change, Government Transfers, and the Distribution of Income," Monthly Labor Review, 100, April 1977 .

David, Martin and Paul Menchik, "Aspects of the Lifetime Distribution

of Income and Wealth," mimeo, May 1979.

Easterlin, Richard A., "Does Economic Growth Improve the Human Lot?

Some Empirical Evidence," in P.A. David and M.W. Reder (eds.),

Nations_and_Households in Economic Growth: Essays in Honor of Mosses Abramovitz (N.Y.: Academic Press), 1974 .

Eisner, Robert, "Capital Gains and Income: Real Changes in the Value of Capital in the United States, 1946-1977," to appear in Dan Usher (ed.), The Measurement of Capital, Studies in Income and wealth, Vol. 45, University of Chicago press. for the National Bureau of Economic Research, 1980.

Feldstein, Martin S., "Social Security and the Distribution of Wealth, " Jourrnal of the Amer December $1976,71(356)$, pp. 800-807.

Fuchs, Victor R., "Redefining Poverty and Redistributing Income," The Public Interest, Summer, 1967 . 
Gariin:el, Irwin and Robert Haveman, "Capacity, Choice, and

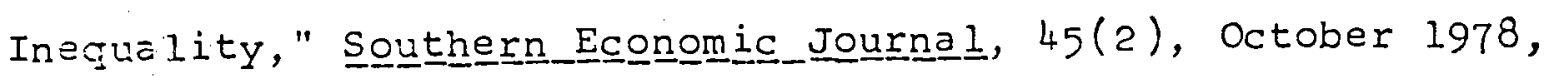
po. $421-431$.

Gini, Corrado, "On the Measure of Concentration with Especial

- Re Eerence to Income and Wealth," Cowles Commissiọn, 1936.

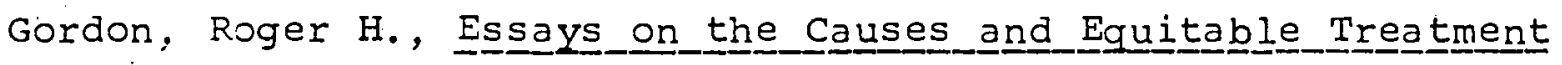

으 Differences_in Earnings and Ability, Unpublished Ph.D.

Dissertation, M.I.T., 1976.

Gordon, Roger H., "A Search for Consistent Welfare Measures,"

mimeo, Princeton University, July 1977 .

Gordon, Roger H. and Alan S. Blinder, "Market Wages, Reservation

Wages, and Retirement Decisions," mimeo, Princeton University,

September $19: 9$.

Fenle, Eater, "Exploring the Distribution of Earned Income,"

Bo=tily_Labor Review, Vol. 95, No. 12, December 1972, pp. 16-27.

.. Siofiman, Saul and Irripesh.Padder, "Income Inequality," in G. J.

Dun:an and J.:. Morgan (eds.), Eive_Thousand American Eamilies

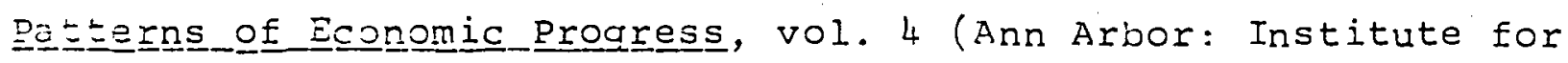

Social Research, University of Michigan), 1975, pp. 333-356.

Rilpet:ick, Robert W., "The Income Elasticity of the poverty Iine,"

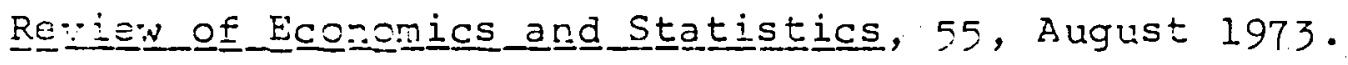

Konen, indrew I., Herbert S. Parnes and John R. Shea, "Income

Instability Among Young and Middle Aged Men," in/Smith (ed.),

Th르킅으미 Distribution of Income_and Wealth, vol. 39

( $:=\cdots$ York: Columbia University press) 1975, pp. 151-207. 
Kravis, Irving B., "International Differences in the Distribution

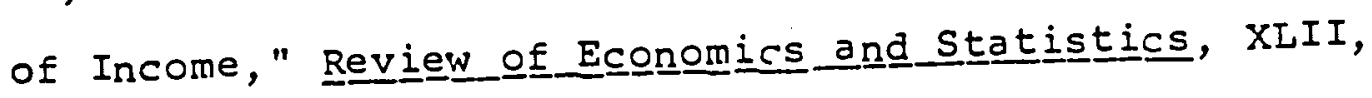

$\therefore$... November 1960 , pp. $400-416$.

Kravis, Irving B.; The Structure of Income: Scme Quantitative Es Philadelphia:

('University of Fennsylvania ... Press), 1962

Kuznets, Simon, "Demographic Aspects of the Distribution of Income

Among Families: Recent Trends in the United States," in

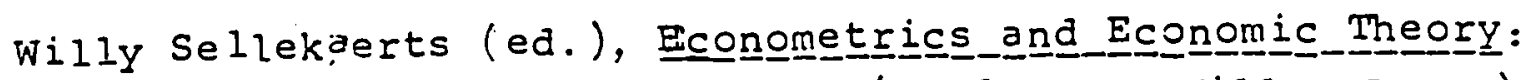

Essays in Honor of Jan Tinbergen (London: MacMillan Press), 1974 , p. $223-245$.

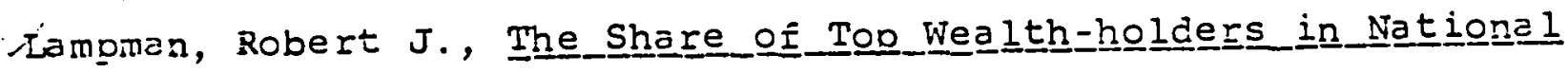

Wealth 122?-105É (Princeton, N.J.: Princeton University Press), 1952 .

Lampman, Robert J., "Measured Inequality of Income: What Does It Mean and What Can It Tel1 Us?", Anna

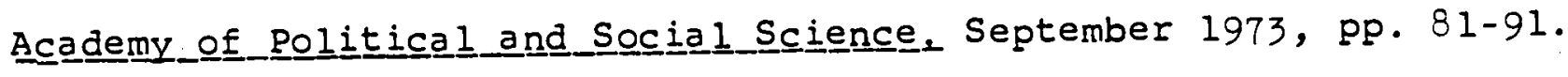

Lampman, Robert J., "Chang Ing Patterns of Income, 1960-1974,"

in Davic Warmer (ed.), Toward New Eurnan Richts: The Social

Policies

published by the Lyndon B. Johnson School of Publis Affoirs, 1977.

Jane, Jonathan P. and James $\mathrm{N}$. Morgan, "Patterns of Change in

Economic status and Family Structure," in G. Duncan and

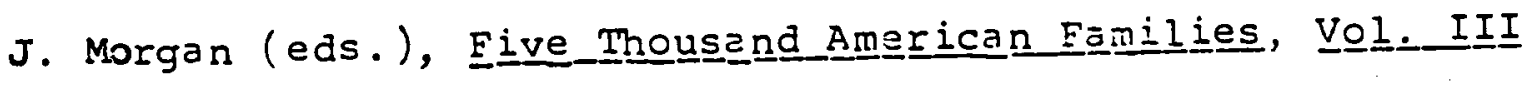

(Ann Arbor: Institute for Social Research), 1975. 
Kansing, John B. and John Sonquist, "A Cohort Analys is of Changes in the Distribution of Wealth," in Lee Soltow (ed.), Six_papers

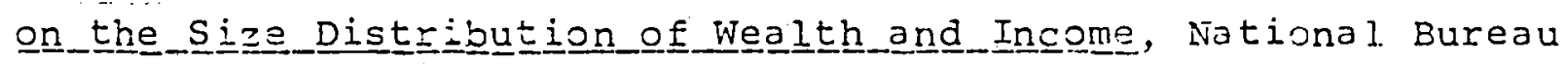
of Economic Research Studies in Income and wealth, vol. 33 (New. York: Columbia university Press), 1969.

Lebargott, stanley, The Ameri (Princeton: N.J.: Princetọn University Press), 1976. . Lillard, Lee A., "Inequality: Earnings versus Human Wealth,"

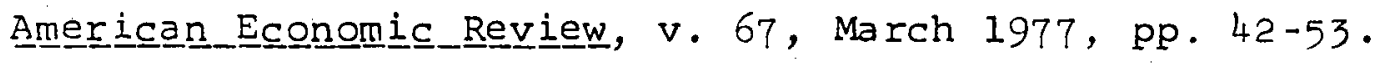

-Iorenz, Maz o.,"Mathods for Heasuring Concentration of Waith,

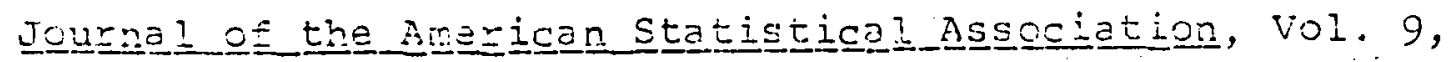
$1905,20.209-219$

- Arrark, Joseoh J, "The Measurement and Trena of Inequality: Comment," Americen Economic Review, June 1977 , po $513-516:$ Girer, Thad, "Aspects of the Variability öf Eamily Income," in G.J. Duncán and J.N. Morgan, Five Thousend_American_Fanilies=

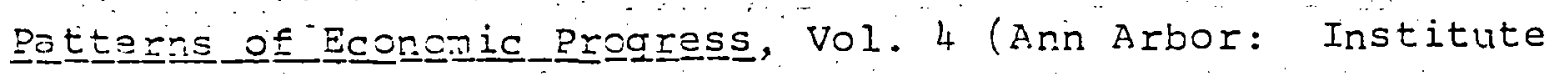
for Social Research, University of Michigan), 1975, po. $201-212$. 
Moore, Geoffrey H. and Janice N. Hedges, "Trends in Labor and Le isure," Monthly Labor Review, Vol. 94, No. 2, February 1971, pp. 3-11.

Morgan, James N. and James D. Smith, "Measures of Economic WellOffness and Their Correlates," American Economic_Review, 59, 1969, pp. 450-462.

-Murray, David, "Sources of Income Inequality in Australia 1968-69," The Economic Recorda, 54(146), August 1978, pp. 159-169. Vorshansky, Mollie, "Counting the Poor: Another Look at the Poverty Population," Social Security. Bulletin, $28: 1$, January 1965 , pp. $3-29$.

Paglin, Morton, "The Measurement and Trend of Inequality: A Basic Revision," American_Economić Review, 55, Sept. 1975, pp. 598-609. Pareto, Vilfredo, Cours d'Economie Polititique (Rouge :

Lausanne), 1897.

'Plotnick, Robert and Timothy Smeeding, "Poverty and Income Transfers:

Past Trends and Future Prospects," Public Policy, Summer, 1979. Projector, Dorothy S. and Gertrude S. Weiss, Survey of Financial Characteristics of Consumers, Federal Reserve Technical Paper (Washington, D.C.: Board of Governors of the Federal Reser. System), 1965 .

Pyatt, Graham, ion the Interpretation and Disaggregation of Coefficients, Economic Journal, vol 86 , June 1975, pp. $243-255$ $\vdots$ 
Radner, Daniel B., "Federal Income Taxes, Social Security Taxes, and the U.S. Distribution of Income, 1972," Working Paper No. 7, Office of Research and Statistics, Social Security Administration - April 1979.

Rainwater, Lee, What 으 Incogome (New York: Basic Books), 1974 .

Reimers, cordelia, "Is the Average Age at. Retirement Changing?",

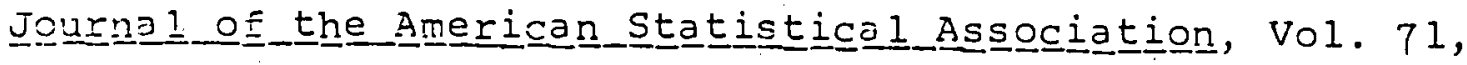
No. 355 , September 1976, pp. 552-558.

Reynolds, Morgan and Eugene Smolensky, Publi ic Expenditurreses, Taxeses. and the Distribution of Income: The U.S. 1950. 1961. 1970

(New York: Academic Press), 1977.

Reynolds, Morgan and Eugere Smolensky, "The Fading Effect of

Government on Inequality," Chalilenenge, July-August 1978, pp. $32-37$.

Rivlin, Alice M., "Income Distribution: Can Economists Help?",

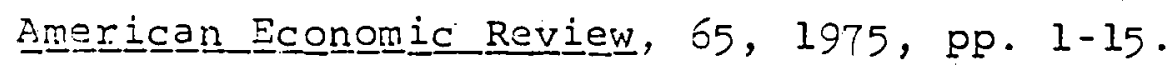

Ross, Heather L. and Isabel V. Sawhill, Time of Transiiㅡ느므 (Washington: Urban Institute), 1975.

- Rothischild, Michael and Joseph E. Stiglitz, "Some Further Results

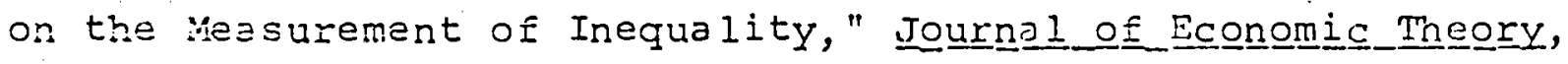
Vol. ó, 1973, pp. 188-20'4. 
Ś́wyer, Malcolm, "Income Distribution in OECD Countries," OEECD Qccásienal studies, July 1976, pp. 3-36. FSchultz, T. Paul, "Long-Term Change in Personal Income Distribution: Theoretical Approaches, =Evidence, and Explanations, "in D.M. Levine and M.J. Eane (eds"), The "Ineauality" controversv, (New York: Basic Books), 1975 , pp: 147-169.

Sen, Amartya K., On Economic Inequality (New York: Norton), 1973. Shorrocks, Anthony, "Income Inequality and Income Mobility," Journal_of Econgomic Theoryy: 19 (1978), pp. 376-393.

Sirageldin, Ismail', Non-Market Comoonents of Nätiongol Income (Ann Aroor: University of Michigan, Survey Research Center), .1959

Smeeding, Timothy M., "The Antipoverty Effectiveness of In-Kind Transfers," Jou Smeeding, Timothy; "On the Distribution'of Net Income: Comment," Southern Economic Journa 1, January 1979a, pp. $932-944$. Smeeding, Timothy M., "Still More on the Distribution of Net Income: Further, Comment," mimeo, $1979 b$.

Smeeding, Timothy M., "Are Sales Taxes Progressive?", mimeo, 19790. 
ismith,"James D., "The concentration' of Personal wealth in America, $1969, "$ The Review of Income and weolth, Ser. 20, No. 2, 1974, pp. $143-180$.

Smith, James D. and Stephen D. Franklin, "The Concentration of Personai wealth, 1922-1969," American Economic Revieww, 64 , $197^{4}, \mathrm{pp} .162-167$.

and Robert Plotnick, Smolensky, Eugene, Laanna Stiefel, Maria Schmundt, /. "Adding In-Kind Transfers to the Personal Income and Outlay Account: Implications for the Size Distribution of Income," in F. Thomas Juster (ed.), The Distribution of Economic well-3eing, volume 41 in studies

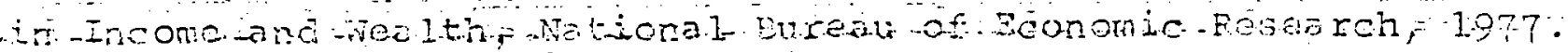

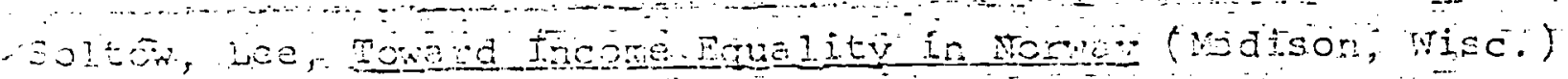
2965

Staffurd, Frank and Greg Duncan, "The Use of Time and Technology by Households in the United States," mimeo, University of Michigan, July 1977 .

Stigler, George $\pi .$, "General Economic Conditions and National Elections," Anerican Economic Review, Vol. 63, No. 2, May 1973, pp. 160-167.

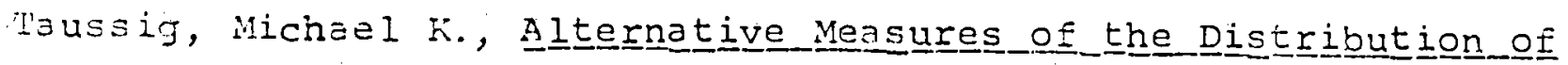
Economic Nelfaze (Princeton, N.J.: Industrial Relations Section, Princeton University), 1973.

-Taussig, Michael $\mathrm{K}$., "Trends in Inequality of Well-offness in the United states Since World War II," Confeerence on the Income Inegua Iivin the U.S. (Madison, wisc.: Institute for Research on Dovarty), 1977 . 
-Thurow, Lester C., "Manpower Programs As Income Redistribution," M.I.T., mimeo, July 1979.

Vóndope, Peter, "Aspects of the Dynamics of Consumer Behavior: Income and Savings Over Two Years from the 1954 Reinterview

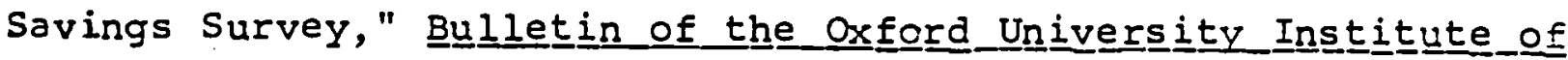
Statistics, XX, February 1953, pp. 65-106.

trieinstein, Michael M. and Eugene Smolensky, "Poverty," mimeo, March 197.6, forthcoming in Díctiㅡonarv of American E드으요iㄷ His느으모.

$\therefore$ Weisbrod, Burton $A$. and W. Lee Hansen, "An Income-Net Worth Approach

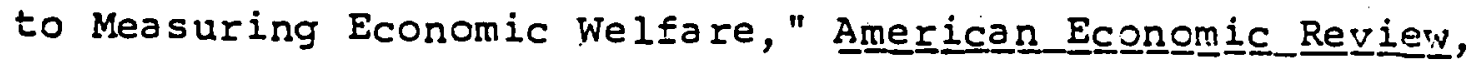
58, 1969, p. 1315-1329. 